Review

\title{
Total Synthesis of Annonaceous Acetogenins Belonging to the Non-Adjacent Bis-THF and Non-Adjacent THF-THP Sub-Classes
}

\section{Ian B. Spurr and Richard C. D. Brown *}

The School of Chemistry, The University of Southampton, Highfield, Southampton SO17 1BJ, UK; E-Mail: ibs@soton.ac.uk (I.B.S.)

* Author to whom correspondence should be addressed; E-Mail: rcb1@soton.ac.uk.

Received: 14 December 2009 / Accepted: 23 December 2009 / Published: 21 January 2010

\begin{abstract}
The synthesis of the subgroups of acetogenins containing non-adjacent bis-THF and non-adjacent THF-THP core units is reviewed. Specifically, total syntheses of gigantecin, 4-deoxygigantecin, cis-sylvaticin, squamostatin-C, squamostatin- $\mathrm{D}$, sylvaticin and mucocin are discussed.
\end{abstract}

Keywords: annonaceous acetogenins; non-adjacent bis-THF; tetrahydrofuran; tetrahydropyran; asymmetric synthesis; 1,2-diols; epoxides; cytotoxic natural products; anti-tumour

\section{Introduction}

The annonaceous acetogenins are a group of natural products isolated from the Annonaceae (or custard apple) family of plants [1-9]. Purification of the extracts from the seeds, leaves and twigs of these plants typically yields acetogenins as waxy low-melting substances containing $\mathrm{C}_{32}$ or $\mathrm{C}_{34}$ unbranched fatty acid backbones. At first inspection, many of these acetogenins appear to be structurally similar, sharing a number of common features including 2,5-disubstituted tetrahydrofuran rings (and less commonly tetrahydropyran rings), secondary alcohol groups, and a butenolide or lactone ring. However, structural and stereochemical isomerism coupled with the occurrence of other functional groups means that more than 400 different annonaceous acetogenins have been identified (Figure 1) [2]. 
Due to the large number annonaceous acetogenins that have been isolated and characterised, a system of classification has been introduced, which groups them according to their core structures (Figure 1). In this review attention will focus only on the total synthesis of acetogenins belonging to the non-adjacent bis-THF and non-adjacent THF-THP classes, where the cyclic ether systems are separated by four carbon atoms.

Figure 1. Classification of annonaceous acetogenins.

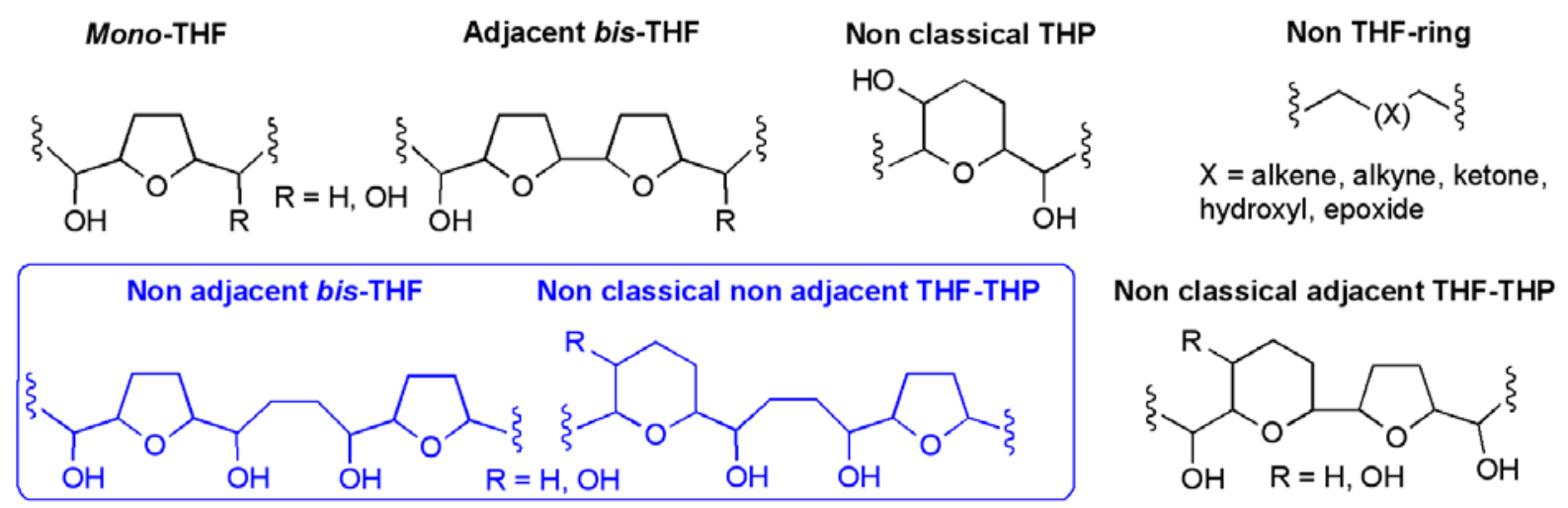

The core classes can be broken down further into sub classes by the nature of the $\gamma$-lactone, but commonly a methyl substituted $\alpha, \beta$-unsaturated $\gamma$-lactone (butenolide) is present with or without hydroxylation at $\mathrm{C} 4$ in the linking chain (Figure 2). Standardised numbering for annonaceous acetogenins begins at the lactone carbonyl carbon $(\mathrm{C} 1)$, the numbering continues down the alkyl backbone (up to $\mathrm{C} 34$ or $\mathrm{C} 36$ ) with the remaining lactone carbons numbered as shown. This numbering will be used throughout this review.

Figure 2. Structures of non-adjacent bis-THF acetogenins gigantecin (1) and 4-deoxygigantecin (2).

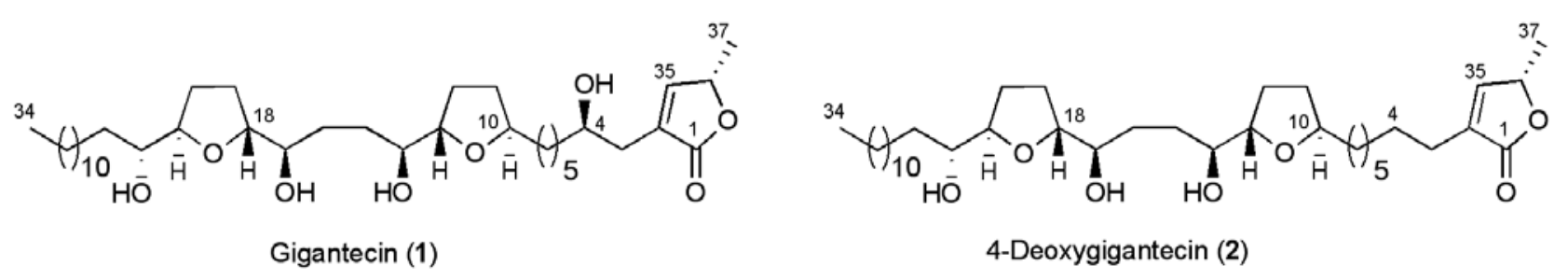

Due to their waxy physical nature, structural assignment of acetogenins by X-ray crystallography has rarely been accomplished. One exception relevant to the current review is gigantecin (1), which yielded an X-ray structure, thus providing confirmation of its relative stereochemistry [10]. Absolute stereochemistry could be deduced on the basis that all of the known acetogenins possess the $S$ configuration within their butenolide ring system (C36 in gigantecin). More typically a combination of various MS and NMR techniques are employed for structural determination, including the Mosher ester method for determining absolute stereochemistry of secondary alcohols [11,12]. Thus, molecular weight is established by ESI mass spectrometry, while THF/THP ring and hydroxyl positions on the alkyl chain are found through careful analysis of mass spectrometry fragmentation data (Figure 3 ). 
Figure 3. EIMS fragmentation for derivatised and un-derivatised cis-sylvaticin (3) [13].

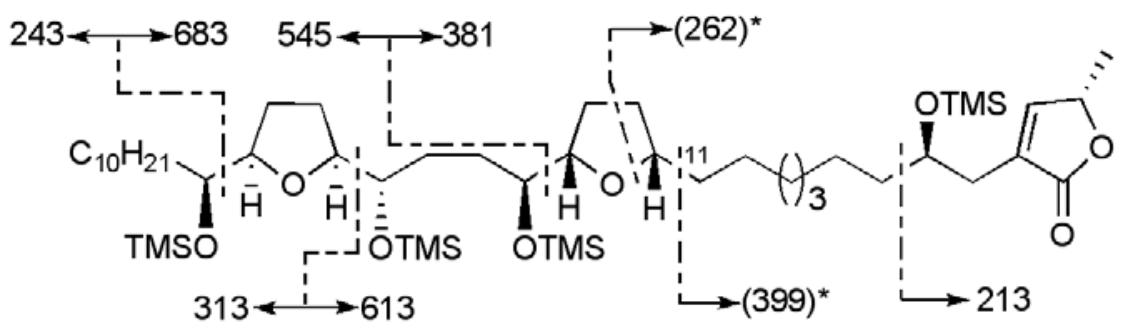

* numbers in parentheses denote EIMS peak from un-derivatised cis-sylvaticin (3)

Comparisons of ${ }^{1} \mathrm{H}$ - and ${ }^{13} \mathrm{C}$-NMR data from synthetic THF/THP cores with isolated acetogenins have been used to determine relative stereochemistry [11,14-17], although some caution should be exercised because certain groups of diastereoisomers containing cores with local symmetry cannot be differentiated $[11,18,19]$. However, none of the structures discussed herein possess local symmetry due to the absence of the hydroxyl group between the central THF ring and the butenolide (C9 of gigantecin, C11 of cis-sylvaticin). An important observation from the ${ }^{1} \mathrm{H}-\mathrm{NMR}$ spectra of THF-diol portion in acetogenins is that carbinol methine protons of hydroxyalkyl THFs possessing threo relative configurations resonate around $\delta 3.4-3.6 \mathrm{ppm}$, while carbinol methine protons of the corresponding erythro compounds resonate at $\sim \delta 3.8 \mathrm{ppm}$ [14]. Therefore, from the ${ }^{1} \mathrm{H}-\mathrm{NMR}$ spectrum of cissylvaticin (3) it can be deduced that two of the carbinol groups flanking the THF rings had threo relative configurations and the other one had an erythro relationship, although their exact positions could not be assigned purely from the ${ }^{1} \mathrm{H}-\mathrm{NMR}$ spectrum of cis-sylvaticin (Figure 4) [13].

Figure 4. Partial ${ }^{1} \mathrm{H}-\mathrm{NMR}$ spectrum of cis-sylvaticin (3) showing carbinol methine resonances for threo configured hydroxyalkyl THFs (C15/C16 and C19/C20).

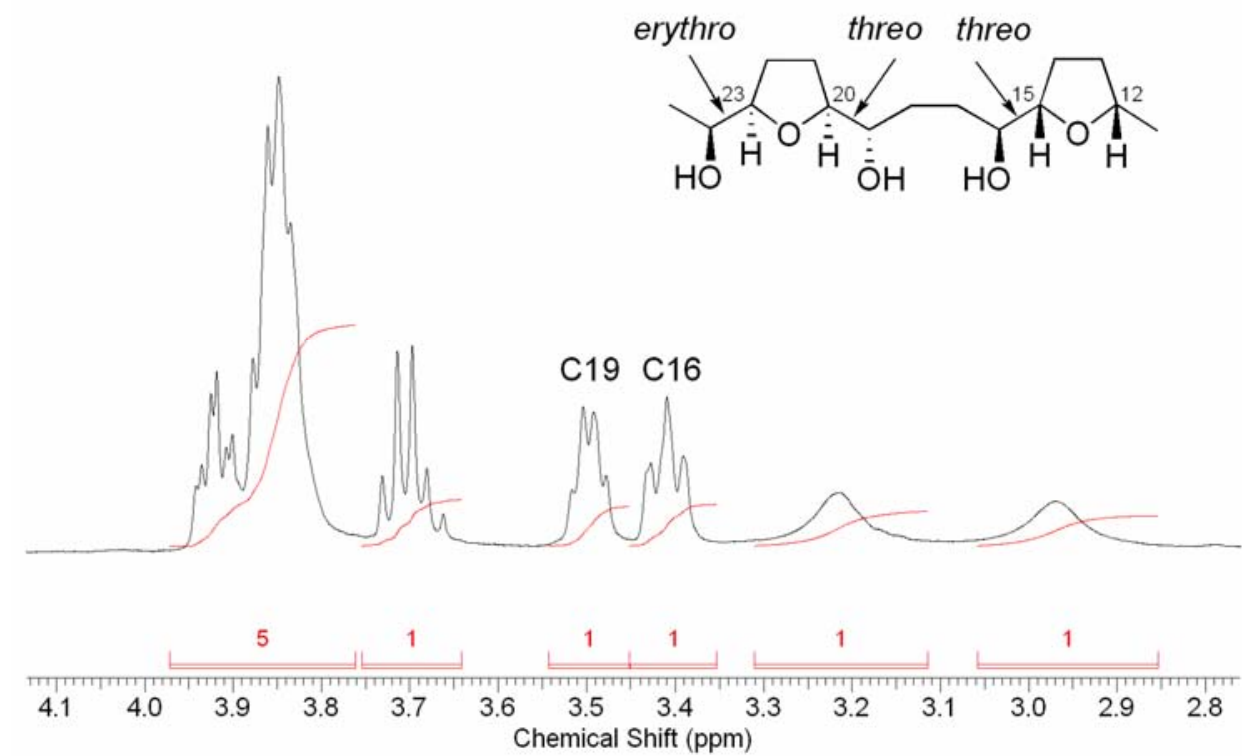

The relative relationship between $\mathrm{C} 16$ and $\mathrm{C} 19$ in cis-sylvaticin was established through ${ }^{1} \mathrm{H}-\mathrm{NMR}$ analysis of the formylidene acetal 4a (Scheme 1). Subsequent formation and NMR analysis of the 
$\mathrm{C} 4, \mathrm{C} 24$ di-Mosher ester derivatives $\mathbf{4} \mathbf{b}$ then provided the absolute stereochemistry at these stereogenic centres, and therefore in the non-adjacent bis-THF core [13]. In other non-adjacent bis-THF acetogenins, absolute stereochemistry was tentatively assigned on the basis of analogy with known structures, awaiting confirmation through total syntheses.

Scheme 1. Synthesis of derivatives to enable stereochemical determination for cis-sylvaticin.

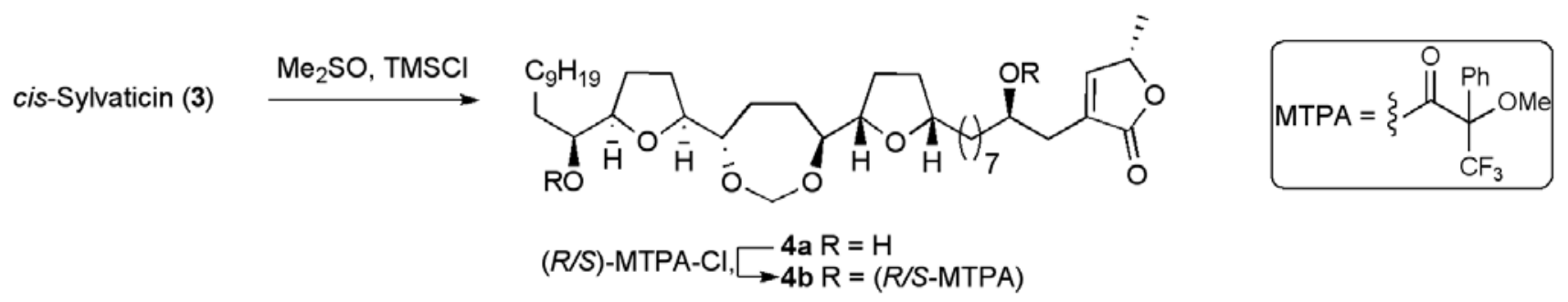

The annonaceous acetogenins have many interesting biological effects, including in vivo antitumor, anti-parasitic, pesticidal, antimalarial and antibacterial activities [2-9]. Most notably Annonaceous acetogenins act as cytotoxic anti-tumour agents, some of them possessing exceptional cytotoxicity in several human tumor cell lines $\left(\mathrm{ED}_{50}>10^{-12} \mu \mathrm{g} / \mathrm{mL}\right)$ [20,21]. Interestingly, anti-tumor activity can extend to multi-drug resistant (MDR) cancer cell lines [22,23]. Cytotoxic and anti-tumour properties of Annonaceous acetogenins are linked to their potent inhibition of mitochondrial complex I, and NADH oxidases found in cancer cells [24-27]. In fact some acetogenins rank among the most potent known inhibitors of complex I [28-31].

\section{Total Syntheses of Non-Adjacent Bis-THF Acetogenins}

Annonaceous acetogenins have provoked considerable interest from synthetic chemists and many total syntheses have been reported in the literature. These syntheses have been reviewed previously by several groups [2,32-36], including a substantial recent review by Li et al. in 2008 [37]. Due to the significant number of total syntheses of the Non-Adjacent compounds, we felt that a detailed and up to date review dedicated to this acetogenin sub-classes would provide a valuable resource for researchers working with acetogenins. Herein total syntheses of squamostatin-D, 4-deoxygigantecin, gigantecin, squamostatin-C, cis-sylvaticin, sylvaticin and mucocin will be discussed.

Before examining these total syntheses in detail it is important to appreciate the structural relationships between these different natural products synthesised. Gigantecin, squamostatin-C, cissylvaticin and sylvaticin are isomeric structures: gigantecin and squamostatin-C differ in the position of the non-Adjacent bis-THF unit along the carbon backbone, while cis-sylvaticin, sylvaticin and squamostatin- $\mathrm{C}$ are diastereoisomers. 4-Deoxygigantecin is isomeric with squamostatin- $\mathrm{D}$, the two structures differing only in the position of the non-adjacent bis-THF core and the configuration of their outermost carbinol groups (C22 and $\mathrm{C} 24$ respectively). In order to approach the total synthesis of these molecules, methods for the stereocontrolled formation of trans and cis configured THF diols will be required, which also allow for control of the vicinal oxygen functionalities. In addition, the correct connectivity between the two cyclic ether systems needs to be established. The successful realization of these objectives will be discussed within the context of the total syntheses of non-adjacent bis-THF 
acetogenins. Incomplete syntheses, the preparation of analogues and model studies will not be reviewed here.

Figure 5. Structures of non-adjacent bis-THF and non-adjacent THF-THP acetogenins.
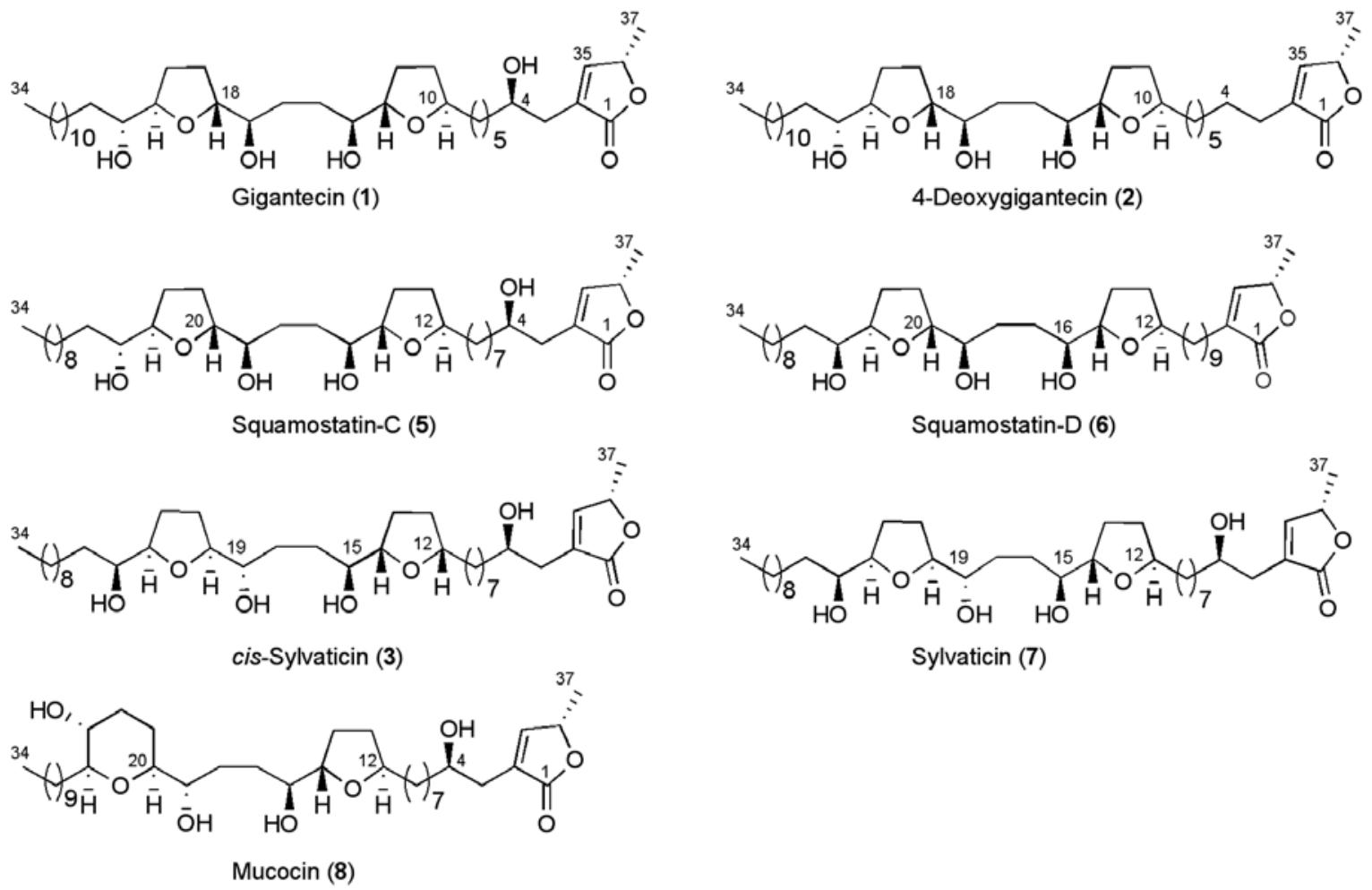

\subsection{Total Synthesis of Squamostatin-D (6)}

Squamostatin-D (6) is a nonadjacent bis-THF acetogenin isolated from the crushed seeds of Annona squamosa L [15]. Fujimoto and co-workers achieved partial structural assignment of the natural product using mass spectrometry and ${ }^{13} \mathrm{C}$ NMR spectroscopy. On the basis of NMR data they were able to determine the relative stereochemistry in the non-adjacent bis-THF core, and that both THF rings are trans configured. The absolute stereochemistry awaited confirmation by total synthesis.

Figure 6. Marshall's approach to squamostatin-D (6).

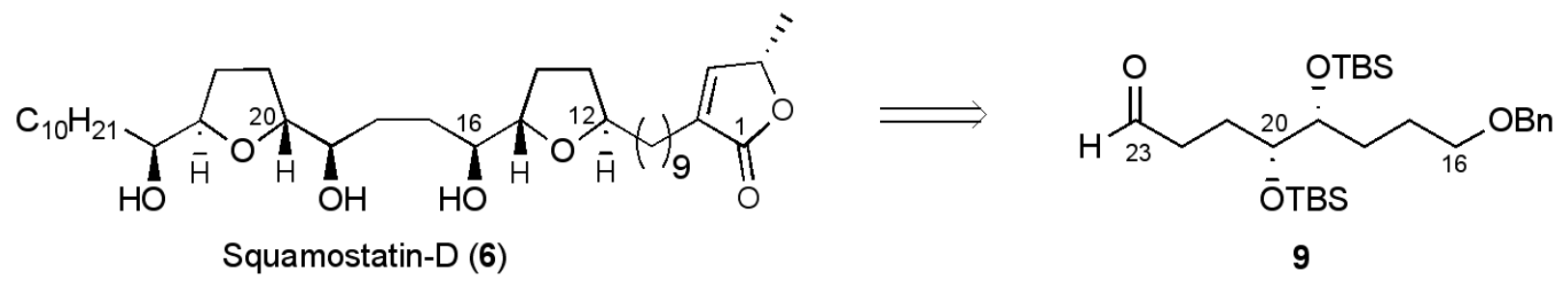

In 1998 Marshall et al. reported the total synthesis of squamostatin-D (6) using a linear approach from the known aldehyde 9 (Figure 6) [38]. A key feature in their synthesis was the implementation of highly diastereoselective additions of enantiomerically enriched $\gamma$-oxygenated allylic tin and indium reagents to aldehydes (Scheme 2) [39]. 
Scheme 2. Synthesis of aldehyde 13.<smiles>O=CCCC([OH2+])[C@H](CCCO)O[SbH2]</smiles>

9

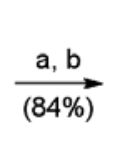

$\underset{(92 \%)}{\stackrel{e, f}{\longrightarrow}}$<smiles>COC(OC)[C@@H]1CC[C@H]([C@@H]([14CH3])OC)O1</smiles>

11<smiles>COC(=O)CC[C@H](OC)C(=O)CC[C@@H](OC)C(OC)OC</smiles>

13

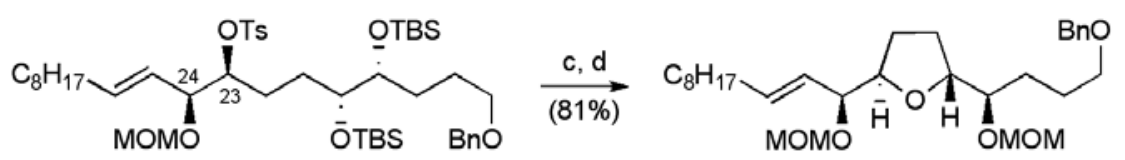

10 $\underset{(90 \%)}{\stackrel{g}{\longrightarrow}}$

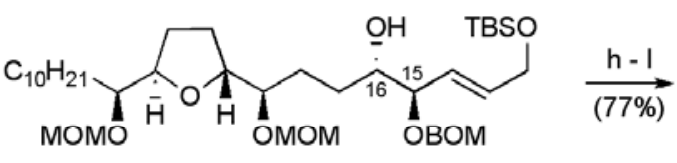

12

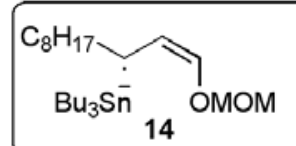

Reagents and conditions: a) $\mathbf{1 4}, \mathrm{CH}_{2} \mathrm{Cl}_{2}$, then $\mathrm{BF}_{3} \cdot \mathrm{OEt}_{2}$; b) $p$-TsCl, pyridine; c) TBAF, THF; d) MOMCl, DIPEA, $\mathrm{CH}_{2} \mathrm{Cl}_{2}$; e) $\mathrm{H}_{2}, \mathrm{Pd} / \mathrm{C}$, EtOH; f) Dess-Martin periodinane; g) $\mathrm{InCl}_{3}$, EtOAc, then 15; h) MOMCl, DIPEA, $\mathrm{CH}_{2} \mathrm{Cl}_{2}$; i) $\mathrm{H}_{2} / \mathrm{Rh}_{-} \mathrm{Al}_{2} \mathrm{O}_{3}$, EtOAc; j) TBAF, THF; 1) Dess-Martin periodinane.

The addition allylic tin reagent 14 to aldehyde $\mathbf{8}$ was used to set up the $(23 R, 24 R)$ threo configuration between $\mathrm{C} 23$ and $\mathrm{C} 24$ in squamostatin-D. The resulting secondary alcohol was converted to tosylate 10, which cyclized upon exposure to TBAF to afford aldehyde $\mathbf{1 1}$ after a series of protecting group and functional group manipulations. The aldehyde $\mathbf{1 1}$ underwent an erythro selective addition of an $\gamma$-oxygenated allylic indium reagent derived from organotin 15, thereby establishing the $15 R, 16 S$ configuration in $\mathbf{1 2}$. The aldehyde 13, obtained from secondary alcohol 12, underwent a highly diastereoselective $(d r>95: 5)$ addition of the organozinc reagent 16 in the presence of bistriflamide ligand 20 (Scheme 3). Construction of a fully protected C1-C34 fragment 17 containing the non-adjacent bis-THF core was completed by closure of the second THF ring by displacement of the C15 carbinol.

The butenolide portion was completed through application of chemistry described by Yao et al [40]. Deprotonation of ester 17 allowed reaction with aldehyde 21 to give an aldol product, which when desilylated, delivered lactone 18. Dehydration of lactone 18 was achieved with $\mathrm{Tf}_{2} \mathrm{O}$ and $\mathrm{Et}_{3} \mathrm{~N}$ and deprotection of the resulting butenolide 19 completed the synthesis of squamostatin-D (6). Squamostatin-D was synthesised in 27 linear steps from 1,4-butandiol in a total yield of 5.5\%.

Comparisons between NMR spectroscopic data, optical rotation values and melting points for synthetic and natural materials supported the relative and absolute stereochemistry proposed for squamostatin-D (6). Further confirmation of the correct absolute stereochemical assignment was provided through synthesis of the tri- $(R)$-Mosher ester derivative of squamostatin-D, and comparison of ${ }^{1} \mathrm{H}$ NMR data with that obtained by Fujimoto's group for the isolated natural product. 
Scheme 3. Total synthesis of squamostatin-D (6).
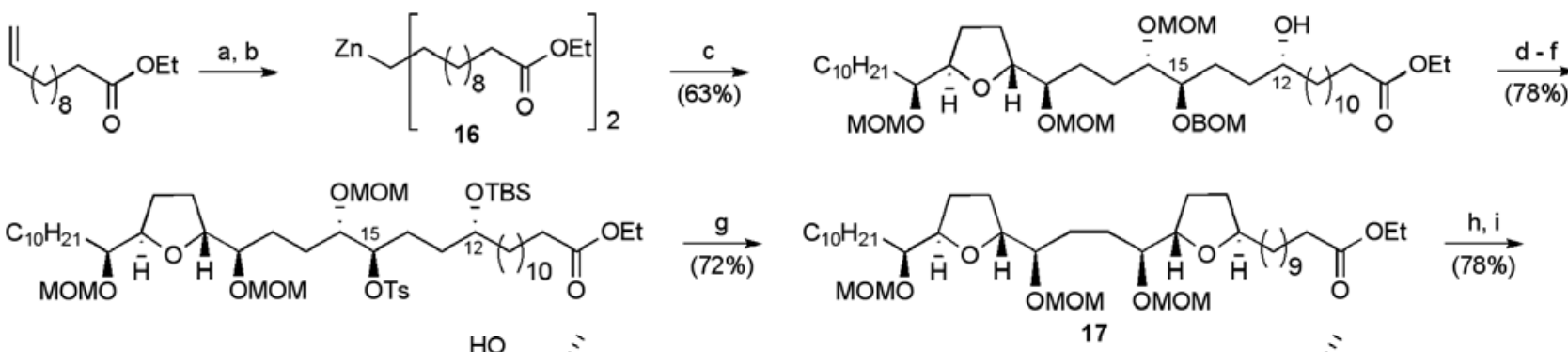

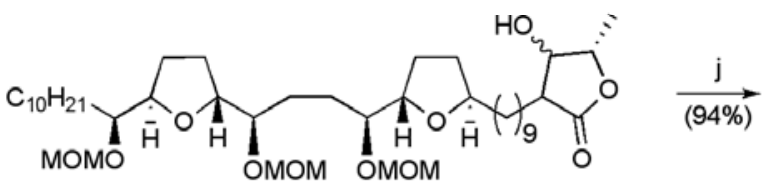

18

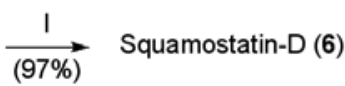
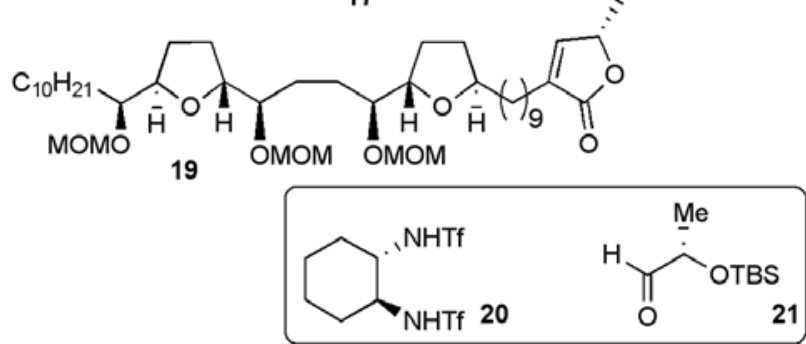

Reagents and conditions: a) $\mathrm{Et}_{2} \mathrm{BH}$; b) $\mathrm{Et}_{2} \mathrm{Zn}$; c) $\mathrm{Ti}(\mathrm{O}-i \mathrm{Pr})_{4}, \mathrm{MePh}, \Delta$, then 13 ; d) $\mathrm{TBSCl}$, imidazole, DMF; e) $\mathrm{H}_{2}, \mathrm{Pd} / \mathrm{C}$, EtOH; f) $p$-TsCl, pyridine; g) TBAF, THF; h) LDA, THF, then 21; i) TBAF, THF; j) $\left.\left(\mathrm{CF}_{3} \mathrm{CO}\right)_{2} \mathrm{O}, \mathrm{Et}_{3} \mathrm{~N}, \mathrm{CH}_{2} \mathrm{Cl}_{2} ; \mathrm{l}\right) \mathrm{HCl}$, THF, $\mathrm{MeOH}$.

\subsection{Total Synthesis of 4-Deoxygigantecin (2)}

4-Deoxygigantecin (2), a structural isomer of squamostatin-D, was isolated by McLaughlin's group from Goniothalamus giganteus [41], and its absolute stereochemistry was not known prior to synthesis. However, the non-adjacent bis-THF core stereochemistry was assumed to match that of gigantecin (1) which had been assigned by X-ray crystallography [10]. Makabe and co-workers reported a synthesis of 4-deoxygigantecin (2) in 1998, which took advantage of a Pd-catalysed crosscoupling to link the THF and butenolide fragments (Figure 7), each of which was assembled in a linear fashion [42-44].

Figure 7. Overview of Makabe's approach to 4-deoxygigantecin (2).

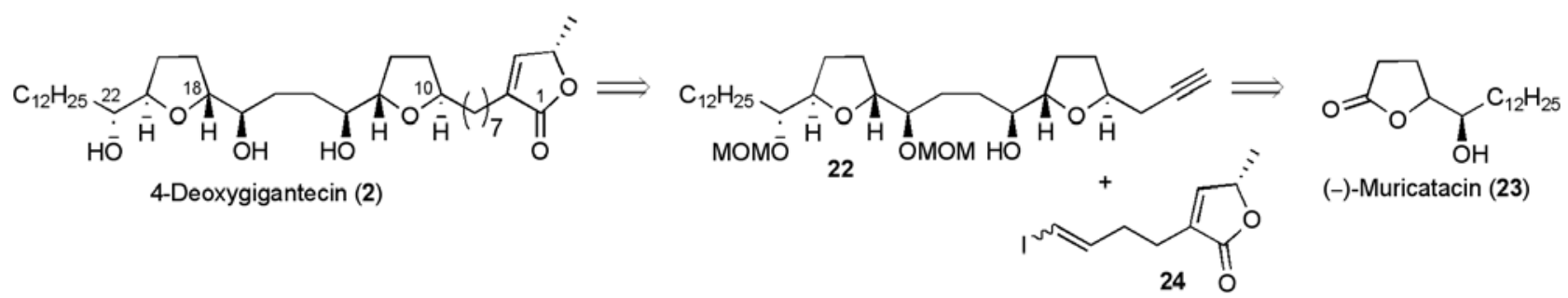

Bis-THF alkyne 22 was synthesised from mono-THF acetogenin derivative (-)-muricatacin (23), which is avaliable in 7 steps from propargyl alcohol in $27 \%$ yield using the Sharpless asymmetric dihydroxylation to set the $\mathrm{C} 21$ and C22 stereochemistry [45]. Protection of (-)-muricatacin (23), DIBAL-H reduction and Wittig olefination delivered the Z-alkene 25 (Scheme 4). Subsequent epoxidation and cyclisation occurred with little stereoselectivity (26a:26b $\sim 3: 2$ ), and the resulting mixture of tetrahydrofurans was separated following derivatisation. The desired mono-THF diastereoisomer 27 was taken through 10 steps to $E$-alkenol 28, which was mesylated prior to 
Sharpless-AD and closure of the second THF under basic conditions. The left hand fragment 22 was synthesised in 25 steps from propargylic alcohol in $1.9 \%$ yield.

Scheme 4. Synthesis of bis-THF alkyne 22.
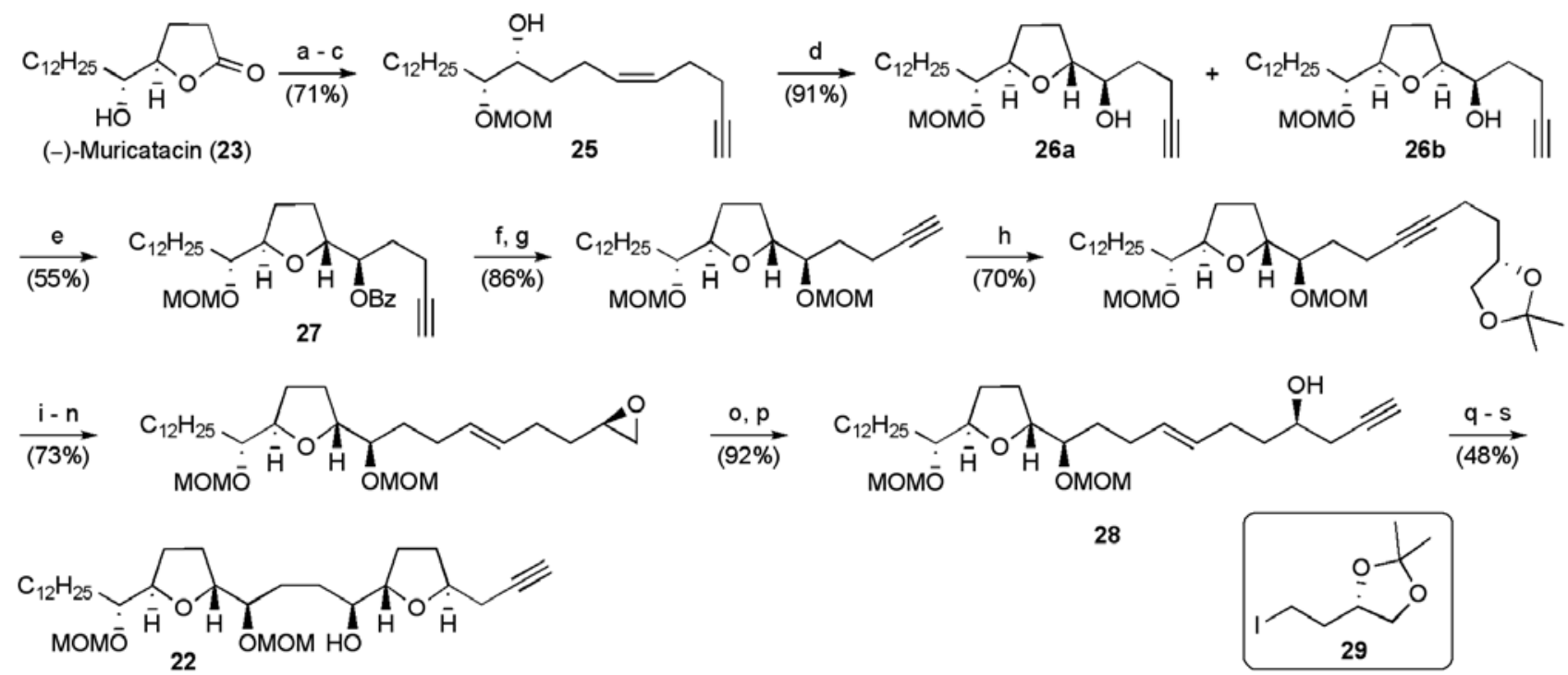

Reagents and conditions: a) MOMCl, DIPEA, $\mathrm{CH}_{2} \mathrm{Cl}_{2} ;$ b) DIBAL-H, $\mathrm{CH}_{2} \mathrm{Cl}_{2}$;

c) $\mathrm{HC} \equiv \mathrm{C}\left(\mathrm{CH}_{2}\right)_{3} \mathrm{Ph}_{3} \mathrm{P}^{+} \mathrm{I}^{-}, \mathrm{NaOMe}$, DMF; d) $m$-CPBA, $\mathrm{CH}_{2} \mathrm{Cl}_{2}$; e) $\mathrm{BzCl}$, pyridine; f) $\mathrm{NaOH}, \mathrm{MeOH}$;

g) MOMCl, DIPEA, $\mathrm{CH}_{2} \mathrm{Cl}_{2}$; h) $n$-BuLi, THF, then 29; i) $\mathrm{Na} / \mathrm{NH}_{3}, t$-BuOH, THF; j) $60 \% \mathrm{AcOH}$,

$\Delta$; l) TBSCl, Et ${ }_{3} \mathrm{~N}$, DMAP, $\mathrm{CH}_{2} \mathrm{Cl}_{2}$; m) $\mathrm{MsCl}, \mathrm{Et}_{3} \mathrm{~N}, \mathrm{CH}_{2} \mathrm{Cl}_{2}$; n) TBAF, THF, then $10 \% \mathrm{NaOH}$;

o) $\mathrm{TMSC} \equiv \mathrm{CH}, n$-BuLi, $\mathrm{BF}_{3} \cdot \mathrm{OEt}_{2}$, THF; p) TBAF, THF; q) $\mathrm{MsCl}, \mathrm{Et}_{3} \mathrm{~N}$; r) AD-mix- $\alpha, t$-BuOH$\mathrm{H}_{2} \mathrm{O}$; s) Triton $\mathrm{B}, \mathrm{MeOH}$.

Ethyl $(S)$-lactate served as the source of chirality for the butenolide portion of the molecule, which was prepared in 12 steps and 14.6\% yield. An established route provided lactone 30, which was alkylated to give alcohol 31 (Scheme 5) [46]. Cleavage of the THP group followed by sulfide oxidation and thermal elimination of sulfenic acid returned the butenolide 32 containing a free primary alcohol group that was oxidised and converted to the vinyl iodide $\mathbf{2 4}$ using a Takai olefination.

Scheme 5. Synthesis of butenolide fragment 24.

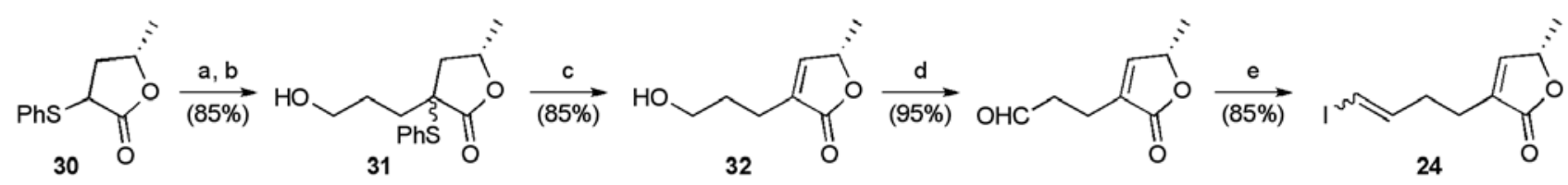

Reagents and conditions: a) NaHMDS, THF/HMPA, I( $\left.\mathrm{CH}_{2}\right)_{3} \mathrm{OTHP}$; b) $p$-TsOH, $\mathrm{MeOH}$; c) $m$ CPBA, then $\Delta$; d) Dess-Martin periodinane, $\mathrm{ClCH}_{2} \mathrm{CH}_{2} \mathrm{Cl}$; e) $\mathrm{CrCl}_{2}, \mathrm{CHI}_{3}$, THF.

The fragments 22 and 24 could then be combined using Sonogashira chemistry to give enyne $\mathbf{3 3}$ (Scheme 6). A selective catalytic hydrogenation followed by global deprotection gave (+)-4deoxygigantecin (2) in 28 linear steps and 1.2\% yield from propargylic alcohol. ${ }^{1} \mathrm{H}$ NMR and optical rotation were consistent with the data reported for the natural sample of 4-deoxygigantecin (2). 
Scheme 6. Total synthesis of 4-deoxygigantecin (2)

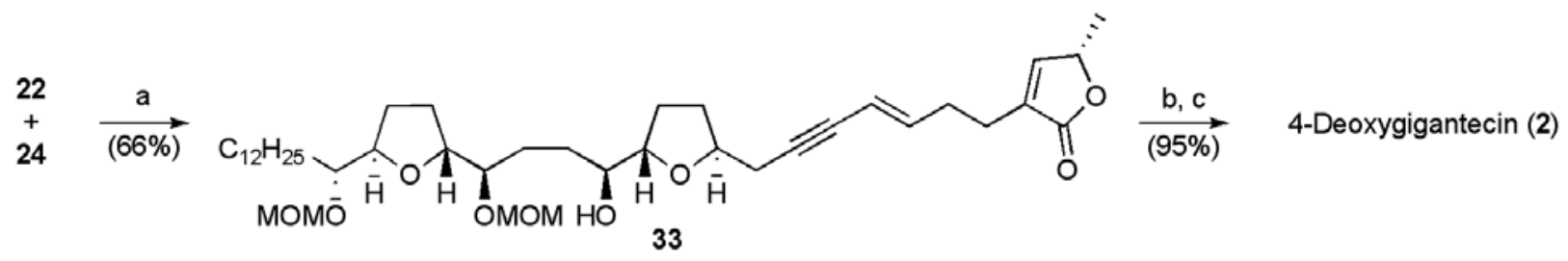

Reagents and conditions: a) $\mathrm{Pd}\left(\mathrm{PPh}_{3}\right)_{4}, \mathrm{CuI}, \mathrm{Et}_{3} \mathrm{~N}, \mathrm{MePh}$; b) $\left.\mathrm{H}_{2}, \mathrm{Rh}\left(\mathrm{PPh}_{3}\right)_{3} \mathrm{Cl}, \mathrm{C}_{6} \mathrm{H}_{6} ; \mathrm{c}\right) \mathrm{BF}_{3} \cdot \mathrm{OEt}_{2}, \mathrm{Me}_{2} \mathrm{~S}$.

\subsection{Total Syntheses of Gigantecin (1)}

Gigantecin (1) is structurally identical to 4-deoxygigantecin, apart from presence of a $\mathrm{C} 4$ secondary alcohol possessing the $R$ configuration. Interestingly, gigantecin (1) has been isolated from two different sources in geographically distinct locations; the bark of Goniothalamus giganteus in Southeast Asia and from the seeds of the Brazilian plant Annona coriacea [10,47]. Assignment of the gross structure and partial stereochemical determination was initially performed using spectroscopic methods. Subsequently, the structure and stereochemistry of gigantecin was established by X-ray crystallography [10]. Gigantecin (1) demonstrated potent cytotoxicity against human tumor cell lines. The cells lines in decreasing activity are U251MG (glioblastoma multiforme) > HT-29 (colon adenocarcinoma) $>$ A-549 (lung carcinoma) $>$ MCF-7 (breast adenocarcinoma). The $\mathrm{ED}_{50}$ values were between $4.3-0.003 \mu \mathrm{g} / \mathrm{mL}$ [47]. There have been two total syntheses of gigantecin reported by the groups of Crimmins and Hoye in 2004 and 2006 respectively [48,49].

Crimmins' synthesis is based on a convergent coupling strategy with 3 main fragments 34, 35 and 36 (Figure 8) [48]. Distinctive features of this route are the use an asymmetric glycolate aldol reaction to assemble acyclic ethers and set the required stereochemistry at C13, C14, C21 and C22 [50], and closure of the five-membered oxygen heterocycles under ring-closing metathesis conditions. The synthesis of the central THF fragment 35 required glycolate 37, which was derived from $(S)$-benzyl glycidyl ether (Scheme 7). The chiral auxiliary-controlled asymmetric glycolate aldol reaction gave alcohol 38 with high selectivity ( $>20: 1$ major:all other isomers).

Figure 8. Crimmims' approach to gigantecin (1).
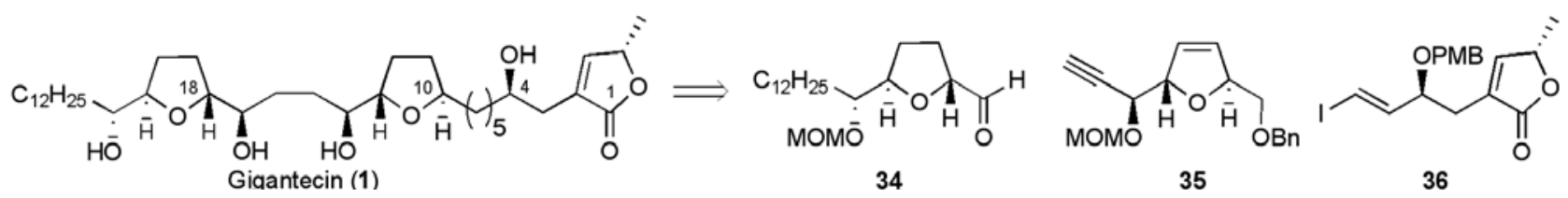

From aldol 38, a series of functional group manipulations returned diene 39, which cyclised in the presence of the second-generation Grubbs catalyst $(5 \mathrm{~mol} \%)$ to give dihydrofuran 40. Fragment 35 was obtained by removal of the silyl group, completing its synthesis in 10 steps from $(S)$-benzyl glycidyl ether in 52\% yield. The left hand fragment 34 was created in an analogous manner via the enantiomeric glycolate ent-37 (Scheme 8), in 11 steps from $(R)$-benzyl glycidyl ether and 38\% overall yield. 
Scheme 7. Synthesis of alkyne fragment 35.
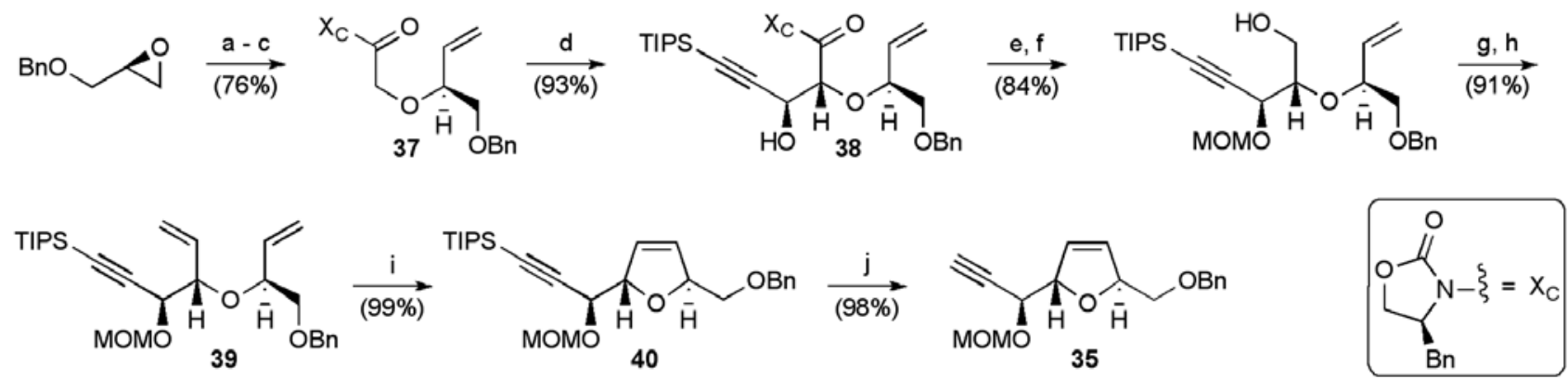

Reagents and conditions: a) $\mathrm{Me}_{3} \mathrm{~S}^{+} \mathrm{I}^{-}$, $n$-BuLi, THF; b) $\mathrm{NaH}, \mathrm{BrCH}_{2} \mathrm{CO}_{2} \mathrm{H}$, THF; c) $\mathrm{Me}_{3} \mathrm{CCOCl}$, $\mathrm{Et}_{3} \mathrm{~N}$, THF, (S)-lithio-4-benzyl-oxazolidin-2-one; d) $\mathrm{TiCl}_{4}$, DIPEA, NMP, triisopropylsilanylpropynal, $\mathrm{CH}_{2} \mathrm{Cl}_{2}$; e) MOMCl, DIPEA, $\mathrm{CH}_{2} \mathrm{Cl}_{2}, \mathrm{DMAP}$; f) $\mathrm{LiBH}_{4}, \mathrm{MeOH}, \mathrm{Et}_{2} \mathrm{O}$; g) $(\mathrm{COCl})_{2}$, DMSO, $\mathrm{Et}_{3} \mathrm{~N}, \mathrm{CH}_{2} \mathrm{Cl}_{2}$; h) $\mathrm{Ph}_{3} \mathrm{P}=\mathrm{CH}_{2}$, THF; i) $\mathrm{Cl}_{2}\left(\mathrm{Cy}_{3} \mathrm{P}\right)(\mathrm{IMes}) \mathrm{Ru}=\mathrm{CHPh}, \mathrm{CH}_{2} \mathrm{Cl}_{2}$; j) $n-\mathrm{Bu}_{4} \mathrm{NF}$, THF.

Scheme 8. Synthesis of aldehyde fragment 34.

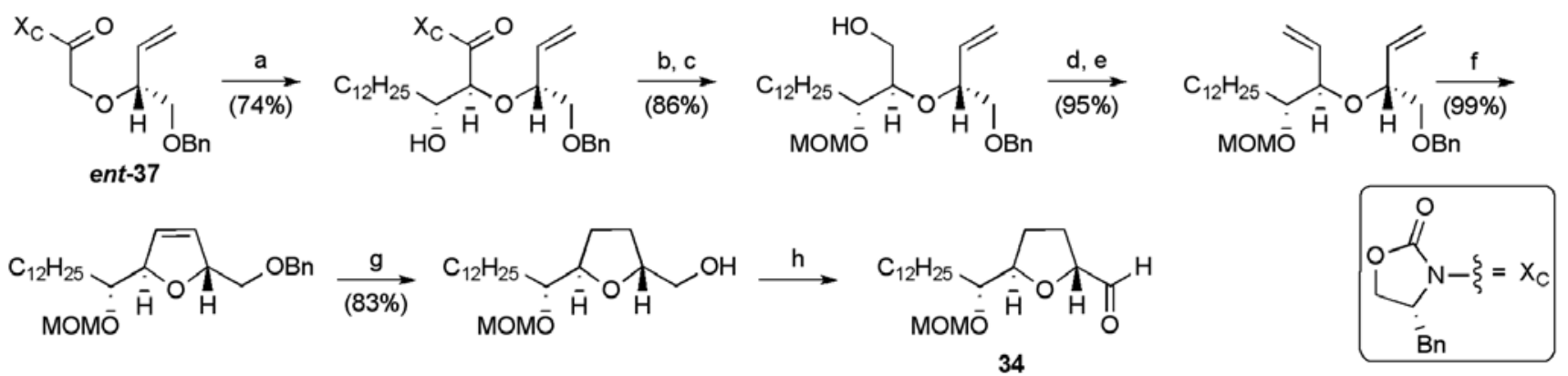

Reagents and conditions: a) $\mathrm{TiCl}_{4}$, DIPEA, NMP, tridecanal; b) $\mathrm{MeOCH}_{2} \mathrm{Cl}$, DIPEA, DMAP; c) $\mathrm{LiBH}_{4}, \mathrm{MeOH}, \mathrm{Et}_{2} \mathrm{O}$; d) $(\mathrm{COCl})_{2}, \mathrm{DMSO}, \mathrm{Et}_{3} \mathrm{~N}$; e) $\mathrm{Ph}_{3} \mathrm{P}=\mathrm{CH}_{2}$, THF; f) $\mathrm{Cl}_{2}\left(\mathrm{Cy}_{3} \mathrm{P}\right)(\mathrm{IMes}) \mathrm{Ru}=\mathrm{CHPh}$, $\left.\left.\mathrm{CH}_{2} \mathrm{Cl}_{2} ; \mathrm{g}\right) \mathrm{H}_{2}, \mathrm{Pd} / \mathrm{C} ; \mathrm{h}\right)(\mathrm{COCl})_{2}, \mathrm{DMSO}, \mathrm{Et}_{3} \mathrm{~N}$.

Auxiliary-controlled diastereoselective alkylation of imide 41 afforded 42 ( $\mathrm{dr}>$ 98:2, Scheme 9) correctly established the $\mathrm{C} 4$ stereogenic centre needed in the butenolide fragment [51]. Reductive cleavage of the $N$-acyloxozolidinone 42, and subsequent TBS protection of the resulting primary alcohol afforded vinyl bromide 43. Lithium-bromine exchange and trapping with $\mathrm{CO}_{2}$ gave an acrylic acid, which was coupled with secondary alcohol $\mathbf{4 7}$ under Mitsunobu conditions to provide diene 44. The diene was subjected to RCM delivering butenolide 45. Deprotetion of the primary alcohol, oxidation and Takai olefination secured the desired butenolide fragment $\mathbf{3 6}$ in 11 steps from 4-methoxybenzyl alcohol.

Final fragment assembly commenced with the union of the THF fragments 34 and 35 using an asymmetric acetylide addition to afford a single detectable diastereoisomer 48 (Scheme 10). Conversion of benzyl ether 48 to a terminal alkyne 49 then permitted attachment of the butenolide fragment 36 under Sonogashira conditions. Selective hydrogenation of the resulting eneyne $\mathbf{5 0}$ followed by global deprotection provided gigantecin (1) in 19 linear steps from benzyl glycidyl ether with a yield of $6.5 \%$. 
Scheme 9. Synthesis of butenolide fragment 36.

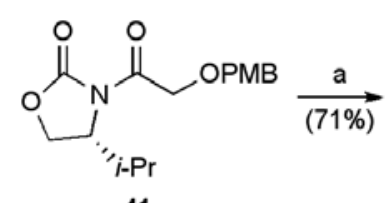

41

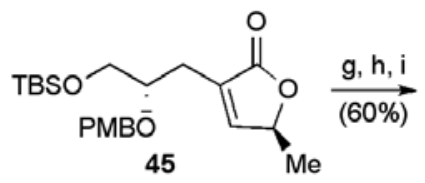<smiles>C=C(Br)CC(O[Na])C(=O)N1C(=O)OC[C@H]1[14CH3]</smiles><smiles>C=C(Br)CC(C[13CH3])C[18OH]</smiles>

43<smiles>[M]C(C=C)OC(=O)C(=C)CC(COC(C)(C)C)OCC</smiles>

44

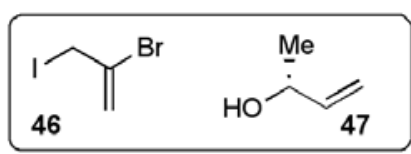

Reagents and conditions: a) $\mathrm{NaN}\left(\mathrm{SiMe}_{3}\right)_{2}$, THF, 46; b) $\mathrm{NaBH}_{4}$, THF, $\mathrm{H}_{2} \mathrm{O}$; c) TBSCl, imidazole, $\mathrm{CH}_{2} \mathrm{Cl}_{2}$; d) $t$-BuLi, THF; $\mathrm{CO}_{2}$; e) DEAD, $\mathrm{Ph}_{3} \mathrm{P}$, THF, 1.21; f) $\mathrm{Cl}_{2}\left(\mathrm{Cy}_{3} \mathrm{P}\right)(\mathrm{IMes}) \mathrm{Ru}=\mathrm{CHPh}, \mathrm{CH}_{2} \mathrm{Cl}_{2}$; g) $3 \mathrm{HF} \cdot \mathrm{Et}_{3} \mathrm{~N}, \mathrm{CH}_{3} \mathrm{CN}$; h) $(\mathrm{COCl})_{2}, \mathrm{DMSO}, \mathrm{Et}_{3} \mathrm{~N}, \mathrm{CH}_{2} \mathrm{Cl}_{2}$; i) $\mathrm{CHI}_{3}, \mathrm{CrCl}_{2}, \mathrm{THF}$.

Scheme 10. Total synthesis of gigantecin (1).
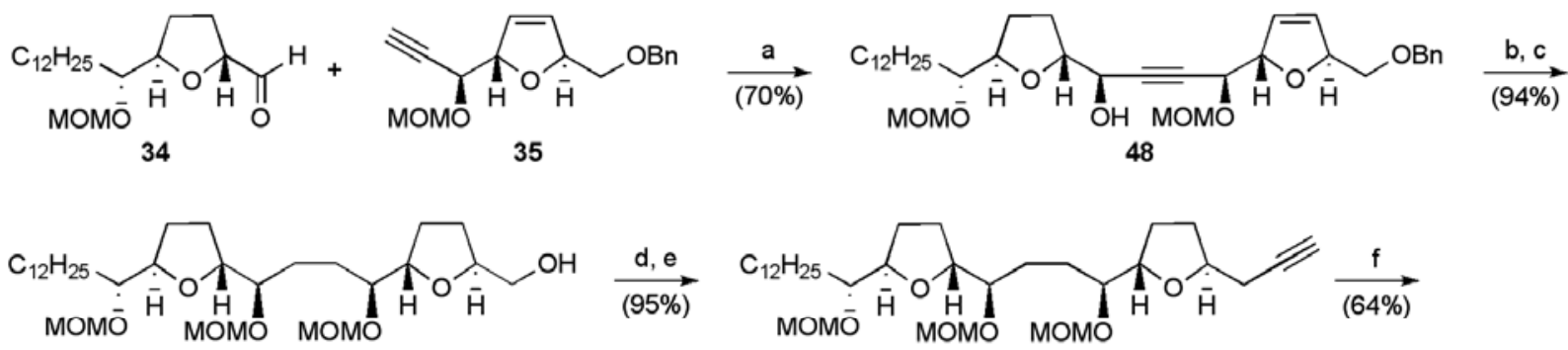

49

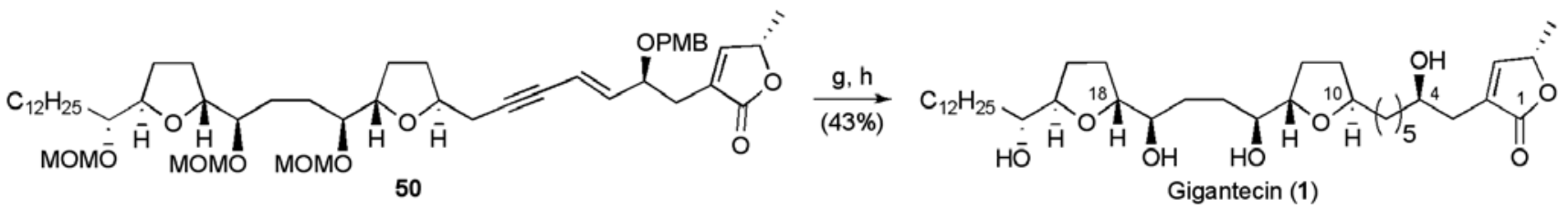

Reagents and conditions: a) $\mathrm{Zn}(\mathrm{OTf})_{2},(-)-N$-methylephedrine, $\mathrm{PhCH}_{3}$; b) $\mathrm{MOMCl}$, DIPEA, $\mathrm{CH}_{2} \mathrm{Cl}_{2}$, DMAP; c) $\mathrm{H}_{2}, \mathrm{Pd} / \mathrm{C}, \mathrm{EtOH}$; d) $\mathrm{Tf}_{2} \mathrm{O}, \mathrm{Et}_{3} \mathrm{~N}, \mathrm{CH}_{2} \mathrm{Cl}_{2}$; e) $\mathrm{Me}_{3} \mathrm{SiCCH}, n$-BuLi, THF, HMPA; $\mathrm{MeOH}$; f) 36, $\left.\left.\mathrm{Pd}\left(\mathrm{PPh}_{3}\right)_{4}, \mathrm{CuI}, \mathrm{DIPEA}, \mathrm{THF} ; \mathrm{g}\right) \mathrm{H}_{2}, \mathrm{Rh}\left(\mathrm{PPh}_{3}\right)_{3} \mathrm{Cl}, \mathrm{C}_{6} \mathrm{H}_{6}, \mathrm{EtOH}, \mathrm{LiI} ; \mathrm{h}\right) \mathrm{BF}_{3} \bullet \mathrm{OEt}_{2}$, $\mathrm{Me}_{2} \mathrm{~S}$.

Hoye's approach to gigantecin also exploited a convergent three fragment approach, using a onepot double metathesis reaction to unite the THF fragments and couple the butenolide portion (Figure 9) [49].

Figure 9. Hoye's metathesis-based approach to gigantecin (1).

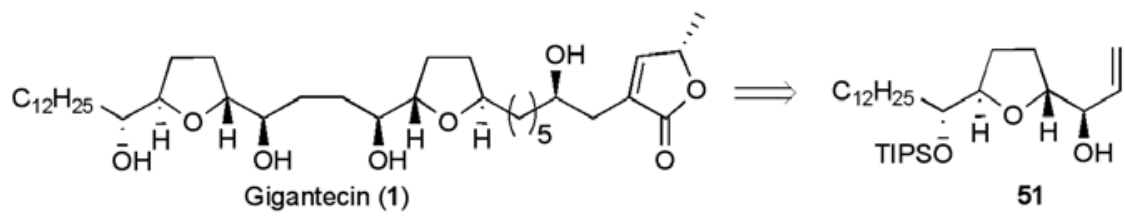<smiles>C=CCC1CC[C@](O)([C@H](O)C=C)O1</smiles><smiles>C=CCC[C@H](O)CC1=C[C@@H](C)OC1=O</smiles> 
Both trans-THF moieties present within fragments $\mathbf{5 1}$ and $\mathbf{5 2}$ were installed by means of selective iodoetherification reactions. The synthesis of left hand fragment $\mathbf{5 1}$ proceeded by way of the lactone 54 (4 steps from tridecanal in 73\% yield, Scheme 11). DIBAL-H reduction of lactone 54 to the lactol and olefination gave ester 55. Reduction of 55, and iodoetherification of the resulting allylic alcohol afforded the iodohydrin as a 4:1 mixture of isomers favouring the desired trans THF $\mathbf{5 6}$. Fragment $\mathbf{5 1}$ was completed by reaction of the iodohydrin 56 with dimethylsulfonium methylide. Overall the fragment synthesis required 9 steps from tridecanal and proceeded in $19.3 \%$ yield.

Scheme 11. Synthesis of left hand THF fragment 51.
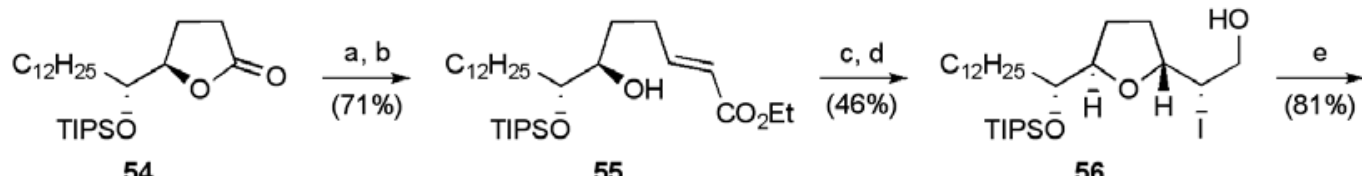

56

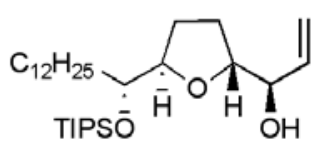

51

Reagents and conditions: a) DIBAL-H, PhMe; b) $\mathrm{Ph}_{3} \mathrm{PCHCO}_{2} \mathrm{Et}, \mathrm{PhMe}$; c) DIBAL-H, PhMe; d) $\mathrm{I}_{2}$, $\mathrm{K}_{2} \mathrm{CO}_{3}$, THF; e) $\mathrm{Me}_{3} \mathrm{~S}^{+} \mathrm{I}^{-}, n$-BuLi, THF.

A Leighton asymmetric allylation of aldehyde 57 was employed to introduce the $\mathrm{C} 11$ stereogenic centre in the hydroxyester 58 (Scheme 12). The trans-THF ring was then created using a similar iodoetherification approach, followed by reaction with the sulfonium ylide to give the second THF fragment 52 in 7 steps from $\gamma$-butyrolactone in a total yield of $9.4 \%$.

Scheme 12. Synthesis of the central THF fragment 52.

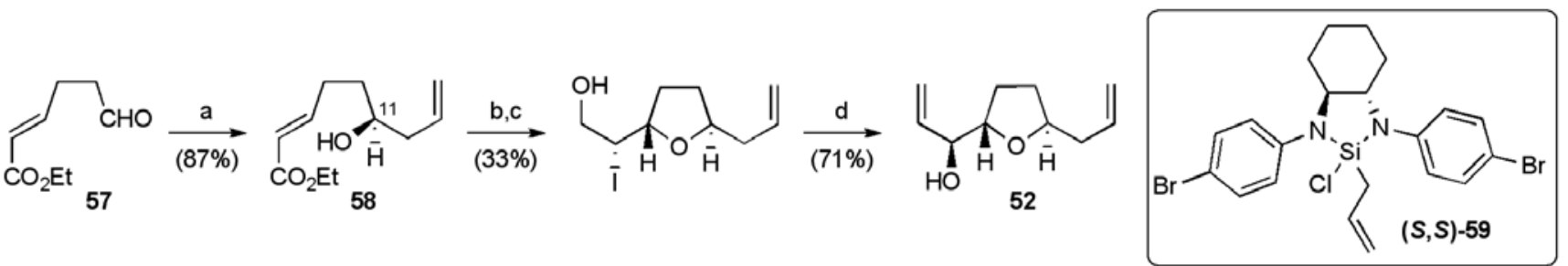

Reagents and conditions: a) (S,S)-59, $\mathrm{CH}_{2} \mathrm{Cl}_{2}$; b) DIBAL-H, PhMe; c) $\mathrm{I}_{2}, \mathrm{~K}_{2} \mathrm{CO}_{3}$, THF; d) $\mathrm{Me}_{3} \mathrm{~S}^{+} \mathrm{I}^{-}$, $n$-BuLi, THF.

Butenolide fragment 53 was synthesised through a modification of known route (Scheme 13) [52]. Epoxide 60 (available from kinetic resolution of racemic 1,2-epoxy-5-hexene) was opened with the lithiated alkyne 63 to deliver alcohol 61. After a sequence of protecting group manipulations, hydroalumination and iodine quench gave the vinyl iodide 62. Palladium-catalysed carbonylative cyclisation was used to create the butenolide and complete the fragment 53 in an overall yield of $21 \%$ over six steps from racemic 1,2-epoxy-5-hexene.

The sequencing of the double metathesis reaction was critical and, following tethering of the two allylic alcohol fragments 51 and 52, the cross-metathesis reaction between the two type-I olefins was best achieved with 4 equivalents of the butenolide fragment under slow addition of Grubbs II catalyst. The cyclisation also proceeded under the same conditions to give the product 65 in $63 \%$ yield based on triene 64. For further discussion of temporary silicon-tethered RCM see Evans' synthesis of mucocin below. Attempts to perform the RCM first followed by CM led to increased byproduct formation. 
Selective diene reduction with diimide and global deprotection secured gigantecin (1), in a total yield of $4.4 \%$ for the longest linear sequence of 13 steps from tridecanal.

Scheme 13. Synthesis of butenolide fragment 53.

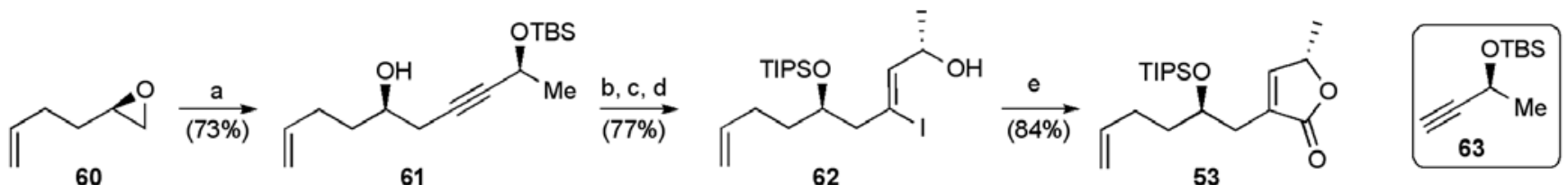

Reagents and conditions: a) 63, $n$-BuLi, $\mathrm{BF}_{3} \cdot \mathrm{OEt}_{2}$, THF; b) TIPSOTf, 2,6-lutidine, $\mathrm{CH}_{2} \mathrm{Cl}_{2}, \mathrm{rt}$; c) PPTS, EtOH; d) (i) Red-Al, THF, (ii) EtOAc, (iii) $\mathrm{I}_{2}$; e) $\mathrm{CO}$ (45 PSI), $\mathrm{Pd}\left(\mathrm{PPh}_{3}\right)_{2} \mathrm{Cl}_{2}, \mathrm{~K}_{2} \mathrm{CO}_{3}$, $\mathrm{H}_{2} \mathrm{NNH}_{2}$, THF.

Scheme 14. Hoye's total synthesis of gigantecin (1).
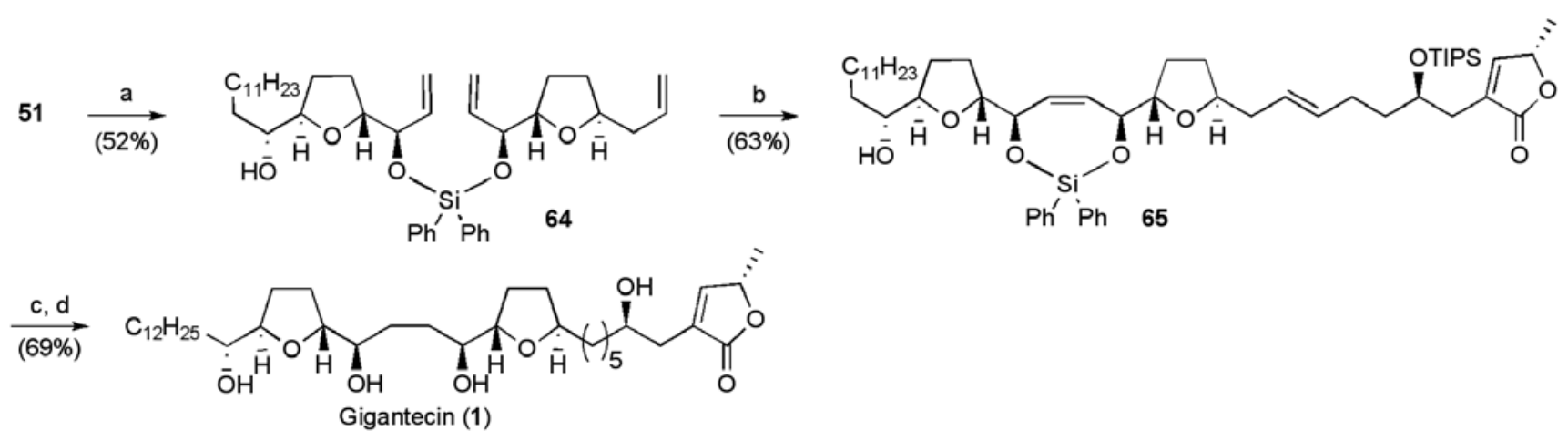

Reagents and conditions: a) $\mathrm{Ph}_{2} \mathrm{SiCl}_{2}$, pyridine, then 52, pyridine; b) 53, $\mathrm{Cl}_{2}\left(\mathrm{Cy}_{3} \mathrm{P}\right)(\mathrm{IMes}) \mathrm{Ru}=\mathrm{CHPh}(20 \mathrm{~mol} \%), \mathrm{CH}_{2} \mathrm{Cl}_{2}$, slow addition; c) TsNHNH${ }_{2}, \mathrm{NaOAc}, \mathrm{H}_{2} \mathrm{O}, \mathrm{DME}$, $\Delta$; d) $5 \% \mathrm{HF} / \mathrm{MeCN}$.

\subsection{Total Synthesis of Squamostatin-C (Bullatanocin) (5)}

Squamostatin-C (5) is a structural isomer of gigantecin, that has been isolated from 2 sources; McLaughlin's group isolated squamostatin-C from from the bark of Annona bullata Rich, while Fujimoto's group isolated squamostatin-C from from the seeds of Annona squamosa [15,53]. Relative and absolute structural assignments were performed using mass spectrometry with EI fragmentation and NMR spectroscopy [54,55]. It is of interest that squamostatin-C (5) demonstrates potent cytotoxicity against colon cell line HT-29 and lung cell line A-549 with ED $_{50}$ values of less than $10^{-8} \mathrm{~g} / \mathrm{mL}[53]$.

Figure 10. Mootoo's route to squamostatin-C (5) using cross-metathesis to form the nonadjacent bis-THF core.

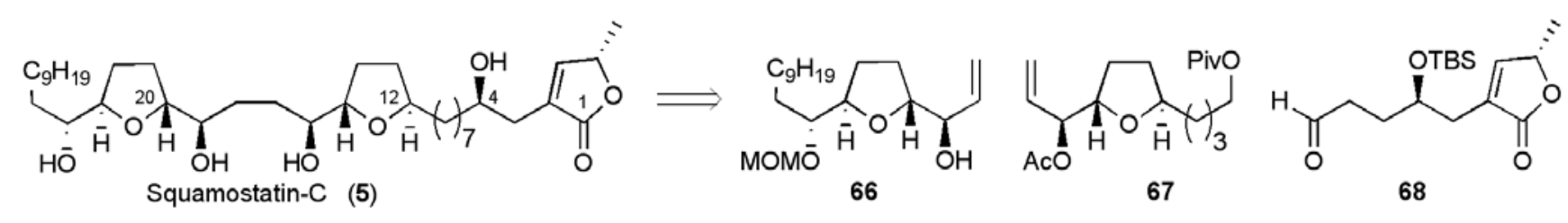


Mootoo's synthetic approach to squamostatin-C (5) centered on three major fragments (Figure 10) $[56,57]$, which were to be combined by cross-metathesis and Wittig olefination reactions. Both of the trans-THF fragments 66 and 67 were created using iodoetherification methodology developed in Mootoo's laboratory [58]. (E)-Ethyl hepta-4,6-dienoate, synthesised by Johnson-Claisen rearrangement of 1,4-pentadien-3-ol, was elaborated through a sequence commencing with regiocontrolled asymmetric dihydroxylation to give the allylic alcohol 69 (ee $>92 \%$, scheme 15) [59]. The alkene 69 was submitted to iodoetherfication reaction conditions using iodonium dicollidine perchlorate (IDCP) in acetronitrile, affording a single diastereoisomeric trans-THF 70. The ten-carbon side chain was introduced by conversion of the iodohydrin $\mathbf{7 0}$ to the epoxide, followed by cuprate addition and protecting group manipulation to give the left hand THF fragment 66 . The overall yield was $12.4 \%$ over 13 steps from 1,4-pentadien-3-ol.

Scheme 15. Synthesis of left hand THF fragment 66.

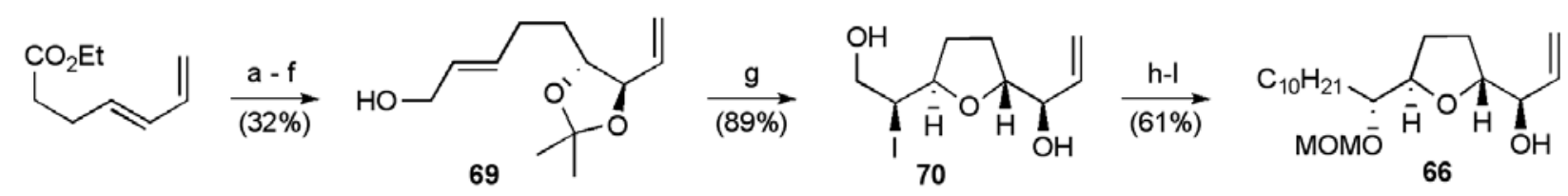

Reagents and conditions: a) AD-mix- $\beta, t-\mathrm{BuOH}-\mathrm{H}_{2} \mathrm{O}, \mathrm{MeSO}_{2} \mathrm{NH}_{2}$; b) DIBAL-H, THF; c) $(\mathrm{MeO})_{2} \mathrm{CMe}_{2}, \mathrm{CSA}, \mathrm{CH}_{2} \mathrm{Cl}_{2}$; d) PCC, $\mathrm{CH}_{2} \mathrm{Cl}_{2}$; e) $\mathrm{Ph}_{3} \mathrm{P}=\mathrm{CHCO}_{2} \mathrm{Me}$; f) DIBAL-H, $\mathrm{CH}_{2} \mathrm{Cl}_{2}$; g) iodonium dicollidine perchlorate, $\mathrm{MeCN}$; h) $\mathrm{K}_{2} \mathrm{CO}_{3}, \mathrm{MeOH}$; i) TBSCl, imidazole, $\mathrm{CH}_{2} \mathrm{Cl}_{2}$; j) $\mathrm{CH}_{3}\left(\mathrm{CH}_{2}\right)_{8} \mathrm{MgBr}, \mathrm{CuBr}$, THF; k) MOMCl, DIPEA, $\mathrm{CH}_{2} \mathrm{Cl}_{2}$; l) TBAF, THF.

The central THF 67 was prepared following a similar route, but switching to AD-mix- $\alpha$ for the selective diene dihydroxylation (Scheme 16). A mixture of alkene isomers 72 ( $Z: E$ 3:1) underwent selective iodoetherification to afford an iodohydrin (trans:cis dr 11:1), which was deiodonated under radical conditions to secure the fragment 67 in 10.2\% yield over 10 steps from 1,4-pentadien-3-ol.

Scheme 16. Synthesis of the right hand THF fragment 67.

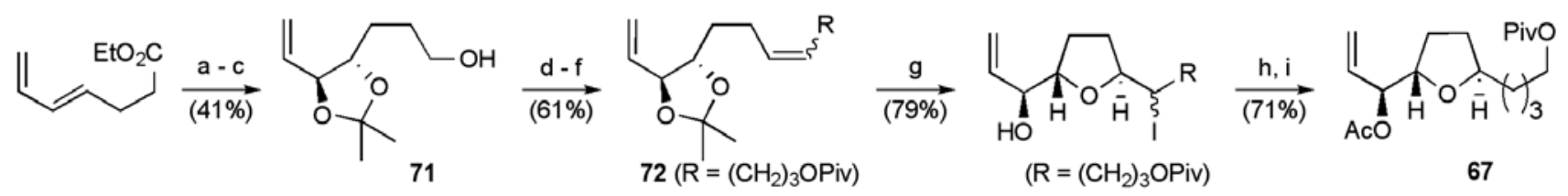

Reagents and conditions: a) AD-mix- $\alpha, t-\mathrm{BuOH}-\mathrm{H}_{2} \mathrm{O}, \mathrm{MeSONH}_{2}$; b) DIBAL-H, THF; c) $(\mathrm{MeO})_{2} \mathrm{CMe}_{2}, \mathrm{CSA}, \mathrm{CH}_{2} \mathrm{Cl}_{2}$; d) Swern oxidation; e) $\mathrm{Ph}_{3} \mathrm{P}=\mathrm{CH}\left(\mathrm{CH}_{2}\right)_{3} \mathrm{OLi}, \mathrm{MePh}$; f) $\mathrm{PivCl}$, pyridine, DMAP; g) iodonium dicollidine perchlorate, $\mathrm{MeCN}$; h) $\mathrm{Bu}_{3} \mathrm{SnH}, \mathrm{MePh}, \mathrm{AIBN}, \Delta$; i) $\mathrm{Ac}_{2} \mathrm{O}$, DMAP

Butenolide 68 was obtained in 14 steps from 6-iodo-1-hexene in a 2.9\% yield (Scheme 17). Dihydroxylation of diene 73 followed by successive recrystallisation afforded tetraol 74 (S:R 20:1) [60]. The tetraol was converted to ester 75, which was subsequently elaborated to the butenolide using an aldol approach [61]. Finally, oxidative cleavage of the terminal olefin secured the fragment 68 containing an aldehyde group needed for coupling. 
Scheme 17. Synthesis of butenolide fragment 68.<smiles>C=CCCCOc1ccc(OCCCC=C)cc1</smiles>

73<smiles>OC[C@@H](O)CCCOc1ccc(OCCC[C@@H](O)CO)cc1</smiles>

74

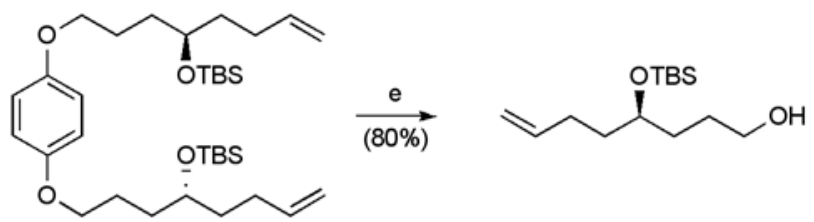

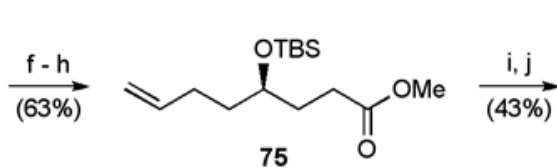<smiles>C=CCC[C@H](CC1C(=O)O[C@H](C)[C@@H]1O)O[Mg]</smiles><smiles>C[C@@H](CCC(=O)O)CC1=C[C@H](C)OC1=O</smiles>

Reagents and conditions: a) AD-mix- $\alpha$; b) TsCl, pyridine; c) $\mathrm{K}_{2} \mathrm{CO}_{3}, \mathrm{MeOH}$; d) allylMgBr, $\mathrm{CuI}$; d) TBSCl, imidazole, $\mathrm{CH}_{2} \mathrm{Cl}_{2}$; e) CAN, $\mathrm{CH}_{3} \mathrm{CN} / \mathrm{H}_{2} \mathrm{O}$; f) $\left.\mathrm{PCC}, \mathrm{CH}_{2} \mathrm{Cl}_{2} ; \mathrm{g}\right) \mathrm{NaClO}_{2}, \mathrm{H}_{2} \mathrm{O}_{2}$; h) $\mathrm{MeOH}$, DCC, DMAP; i) LDA, THF, then (S)-2-(tetrahydropyran-2-yloxy)propanal; j) $p$ - $\mathrm{TsOH}, \mathrm{MeOH}$; k) $\left.\mathrm{MsCl}, \mathrm{Et}_{3} \mathrm{~N}, \mathrm{CH}_{2} \mathrm{Cl}_{2} ; 1\right) \mathrm{AD}-\operatorname{mix}-\beta, t-\mathrm{BuOH} / \mathrm{H}_{2} \mathrm{O}$; m) $\mathrm{NaIO}_{4}, \mathrm{H}_{2} \mathrm{O} / \mathrm{CH}_{2} \mathrm{Cl}_{2} /$ acetone.

Mootoo's team found that the key CM was most effective when 4:1 and 3:1 ratios of fragments 66 and 67 were coupled using Grubbs second-generation catalyst, giving yields of $98 \%$ and $75 \%$ yields respectively (yields based on limiting alkene, Scheme 18). Alkene hydrogenation and a series of protecting group manipulations gave the primary alcohol $\mathbf{7 6}$ that served as a precursor to the phosphonium salt 77. The fragment coupling using the Wittig reaction proceeded in a moderate yield, but afforded an intermediate that was converted to squamostatin-C (5) following selective hydrogenation and global deprotection. Overall the synthesis of squamostatin-C was achieved in 23 steps from $(E)$-ethyl hepta-4,6-dienoate in a total yield $2.2 \%$ (based on the limiting fragment).

Scheme 18. Total synthesis of squamostatin-C (5).
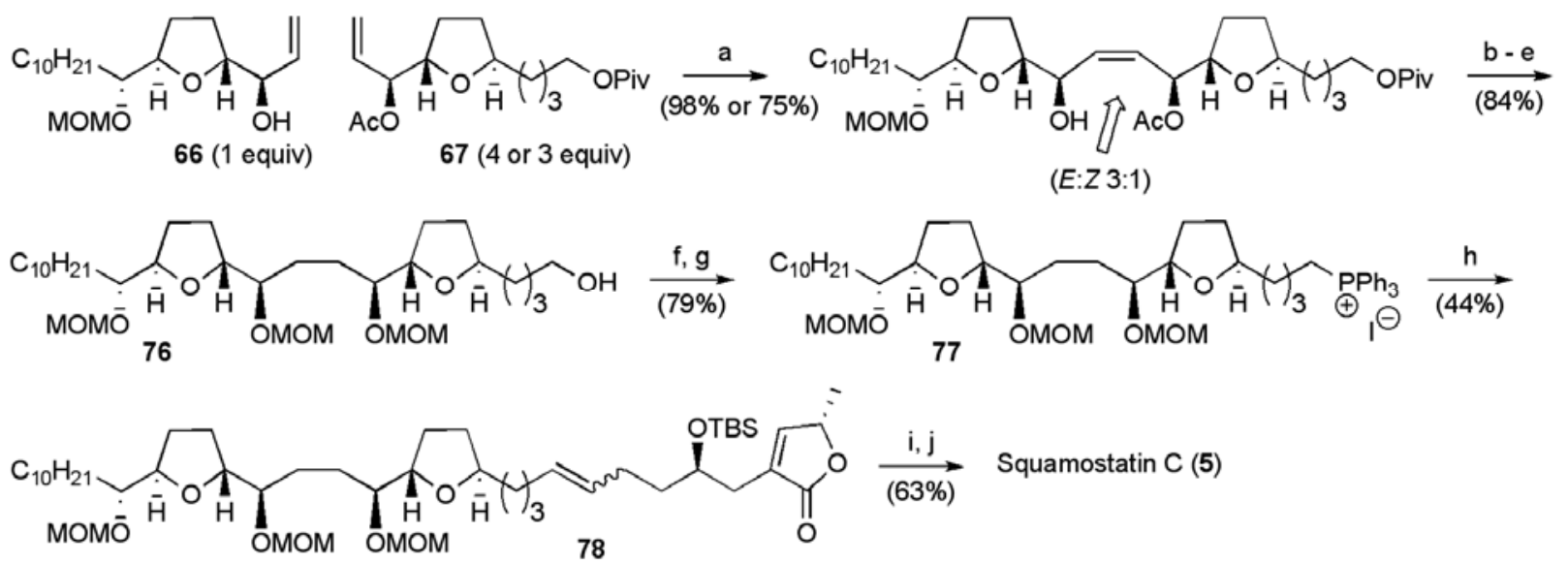

Reagents and conditions: a) Method A: 66 (1 equiv), 67 (4 equiv), $\mathrm{Cl}_{2}\left(\mathrm{Cy}_{3} \mathrm{P}\right)(\mathrm{IMes}) \mathrm{Ru}=\mathrm{CHPh}$ $(10 \mathrm{~mol} \% \times 2), \mathrm{CH}_{2} \mathrm{Cl}_{2}$; Method B: 66 (1 equiv), 67 (3 equiv), $\mathrm{Cl}_{2}\left(\mathrm{Cy}_{3} \mathrm{P}\right)(\mathrm{IMes}) \mathrm{Ru}=\mathrm{CHPh}$ (10 mol \% × 2), $\mathrm{CH}_{2} \mathrm{Cl}_{2}$; b) $\mathrm{H}_{2}, \mathrm{Pd} / \mathrm{C}$, EtOAc; c) $\mathrm{K}_{2} \mathrm{CO}_{3}, \mathrm{MeOH}$; d) MOMCl, DIPEA, $\mathrm{CH}_{2} \mathrm{Cl}_{2}$; e) $\mathrm{NaOMe}, \mathrm{MeOH}$; f) $\mathrm{Ph}_{3} \mathrm{P}, \mathrm{I}_{2}$, imidazole, benzene; g) $\mathrm{Ph}_{3} \mathrm{P}$, DIPEA, MeCN; h) $n$-BuLi, THF, then 68; i) $\mathrm{H}_{2}, \mathrm{Rh}\left(\mathrm{PPh}_{3}\right)_{3} \mathrm{Cl}$; j) $\mathrm{AcCl}, \mathrm{MeOH}-\mathrm{CH}_{2} \mathrm{Cl}_{2}$ 


\subsection{Total Syntheses of cis-Sylvaticin (3)}

cis-Sylvaticin (3) was isolated from the leaf extracts of the Rollinia mucosa (Jacq.) Baill., and exhibits potent cytotoxicity against A-549 (lung carcinoma) and PACA-2 (pancreatic carcinoma) at nanomolar levels [13]. By contrast with the other non-adjacent bis-THF acetogenins discussed herein, both of the 2,5-disubstituted THF rings in cis-sylvaticin (3) possess the cis configuration. These cisTHF systems are ideally suited to synthetic approaches based on oxidative cyclisation of 1,5-dienes by metal oxo species, and both published total syntheses are based on this strategy (Figure 11) [62-65]. Oxidative cyclisation reactions mediated by osmium and permanganate are stereospecific with respect to the addition of the oxygen functionality across the alkenes, and trans-alkenes give rise to threo products while cis-alkenes lead to erythro products [66].

Figure 11. Synthesis of 2,5 cis-disubstituted THF diols by metal oxo mediated oxidative cyclisation.

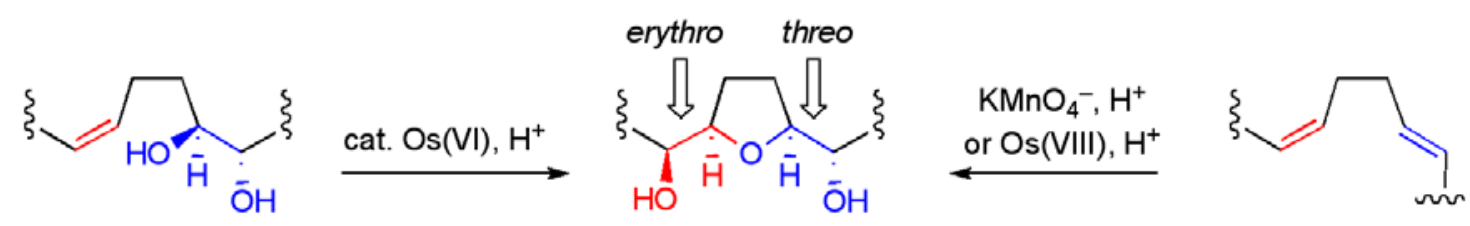

The first report of a total synthesis of 3 came from the Donohoe group in 2006, and made use of an osmium-catalysed double oxidative cyclisation of a protected tetraol $\mathbf{8 1}$ (Figure 12) [62,63,67]. The synthesis of bis-THF fragment $\mathbf{7 9}$ began with tetradecatetraene 82, which is commercially available as a mixture of isomers $(E E, E Z, Z Z)$, or can be separated by chromatography, or was synthesised in three steps from $E, E, E$-cyclododecatetraene.

Figure 12. Donohoe's double oxidative cyclisation approach to cis-sylvaticin.
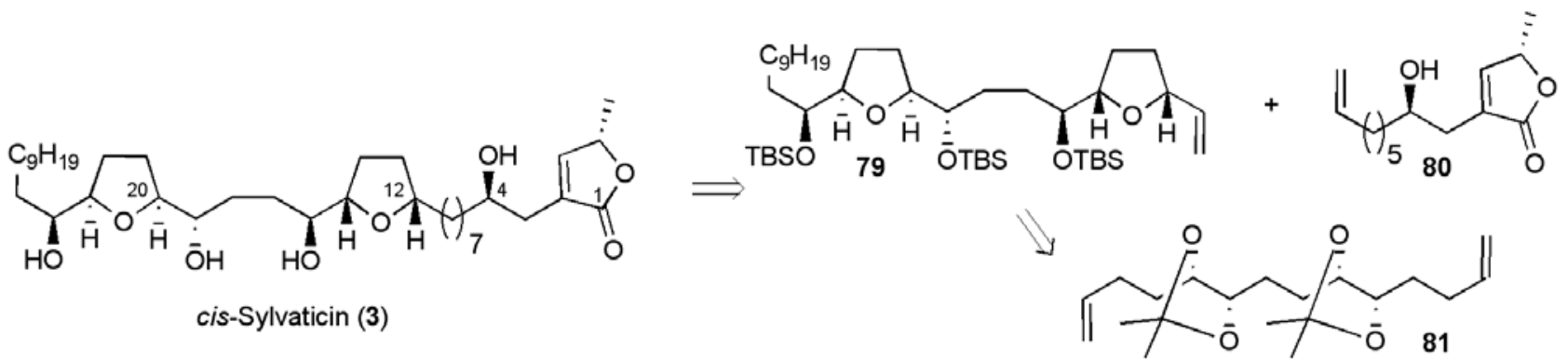

Asymmetric dihydroxylation of tetraene $\mathbf{8 2}$ followed by in situ protection selectively gave diene $\mathbf{8 3}$ (ee $>98 \%$, dr $>95: 5$ ) in 19\% yield from the mixture of isomers or $37 \%$ from pure 82 (Scheme 19). The diene 83 was elaborated to introduce the left hand decyl chain into the oxidative cyclisation substrate 84. Under the acidic conditions of the oxidative cyclisation reaction the acetonide groups were cleaved to reveal the ene-diol systems, which cyclised to afford bis-THF 85 as a single diastereoisomer in high yield. Synthesis of the bis-THF fragment $\mathbf{7 9}$ was completed in four further steps, with an overall yield of $6.4 \%$ from isomerically pure $E, E$-tetradecatetraene 82 (10 steps in total). 
Scheme 19. Synthesis of bis-THF fragment 79.
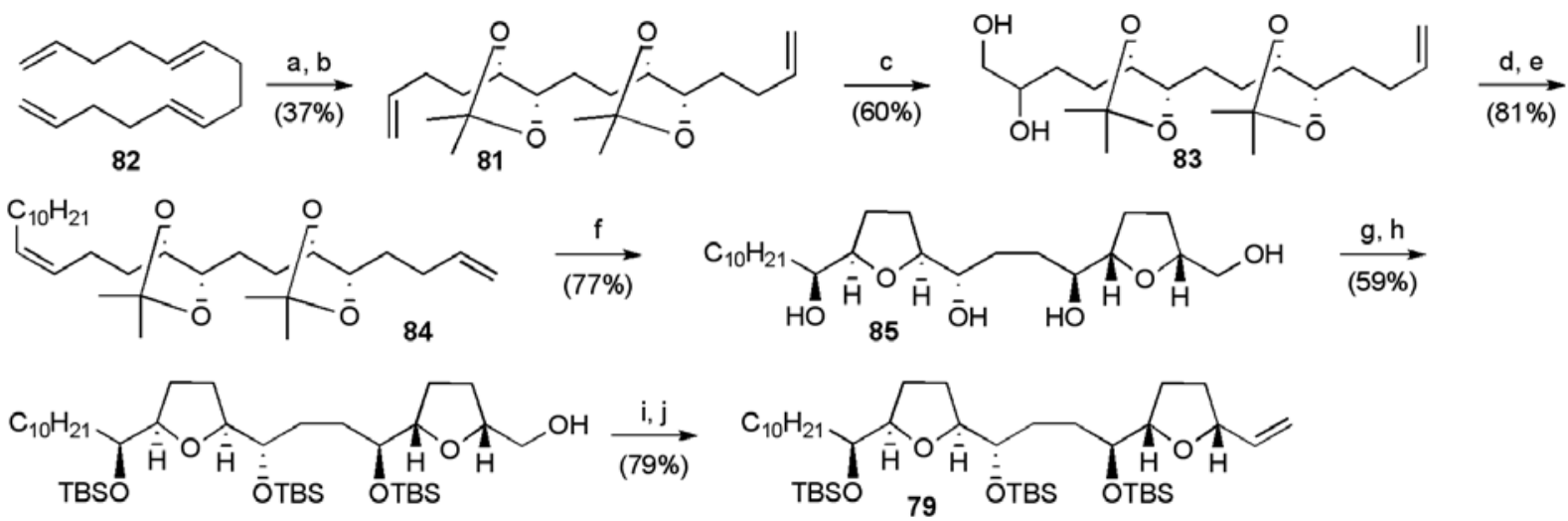

Reagents and conditions: a) AD-mix- $\alpha$; b) $\mathrm{CH}_{2}=\mathrm{CH}(\mathrm{OMe}) \mathrm{CH}_{3}, \mathrm{CSA}$; c) $\mathrm{AD}-$ mix- $\beta$; d) $\mathrm{NaIO}_{4}$;

e) $\mathrm{C}_{10} \mathrm{H}_{21} \mathrm{CH}=\mathrm{PPh}_{3}$; f) $\mathrm{OsO}_{4}\left(5 \mathrm{~mol} \%\right.$ ), acetone, $\mathrm{H}_{2} \mathrm{O}, \mathrm{Me}_{3} \mathrm{NO}$ (5 equiv), TFA, cinnamic acid;

g) TBSOTf, 2,6-lutidine; h) TBAF (1 equiv); i) TPAP, NMO; j) $\mathrm{Ph}_{3} \mathrm{P}=\mathrm{CH}_{2}$, THF.

Assembly of the butenolide fragment $\mathbf{8 0}$ followed a route described previously by Keum et al. (Scheme 20) [68], requiring 6 steps from $(R)$-epichlorohydrin in a total yield of $19.7 \%$.

Scheme 20. Synthesis of butenolide fragment 80 .
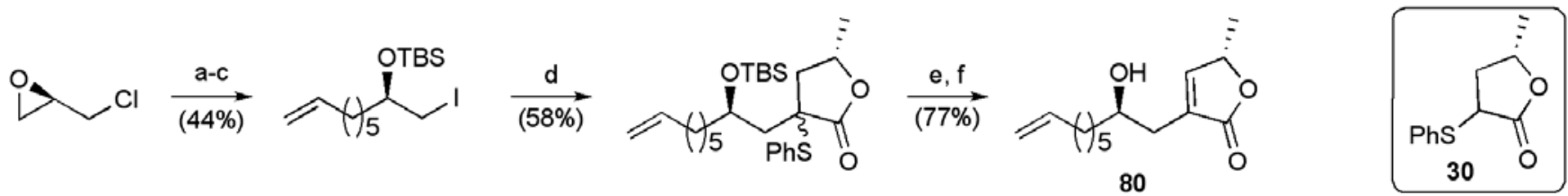

Reagents and conditions: a) $\mathrm{H}_{2} \mathrm{C}=\mathrm{CH}\left(\mathrm{CH}_{2}\right)_{4} \mathrm{MgBr}, \mathrm{CuCN}$; b) NaI; c) TBSOTf; d) 30, LDA, HMPA; e) $m$-CPBA, then $\Delta$; f) $\mathrm{AcCl}, \mathrm{MeOH}$.

The two alkene fragments were then united by cross-metathesis (Scheme 21), returning the product 86 in 79\% yield when excess butenolide fragment (4 equiv) was employed in the presence of Grubbs II catalyst $(10 \mathrm{~mol} \%)$. Diimide reduction and cleavage of the silyl protecting groups completed the synthesis of cis-sylvaticin (3) in only 13 linear steps from tetradecatetraene 82 with a total yield of $3.5 \%$.

Scheme 21. Donohoe's total synthesis of cis-sylvaticin (3).
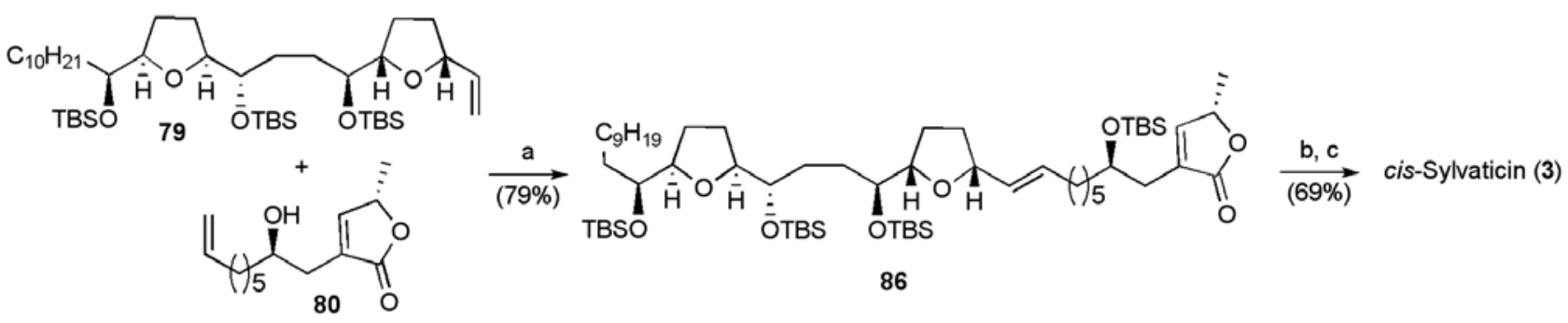

Reagents and conditions: a) 79 ( 1 equiv), 80 (4 equiv), $\mathrm{Cl}_{2}\left(\mathrm{Cy}_{3} \mathrm{P}\right)(\mathrm{IMes}) \mathrm{Ru}=\mathrm{CHPh}(10 \mathrm{~mol} \%)$;

b) $\mathrm{TsNHNH}_{2}, \mathrm{NaOAc}$; c) AcCl, $\mathrm{MeOH}$. 
A total synthesis of $c i s$-sylvaticin has also been achieved in our laboratory using two permanganate promoted oxidative cyclisation reactions of dienes $\mathbf{8 9}$ and $\mathbf{9 0}$ to introduce 7 of the 9 stereogenic centres present in the natural target (Figure 13) [65]. The more complex diene 90 required for the C3C17 fragment 88 was built up from 8-bromooct-1-ene, exploiting a Jacobsen alcoholytic kinetic resolution to correctly establish the $\mathrm{C} 4$ alcohol (ee $>99 \%$, Scheme 22) [69].

Figure 13. Permanganate-mediated approach to cis-sylvaticin (3).

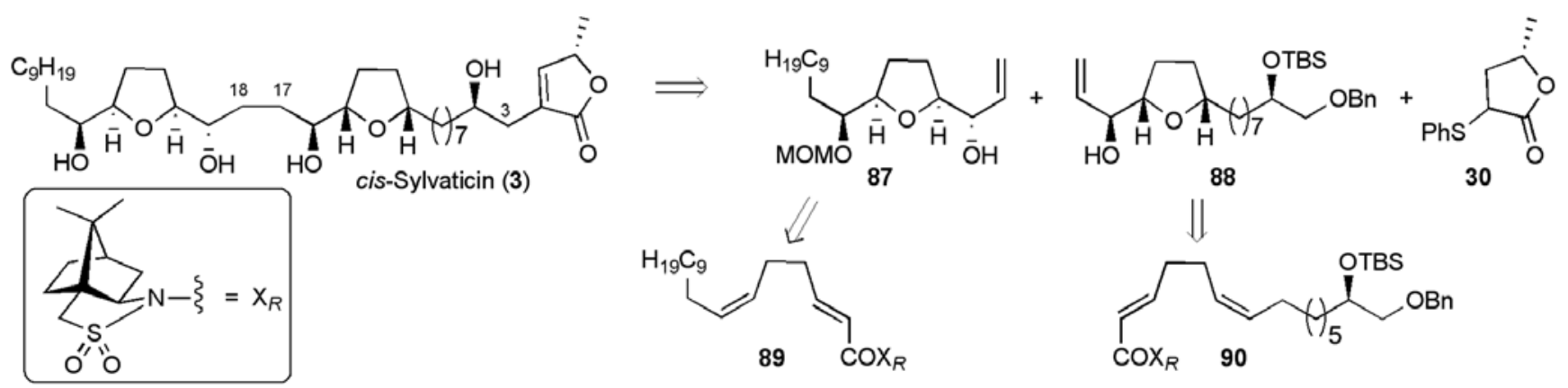

Scheme 22. Synthesis of benzyl ether 91.
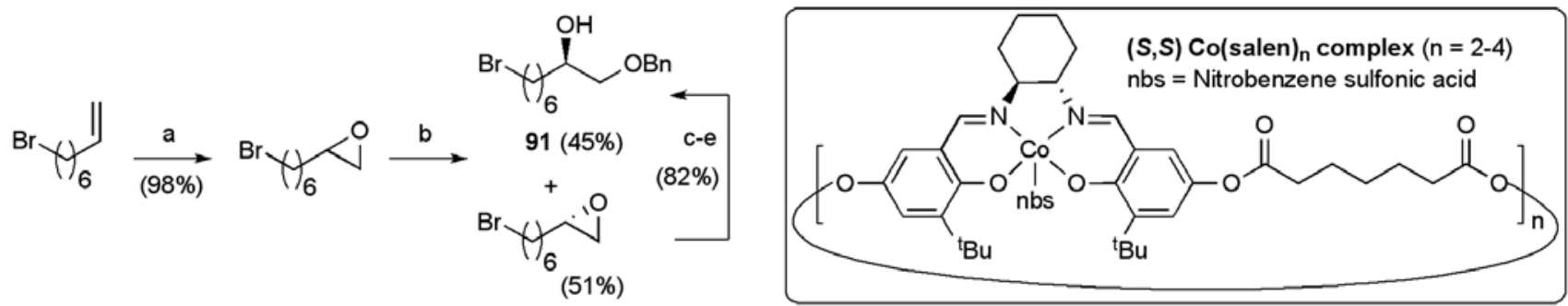

Reagents and conditions: a) $\mathrm{MeReO}_{3}(0.25 \mathrm{~mol} \%), 30 \% \mathrm{H}_{2} \mathrm{O}_{2}, \mathrm{CH}_{2} \mathrm{Cl}_{2} ;$ b) $(S, S) \mathrm{Co}$ (salen $)_{\mathrm{n}}$ complex (0.25 mol \%), $\mathrm{BnOH}, \mathrm{MeCN}$; c) $(R, R) \mathrm{Co}\left(\right.$ salen) ${ }_{\mathrm{n}}$ complex $(0.25 \mathrm{~mol} \%), \mathrm{BnOH}, \mathrm{MeCN}$; d) DIAD, $\mathrm{PPh}_{3}$, 4-nitrobenzoic acid, THF; e) $\mathrm{NaOH}, \mathrm{MeOH}$.

Scheme 23. Synthesis of central THF fragment 88.
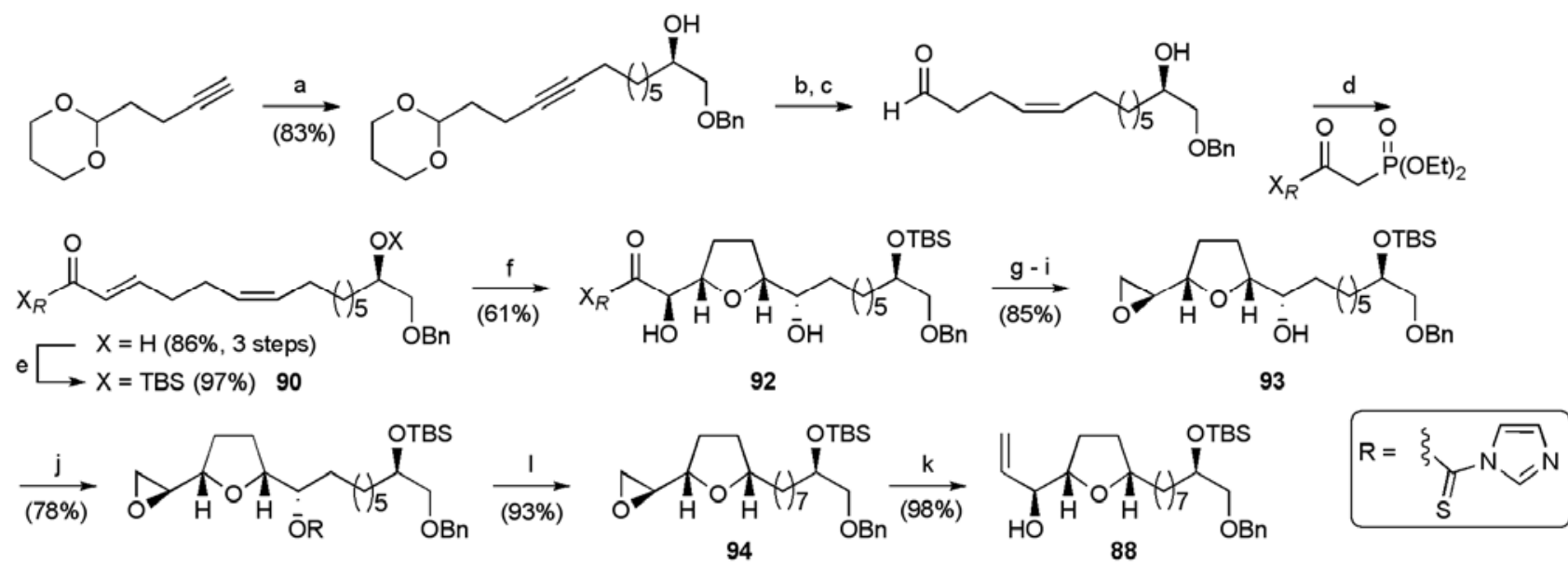

Reagents and conditions: a) $n$-BuLi, HMPA, THF, then 91; b) Lindlar catalyst, $\mathrm{H}_{2}$; c) $\mathrm{H}_{2} \mathrm{SO}_{4} /$ dioxane $/ \mathrm{H}_{2} \mathrm{O}, \Delta$; d) $\mathrm{LiCl}$, DIPEA, MeCN, e) TBSOTf, 2,6-lutidine; f) $\mathrm{KMnO}_{4}$, acetone/AcOH; g) $\mathrm{NaBH}_{4}, \quad \mathrm{THF} / \mathrm{H}_{2} \mathrm{O} ;$ h) $\mathrm{Bu} 2 \mathrm{SnO}, \quad \mathrm{TsCl} ; \quad$ i) $\mathrm{K}_{2} \mathrm{CO}_{3}, \quad \mathrm{MeOH}$; j) thiocarbonyldiimidazole, DMAP, $\mathrm{CH}_{2} \mathrm{Cl}_{2}$; k) AIBN, TTMS, toluene; l) $\mathrm{Me}_{3} \mathrm{~S}^{+} \mathrm{I}^{-}, n-\mathrm{BuLi}$, THF. 
The primary alkyl bromide 91 was converted to the cis,trans 1,5-diene 90 with control over the stereochemistry at both alkenes (Scheme 23). Permanganate oxidative cyclisation then afforded THF diol 92 isolated as a pure diastereoisomer, with diastereocontrol (dr 8.7:1 for the reaction) imparted from the Oppolzer camphorsultam auxiliary [70-73]. Reductive cleavage of the auxiliary followed by conversion of the resulting vicinal diol to the epoxide $\mathbf{9 3}$ enabled selective radical deoxygenation of the secondary alcohol group. Fragment synthesis was completed by treating epoxide $\mathbf{9 4}$ with excess $\mathrm{Me}_{2} \mathrm{~S}=\mathrm{CH}_{2}$, giving allylic alcohol 88 over 14 steps from 8-bromooct-1-ene in a total yield of $21.7 \%$ (17 steps including recycling of ( $S$ )-epoxide).

Similarly, the synthesis of the left hand THF fragment 87 was accomplished in 10 steps from commercially available 1-dodecyne in a total yield of $24.3 \%$ (Scheme 24). In the pivotal step, oxidative cyclisation of diene $\mathbf{8 9}$ afforded a 9:1 mixture of THF diol diastereoisomers from which the major isomer 95 was isolated in 67\% yield [70-73].

Scheme 24. Synthesis of left hand THF fragment 89.

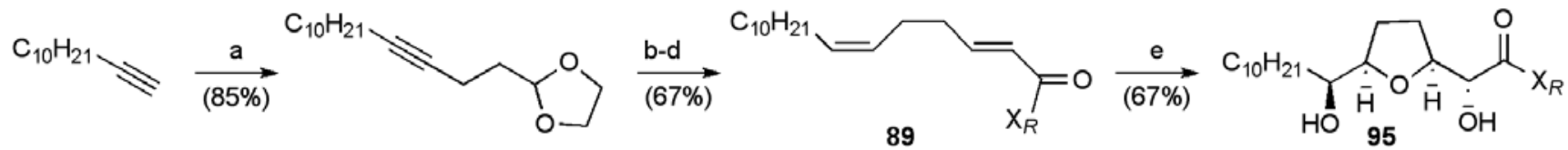

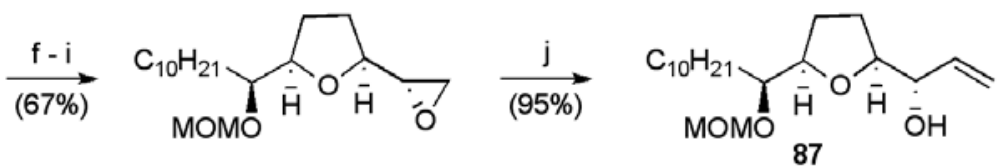

Reagents and conditions: a) $n$-BuLi, HMPA, THF, then 2-(2-bromoethyl)-1,3-dioxolane; b) Lindlar catalyst, $\mathrm{H}_{2}$; c) AcOH, $\mathrm{H}_{2} \mathrm{O}, \Delta$; d) $\mathrm{X}_{R} \mathrm{COCH}_{2} \mathrm{PO}(\mathrm{OEt})_{2}$, LiCl, DIPEA; e) $\mathrm{KMnO}_{4}$, acetone/AcOH; f) $\mathrm{NaBH}_{4}, \mathrm{THF} / \mathrm{H}_{2} \mathrm{O}$; g) $\mathrm{Bu}_{2} \mathrm{SnO}, \mathrm{TsCl}$; h) $\mathrm{K}_{2} \mathrm{CO}_{3}, \mathrm{MeOH}$; i) MOMCl, DIPEA; j) $\mathrm{Me}_{3} \mathrm{~S}^{+} \mathrm{I}^{-}, n$-BuLi, THF.

Scheme 25. Total synthesis of cis-sylvaticin (3).
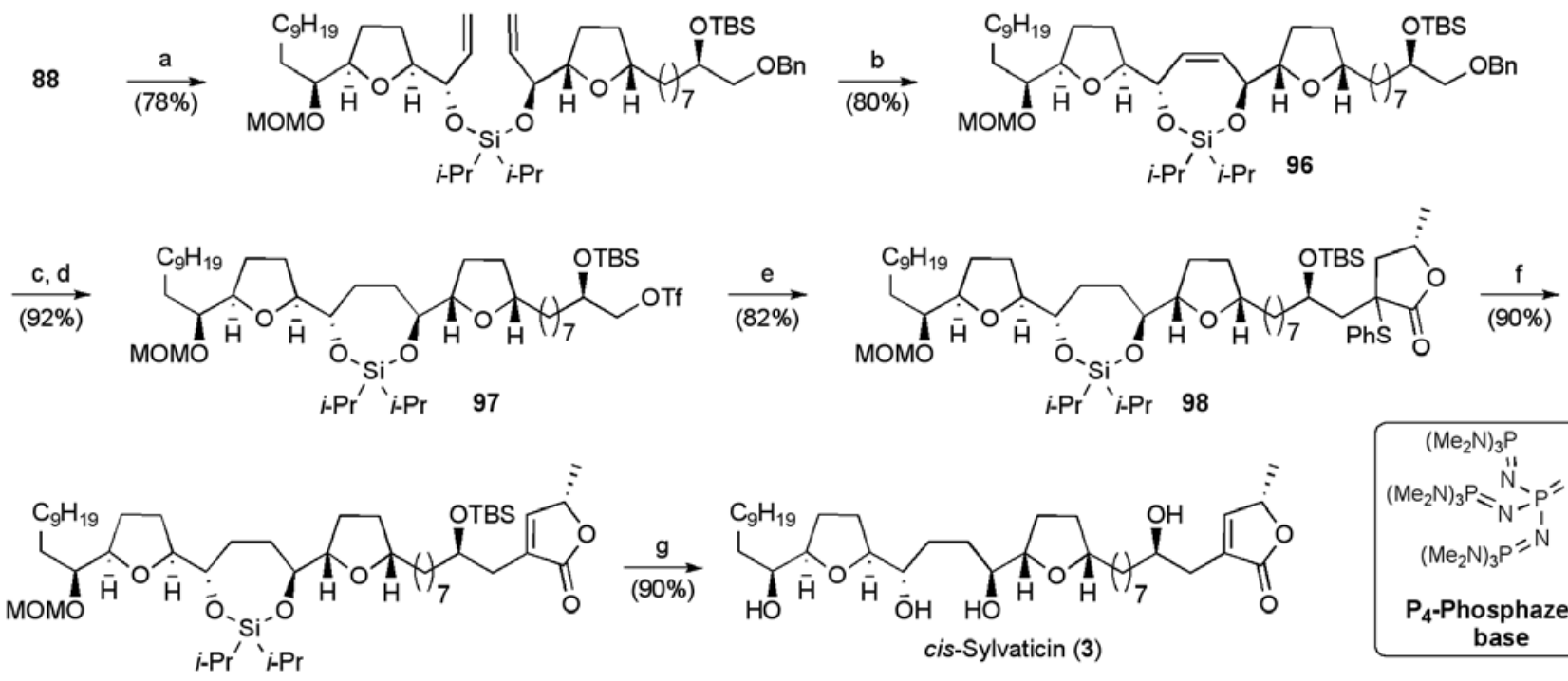

$$
\begin{gathered}
\left(\mathrm{Me}_{2} \mathrm{~N}\right)_{3} \mathrm{P} \\
\left(\mathrm{Me}_{2} \mathrm{~N}\right)_{3} \mathrm{P} \approx_{\mathrm{N}}-\mathrm{Bu} \\
\left(\mathrm{Me}_{2} \mathrm{~N}\right)_{3} \mathrm{P}=\mathrm{N} \\
\mathrm{P}_{4}-\mathrm{Phosphazene} \\
\text { base }
\end{gathered}
$$

Reagents and conditions: a) imidazole, $i-\mathrm{Pr}_{2} \mathrm{SiCl}_{2}, \mathrm{CH}_{2} \mathrm{Cl}_{2}$, then 87; b) $\mathrm{Cl}_{2}\left(\mathrm{Cy}_{3} \mathrm{P}\right)(\mathrm{IMes}) \mathrm{Ru}=\mathrm{CHPh}$ (10 mol \%), $\mathrm{MePh}, 75^{\circ} \mathrm{C}$; c) $\mathrm{H}_{2}, \mathrm{Pd} / \mathrm{C}$, EtOAc; d) $\mathrm{Tf}_{2} \mathrm{O}$, 2,6-lutidine; e) 30, $\mathrm{P}_{4}$-phosphazene base; f) $m$-CPBA, then $\Delta$; g) $\mathrm{AcCl}, \mathrm{MeOH}$. 
Fragments $\mathbf{8 7}$ and $\mathbf{8 8}$ were successfully coupled by a diisopropylsilyl tethered RCM reaction using second-generation Grubbs catalyst (10 mol \%) to give siloxane 96 (Scheme 25). Hydrogenation of the alkene and debenzylation of the RCM product delivered a primary alcohol that was then converted to triflate 97. Alkylation of lactone $\mathbf{3 0}$ was found to proceed efficiently when the $\mathrm{P}_{4}$-phosphazene base was used, delivering sulfide 98 . Sulfide 98 was converted to cis-sylvaticin (3) using the oxidationsulfoxide elimination and global deprotection sequence described previously. The overall yield for the synthesis was $8.3 \%$ for a linear sequence of 21 (24 including inversion of ent-91) steps from 8-bromooct-1-ene.

\subsection{Total Synthesis of Sylvaticin (7)}

Sylvaticin (7) has been isolated from several Annonaceae sources, and has been co-isolated with its C12 epimer $c i s$-sylvaticin (3) $[13,74,75]$. Both compounds exhibit potent cytotoxicity against selected solid human tumour cell lines. A synthesis of sylvaticin was recently disclosed by Donohoe and coworkers, employing the osmium-catalysed oxidative cyclisation to ultimately create both the cis and trans-disubstituted THF ring systems present in the natural product. The approach was based on their earlier synthesis of cis-sylvaticin (Figure 14). However, they needed to convert the central cis-THF diol produced from the oxidative cyclisation to the trans-hydroxy THF system present in sylvaticin [76].

Figure 14. Donohoe's approach to sylvaticin (7).

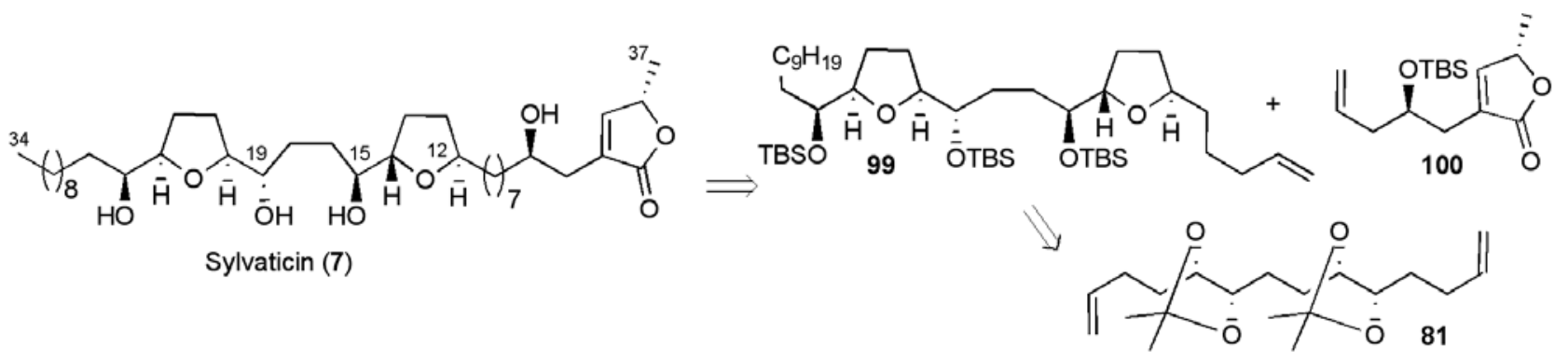

Diol 83, obtained from mono-dihydroxylation of diene $\mathbf{8 1}$ (see Scheme 19) was elaborated in five steps to a new functionalized diene $\mathbf{1 0 1}$ that served as the substrate for an efficient double oxidative cyclisation (Scheme 26). A sequence of selective protecting group manipulations carried out on the oxidative cyclisation product 102 afforded di-mesylate 103, which was reacted with allyl Grignard in the presence of $\mathrm{CuI}$ to provide the substrate $\mathbf{1 0 4}$ for the Lewis-acid promoted hydride shift and intramolecular stereoselective reduction of the intermediate oxa-carbenium 105. After re-protection of the hydroxyl groups, the terminal alkene $\mathbf{1 0 6}$ was then taken through to sylvaticin using the crossmetathesis coupling strategy described above (see scheme 21), achieving a concise synthesis of the target in 19 linear steps and $2.2 \%$ overall yield. 
Scheme 26. Synthesis of sylvaticin (7).

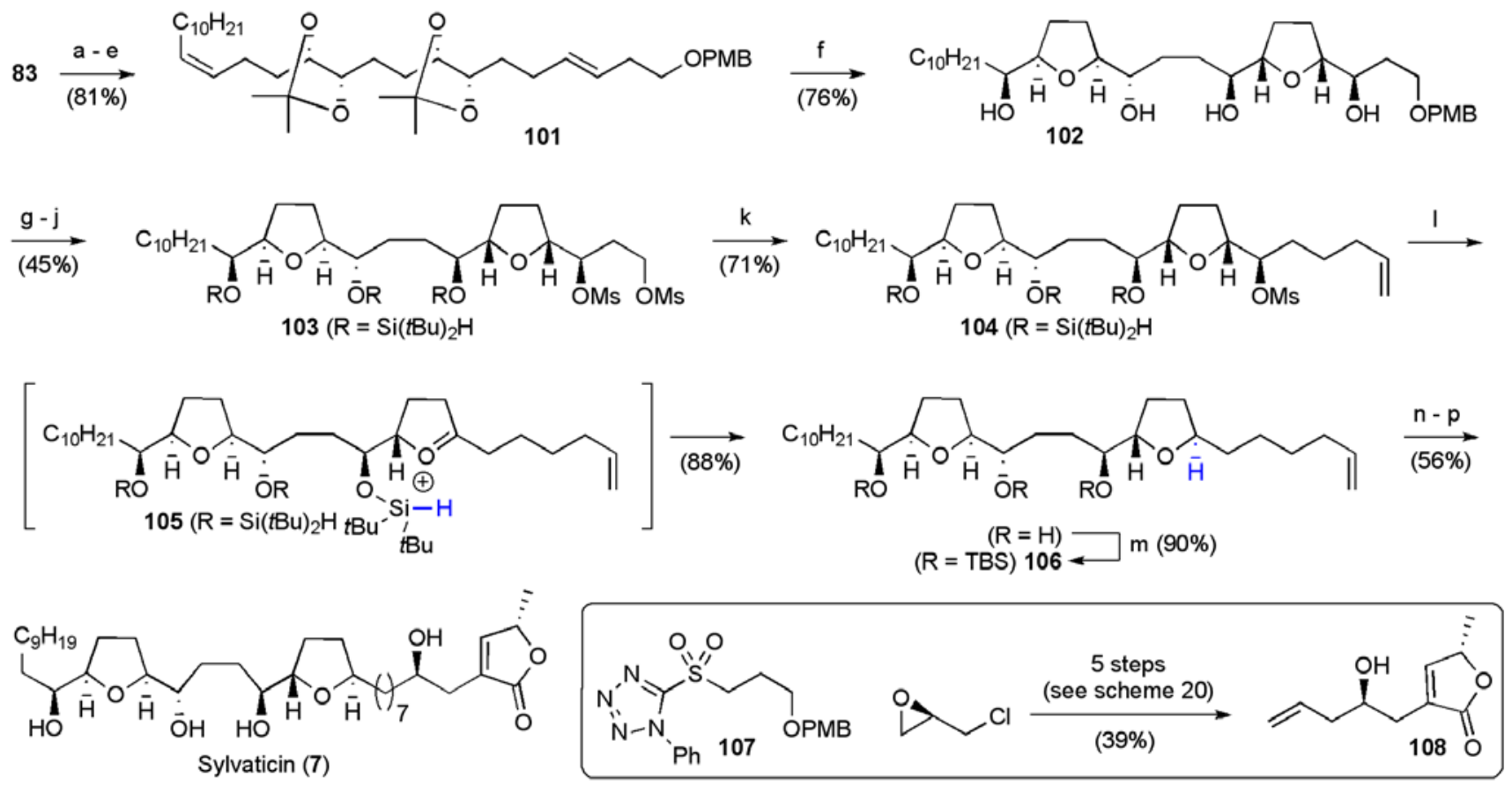

Reagents and conditions: a) $\mathrm{Ac}_{2} \mathrm{O}$; b) $\mathrm{O}_{3}, \mathrm{PPh}_{3}$; c) $\mathrm{C}_{10} \mathrm{H}_{21} \mathrm{CH}=\mathrm{PPh}_{3}$; d) $\mathrm{NaIO}_{4}, \mathrm{~K}_{2} \mathrm{CO}_{3}, \mathrm{MeOH}$, $\mathrm{H}_{2} \mathrm{O}$; e) KHMDS, 107; f) $\mathrm{K}_{2} \mathrm{OsO}_{2}\left(\mathrm{H}_{2} \mathrm{O}\right)_{4}\left(5 \mathrm{~mol} \%\right.$ ), pyridine $\mathrm{N}$-oxide, $\mathrm{CH}_{3} \mathrm{CN}, \mathrm{H}_{2} \mathrm{O}$, citric acid, $\mathrm{Cu}(\mathrm{OTf})_{2} ;$ g) DDQ, $\mathrm{CH}_{2} \mathrm{Cl}_{2} ;$ h) $t$ - $\mathrm{Bu}_{2} \mathrm{HSiCl}$, DMF; i) $\mathrm{I}_{2}, \mathrm{MeOH} ;$ j) $\mathrm{Ms}_{2} \mathrm{O}, \mathrm{CH}_{2} \mathrm{Cl}_{2}$; k) $\mathrm{CH}_{2}=\mathrm{CHCH}_{2} \mathrm{MgBr}$, CuI, $\mathrm{Et}_{2} \mathrm{O}$; 1) $\left.\mathrm{Zn}(\mathrm{OAc})_{2},\left(\mathrm{CF}_{3}\right)_{2} \mathrm{CHOH}, \Delta ; \mathrm{m}\right)$ TBSOTf, 2,6-lutidine; n) 108 (4 equiv), Grubbs/Hoveyda II pre-catalyst (10 mol \%); o) $\mathrm{TsNHNH}_{2}, \mathrm{NaOAc} ; \mathrm{p}$ ) AcCl, $\mathrm{MeOH}$.

\section{Total Synthesis of Non-Adjacent THF-THP Acetogenins}

Only the synthesis of mucocin will be discussed here due to its structural similarity to the nonadjacent bis-THF acetogenins. The total syntheses of montanacin E (109) and montanacin D [77,78], which also contain THP and THF rings separated by a carbon chain, will not be reviewed due to the quite different relationship between the cyclic ethers (Figure 15).

Figure 15. Structures of mucocin (8) and montanacin E (109).
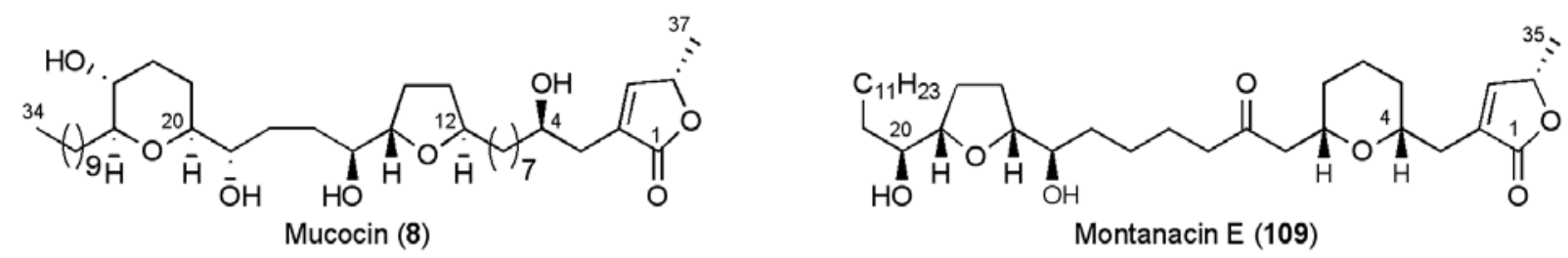

\subsection{Total Syntheses of Mucocin (8)}

Mucocin (8) was the first reported example of an Annonaceous acetogenin that contained a THF ring and an hydroxylated THP ring [79]. Structural assignment was achieved through analysis of MS and NMR data for mucocin, its $(16 \mathrm{OH}, 19 \mathrm{OH})$ formylidene acetal derivative, and the corresponding Moshers esters. Mucocin has proved to be a popular target for synthetic chemists, with no fewer than seven total syntheses reported to date. In 1999 Koert's group disclosed their synthesis of (-)-mucocin 
[80-82]. Their approach required three major fragments 110, 111 and 112, which were to be united by Grignard and Wittig reactions (Figure 16). Critically, the stereochemistry at C16 would be set using a chelation controlled Grignard reaction.

Figure 16. Koert's synthetic approach to (-)-mucocin (8) (1999).

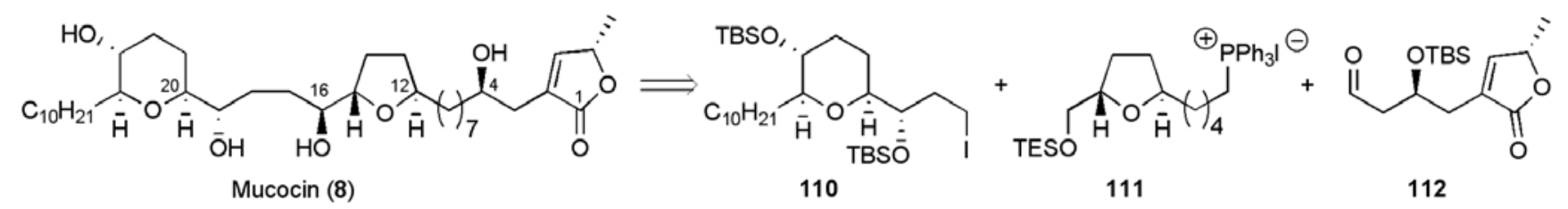

The synthesis of the THP fragment 110 began with $(E)$-dihydromuconic acid (113) using Sharpless asymmetric epoxidation and dihydroxylation reactions to control the stereochemistry at C19, C20, C23 and C24 (steps f and j scheme 27). Critically, acid deprotection of $\mathbf{1 1 4}$ and the ensuing cyclisation of the resulting epoxydiol favoured 6-endo cyclisation over 5-exo due to allylic activation of the former pathway, as highlighted previously in studies on 6-endo epoxide openings by Nicolaou et al [83]. Fragment 110 was synthesised in 17 steps from $(E)$-dihydromuconic acid in 10.8\% yield.

Scheme 27. Synthesis of fragment 110.
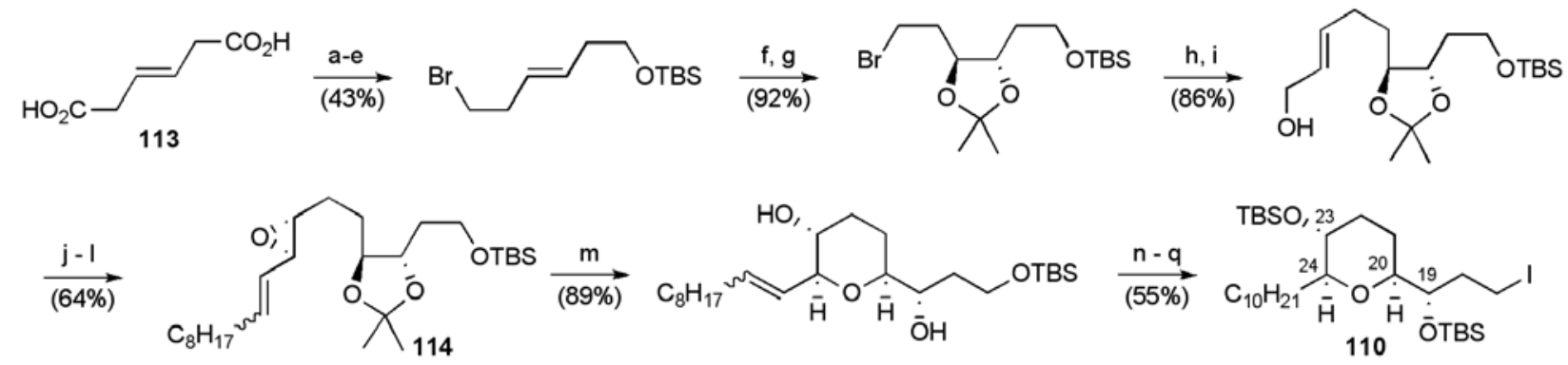

Reagents and conditions: a) TMSCl, $\mathrm{MeOH}$; b) $\mathrm{LiAlH}_{4}$, THF; c) $\mathrm{NaH}, \mathrm{TBSCl}$; d) $p$-TsCl, pyridine, $\mathrm{CH}_{2} \mathrm{Cl}_{2}$; e) LiBr, acetone; f) AD-mix- $\alpha, \mathrm{MeSO}_{2} \mathrm{NH}_{2}, \mathrm{H}_{2} \mathrm{O} / t-\mathrm{BuOH} ;$ g) $p$-TsOH, 2,2dimethoxypropane, $\mathrm{CH}_{2} \mathrm{Cl}_{2}$; h) propargyl alcohol, $n$-BuLi, $\mathrm{NH}_{3} / \mathrm{THF} / \mathrm{DMPU}$; i) Red-Al, THF; j) TBHP, (-)-DIPT, $\left.\mathrm{Ti}(\mathrm{O} i-\mathrm{Pr})_{4}, \mathrm{CH}_{2} \mathrm{Cl}_{2} ; \mathrm{k}\right)$ Dess-Martin periodinane, pyridine, $\mathrm{CH}_{2} \mathrm{Cl}_{2}$; 1) $\mathrm{H}_{19} \mathrm{C}_{9} \mathrm{PPh}_{3} \mathrm{Br}$, NaHMDS, THF; m) $\mathrm{CSA}, \mathrm{CH}_{2} \mathrm{Cl}_{2} / i-\mathrm{PrOH}$; n) $\mathrm{H}_{2}, 5 \% \mathrm{Pt} / \mathrm{C}$, EtOAc; o) TBSOTf, 2,6-lutidine, $\mathrm{CH}_{2} \mathrm{Cl}_{2}$; p) CSA, $\mathrm{CH}_{2} \mathrm{Cl}_{2} / \mathrm{MeOH}$; q) $\mathrm{I}_{2}, \mathrm{PPh}_{3}$, imidazole, $\mathrm{CH}_{2} \mathrm{Cl}_{2}$.

The synthesis of the trans-THF fragment 111 began with TIPS protected $(R)$-glycidol 115 (Scheme 28). Key steps included the use of a reagent controlled organozinc addition to aldehyde 116 (dr 95:5) and a Williamson etherification to close the ring in hydroxymethyl THF 117. Further manipulations returned the Wittig salt 111, which was used crude in the subsequent olefination reaction. 
Scheme 28. Synthesis of Wittig salt 111.
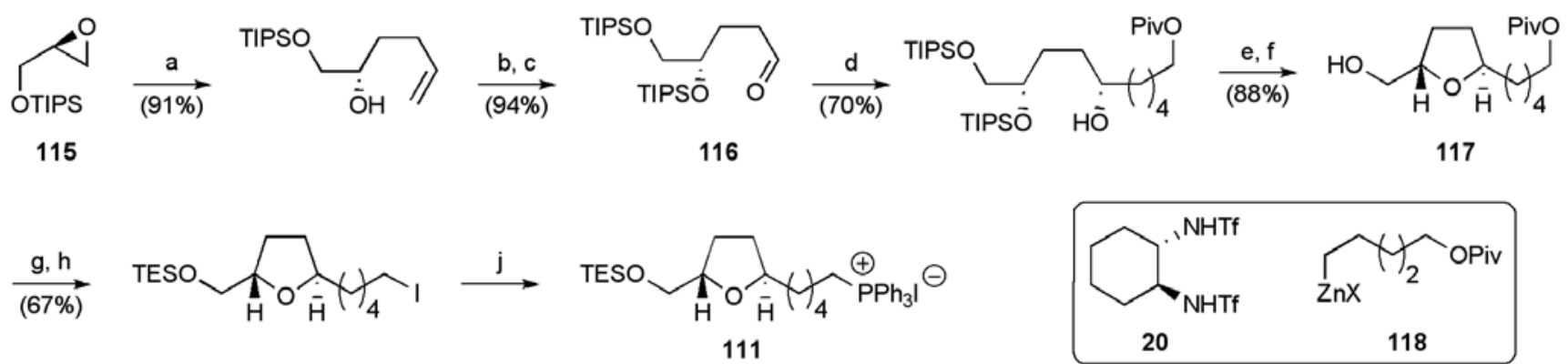

Reagents and conditions: a) $\mathrm{H}_{2} \mathrm{C}=\mathrm{CHCH}_{2} \mathrm{MgBr}, \mathrm{CuI}$, THF b) TIPSOTf, 2,6-lutidine, $\mathrm{CH}_{2} \mathrm{Cl}_{2}$; c) $\mathrm{O}_{3}, \mathrm{CH}_{2} \mathrm{Cl}_{2}, \mathrm{PPh}_{3}$; d) 118, 20, $\mathrm{Ti}(\mathrm{O} i \text {-Pr })_{4}$, xylenes; e) $p$-TsCl, pyridine, $\mathrm{CH}_{2} \mathrm{Cl}_{2}$; f) TBAF, THF; g) TESCl, imidazole, $\mathrm{CH}_{2} \mathrm{Cl}_{2} ;$ h) DIBAL-H, THF; i) $\mathrm{I}_{2}, \mathrm{PPh}_{3}$, imidazole, $\mathrm{CH}_{2} \mathrm{Cl}_{2} ;$ j) $\mathrm{PPh}_{3}$, $\mathrm{CH}_{3} \mathrm{CN} /$ toluene.

Methyl acetoacetate served as the starting material for the assembly of butenolide fragment 112 (Scheme 29), introducing the $\mathrm{C} 4$ stereogenic centre in $\mathbf{1 1 9}$ by enantioselective hydrogenation of the $\beta$ ketoester (ee $=96 \%$ ). The butenolide could then be constructed by alkylation of the dianion of carboxylic acid 120 with $(S)-(-)$-propenoxide, followed by cyclisation to the lactone 121 and dehydrogenation using organoselenium chemistry.

Scheme 29. Synthesis of butenolide 112.

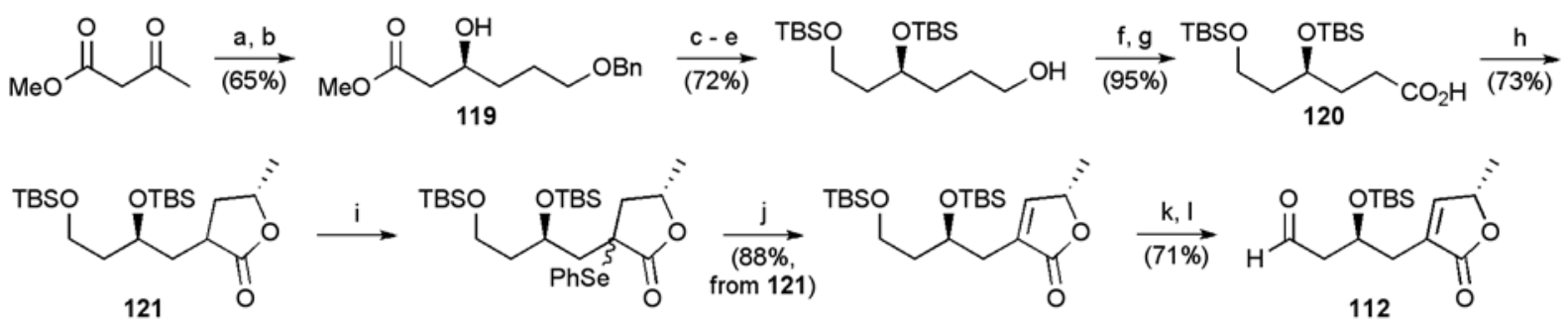

Reagents and conditions: a) $\mathrm{NaH}, n-\mathrm{BuLi}, \mathrm{Br}\left(\mathrm{CH}_{2}\right)_{2} \mathrm{OBn}$, THF; b) $\mathrm{H}_{2}, \mathrm{Ru}(\mathrm{II})-(S)-(-)-\mathrm{BINAP}$; c) $\mathrm{BH}_{3} \bullet \mathrm{SMe}_{2}$, THF; d) TBSCl, imidazole, DMAP, $\mathrm{CH}_{2} \mathrm{Cl}_{2}$; e) $\mathrm{H}_{2}$, Pd/C, EtOAc; f) Swern oxidation; g) $\mathrm{NaOCl}_{2}, \mathrm{NaH}_{2} \mathrm{PO}_{4} \cdot 2 \mathrm{H}_{2} \mathrm{O}$, methyl-2-butene, $\mathrm{H}_{2} \mathrm{O} / t-\mathrm{BuOH}$; h) (i) LDA, THF, (S)-(-)propenoxide; (ii) $\mathrm{PivCl}, \mathrm{Et}_{3} \mathrm{~N}$; i) $\mathrm{KHMDS}, \mathrm{THF}, \mathrm{PhSeCl}$; j) $\mathrm{Mg}$ monoperoxyphthalate, THF/MeOH; k) CSA, $\mathrm{CH}_{2} \mathrm{Cl}_{2} / \mathrm{MeOH}$; 1) Dess-Martin periodinane, pyridine.

With Wittig salt 111 and aldehyde 112 in hand, coupling mediated by NaHMDS afforded alkene 122 as a mixture isomers, which were converted to the aldehyde 123 (Scheme 30). The aldehyde 123 then underwent a stereoselective addition of the organomagnesium reagent derived from iodide $\mathbf{1 1 0}$ under chelation control (dr 4:1). Desilylation of the resulting alcohol 124 secured mucocin (8) in 19 linear steps from methyl acetoacetate in a total yield of $3.3 \%$. 
Scheme 30. Koert's total synthesis of mucocin (8).

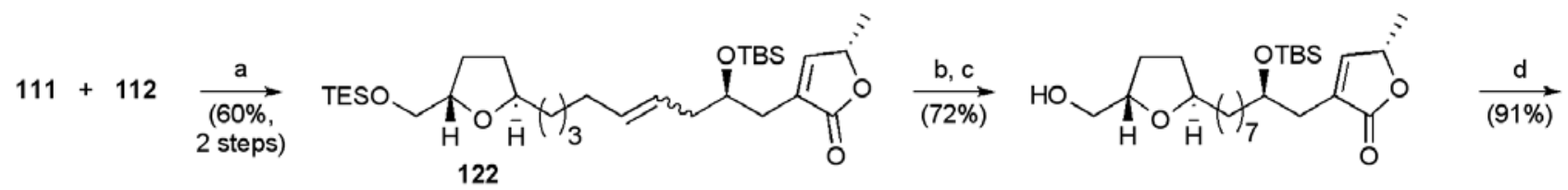

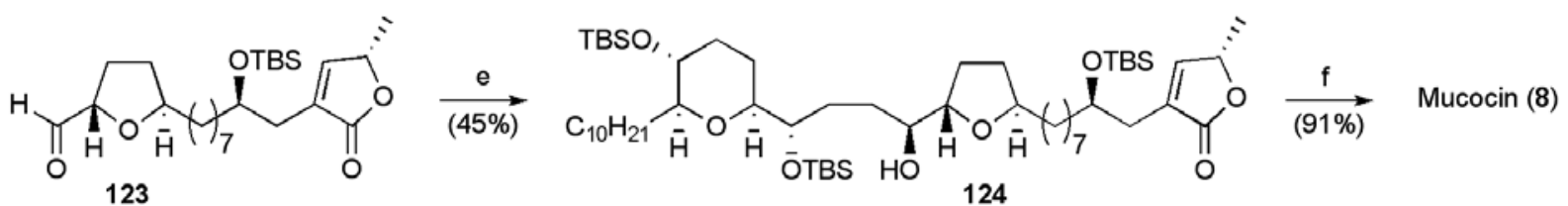

Reagents and conditions: a) NaHMDS, THF; b) $\mathrm{H}_{2}, \mathrm{Rh}\left(\mathrm{PPh}_{3}\right)_{3} \mathrm{Cl}$, benzene; c) CSA, $\mathrm{CH}_{2} \mathrm{Cl}_{2} / \mathrm{MeOH}$; d) Dess-Martin periodinane, pyridine, $\mathrm{CH}_{2} \mathrm{Cl}_{2}$; e) 110, $t$-BuLi, $\mathrm{Et}_{2} \mathrm{O}$, then $\mathrm{MgBr}_{2} \bullet \mathrm{OEt}_{2}$; f) HF, $\mathrm{CH}_{2} \mathrm{Cl}_{2} / \mathrm{MeCN}$.

Sinha and Keinan have advanced a strategy for the synthesis of acetogenins, the so-called the "naked alkyl skeleton approach" [84,85], where an unsaturated carbon backbone is synthesised prior to functionalisation by means of stereocontrolled oxidation reactions (e.g. epoxidation, dihydroxylation and oxidative cyclisation). They applied this concept in their synthesis of mucocin, reported in 1998 [86], where the major fragment 125 was elaborated from a tetraene precursor 127 (Figure 17).

Figure 17. Sinha and Keinan's route to mucocin (8) (1998).

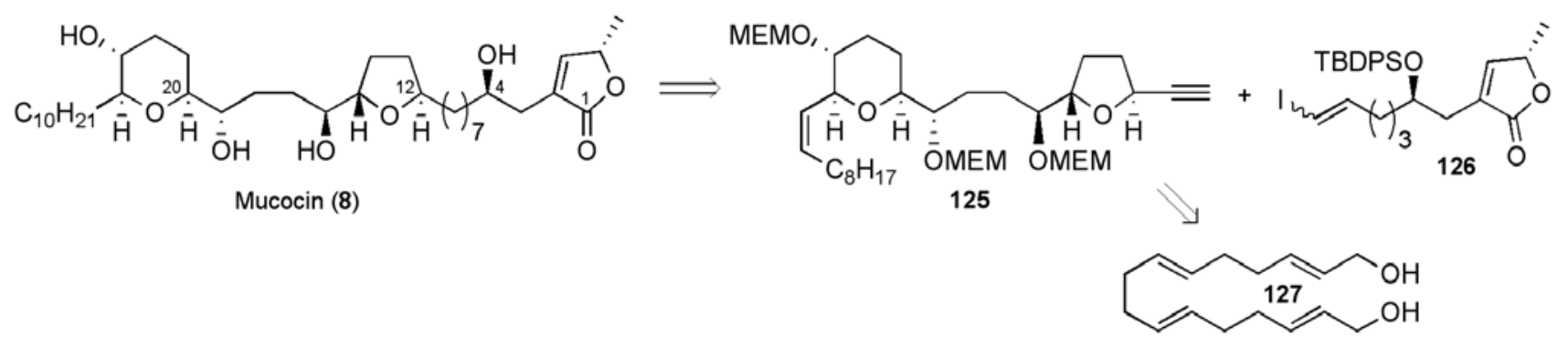

Starting from $(E, E, E)$-cyclododecatriene (128) a two-directional strategy was initially employed to secure the bis-epoxy diol 129 (98\% ee), which was desymmetrised by mono-protection to permit the introduction of the alkyl side-chain (Scheme 31). A double Sharpless asymmetric dihydroxylation of both trans-alkenes gave tetraol 131, setting up the molecule for acid-catalysed regioselective cyclisation. As noted above in the Koert synthesis and with precedent in the work of Nicolaou et al. [80-83], cyclisation to the THP 132 was favoured in the left hand epoxy diol system due to allylic activation of $\mathrm{C} 24$. By contrast, the C14-C11 epoxydiol system closed onto $\mathrm{C} 12$ to give the THF ring, due to a combination of stereoelectronic effects and deactivation of $\mathrm{C} 11$ by the adjacent electronegative silylyether group. The synthesis of the fragment 125 was completed in 18 steps from $(E, E, E)$-cyclododecatriene in $1.3 \%$ overall yield. 
Scheme 31. Synthesis of alkyne 125.
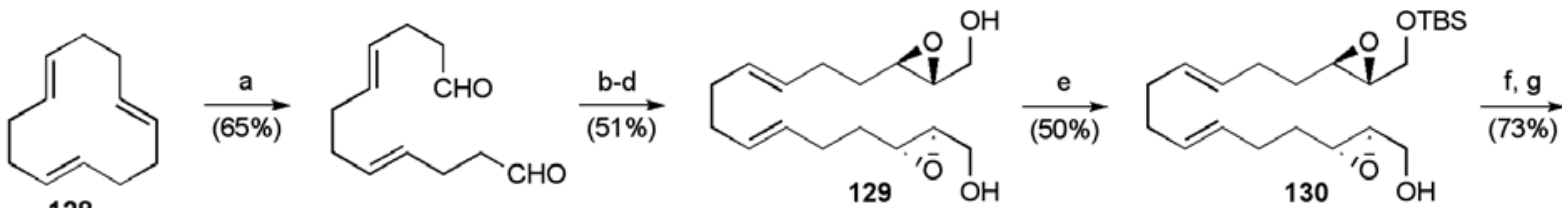

128

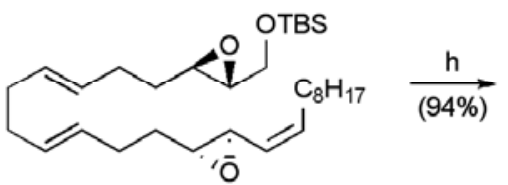

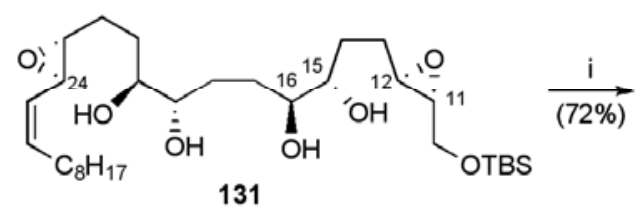

MEMO,

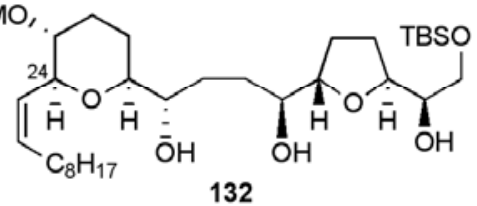

${ }_{(34 \%)}^{\mathrm{j}-n}$

Reagents and conditions: a) (i) $\mathrm{OsO}_{4}$, acetone/ $\mathrm{H}_{2} \mathrm{O}$; (ii) $\mathrm{NaIO}_{4}, \mathrm{CH}_{2} \mathrm{Cl}_{2}$ /acetone;

b) $(\mathrm{EtO})_{2} \mathrm{P}(\mathrm{O}) \mathrm{CH}_{2} \mathrm{CO}_{2} \mathrm{Et}$, NaH, THF; c) DIBAL-H, THF; d) Ti(Oi-Pr) $)_{4},(-)$-DET, TBHP, $\mathrm{CH}_{2} \mathrm{Cl}_{2}$;

e) TBSCl, imidazole, DMF; f) $\mathrm{SO}_{3}$-pyridine, DMSO, $\mathrm{Et}_{3} \mathrm{~N}, \mathrm{CH}_{2} \mathrm{Cl}_{2} ;$ g) $\mathrm{C}_{9} \mathrm{H}_{19} \mathrm{PPh}_{3} \mathrm{Br}$, KHMDS, HMPA/THF; h) AD-mix- $\alpha, \mathrm{MeSO}_{2} \mathrm{NH}_{2}, \mathrm{H}_{2} \mathrm{O} / t-\mathrm{BuOH}$; i) $p$-TsOH, $\mathrm{CH}_{2} \mathrm{Cl}_{2} ;$ j) TsOH, $\mathrm{CH}_{2} \mathrm{Cl}_{2} / \mathrm{MeOH}$; k) $p$-TsOH, $(\mathrm{MeO})_{2} \mathrm{CMe}_{2}, \mathrm{CH}_{2} \mathrm{Cl}_{2}$; l) $p$ - $\mathrm{TsOH}, \mathrm{MeOH} / \mathrm{H}_{2} \mathrm{O}$ (to cleave the $\mathrm{C} 16$, C19-acetonide); m) MEMCl, DIPEA, $\mathrm{CH}_{2} \mathrm{Cl}_{2}$; n) AcOH/ $\mathrm{H}_{2} \mathrm{O}$; o) $\mathrm{NaIO}_{4}, \mathrm{CH}_{2} \mathrm{Cl}_{2}$ /acetone; p) $\mathrm{CBr}_{4}$, $\mathrm{PPh}_{3}, \mathrm{CH}_{2} \mathrm{Cl}_{2} ;$ q) $n$-BuLi, THF.

The vinyl iodide fragment 126 was prepared in 12 steps from $(S)$-dihydro-5-(hydroxymethyl)furan$2(3 \mathrm{H})$-one through application of a route which had previously been published by the same group (Scheme 32) [61]. A Sonogashira coupling reaction between alkyne 125 and vinyl iodide 126 afforded the enyne 134, which was converted to the natural product following hydrogenation and acidic global deprotection. Mucocin (8) was synthesised in a longest linear sequence of 21 steps from $(E, E, E)$ cyclododecatriene $(\mathbf{1 2 8})$ in a total yield of $0.4 \%$.

Scheme 32. Synthesis of vinyl iodide fragment 126 and total synthesis of mucocin (8).

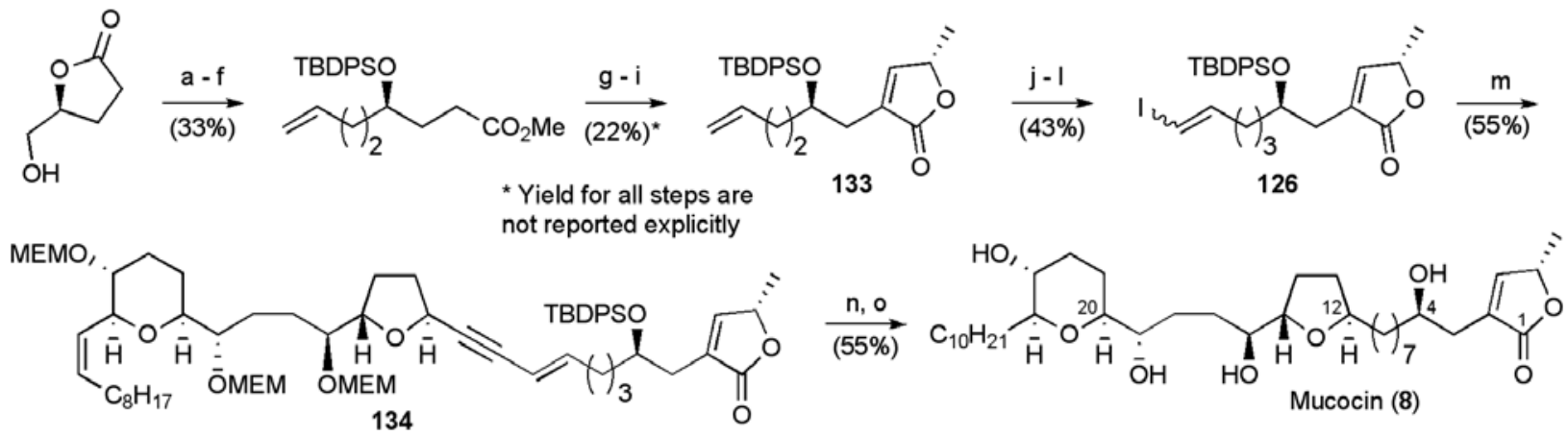

Reagents and conditions: a) NBS, $\mathrm{PPh}_{3}, \mathrm{CH}_{2} \mathrm{Cl}_{2}$; b) $\mathrm{CH}_{2}=\mathrm{CHCH}_{2} \mathrm{SnBu}_{3}$, $\mathrm{AIBN}$; PhMe; c) LiOH (aq), $\mathrm{MeOH}$, then oxalic acid; d) TBDPSCl, imidazole, DMF; e) $\mathrm{MeOH}, \mathrm{K}_{2} \mathrm{CO}_{3}$; f) $(\mathrm{MeO})_{3} \mathrm{CH}$, $\mathrm{TsOH}$; g) LDA, THF, (S)-2-(tetrahydropyran-2-yloxy)propanal; h) $\mathrm{MeOH}, \mathrm{TsOH}$; i) $\mathrm{MsCl}, \mathrm{Et}_{3} \mathrm{~N}$, $\mathrm{CH}_{2} \mathrm{Cl}_{2}$; j) 9-BBN, THF; k) PCC, $\mathrm{CH}_{2} \mathrm{Cl}_{2}$; l) $\mathrm{CHI}_{3}, \mathrm{CrCl}_{2}$, THF; m) 125, $\mathrm{Pd}\left(\mathrm{PPh}_{3}\right)_{2} \mathrm{Cl}_{2}, \mathrm{CuI}, \mathrm{Et}_{3} \mathrm{~N}$, THF; n) $\mathrm{H}_{2}, \mathrm{Rh}\left(\mathrm{PPh}_{3}\right)_{3} \mathrm{Cl}$, benzene, $\left.\mathrm{EtOH} ; \mathrm{o}\right) \mathrm{AcCl}, \mathrm{MeOH}, \mathrm{CH}_{2} \mathrm{Cl}_{2}$. 
The discovery of efficient olefin metathesis reactions has had a profound influence on synthetic strategy in general, and several groups have applied these powerful transformations in total syntheses of mucocin. The synthetic utility of tethered RCM was recognised by Evans and co-workers in their 2003 synthesis of mucocin as a means to unite the THP and THF containing fragments (Figure 18) [59,87-90].

Figure 18. Evans' route to mucocin (8) (2003).

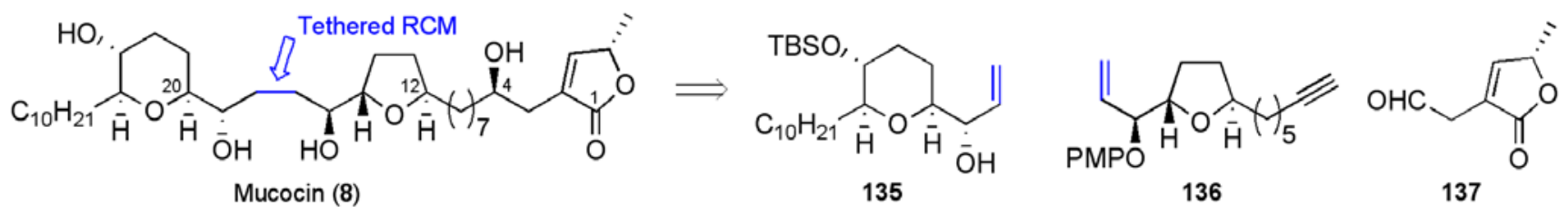

This was the first reported example of the use of a temporary silicon linkage to assist to selective union of two cyclic ether containing fragments applied within in the synthesis of Annonaceous acetogenins, and built upon earlier studies on diastereoselective RCM reactions [91]. It is noteworthy that the trans-disubstituted 1,4-silaketal products were shown to form more slowly under RCM conditions in comparison to the cis-isomers in the diastereoselective cyclisation study by Evans (Figure 19). For the total synthesis of mucocin, the less favoured trans-1,4-silaketal would be required (compare to the formation of cis-silaketal 65 in Scheme 14, and trans-silaketal 96 in Scheme 25).

Figure 19. Diastereoselective tethered RCM reactions of silaketals

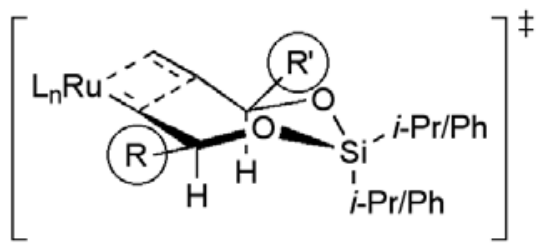

leading to cis-1,4-silaketal (e.g. gigantecin)

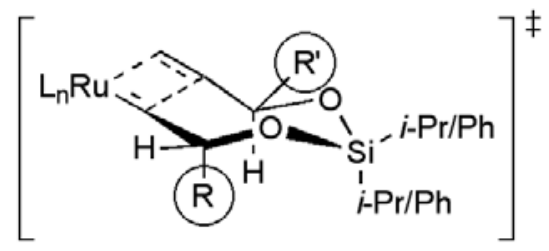

leading to trans-1,4-silaketal (e.g. mucocin, cis-sylvaticin)

Epoxy alcohol 138 (from asymmetric epoxidation of 1,4-pentadien-3-ol in 45\% yield) provided a convenient intermediate for the synthesis of the oxidative cyclisation precursor 139 (Scheme 33). Cobalt mediated oxidative cyclisation returned hydroxymethyl THF 140 with excellent trans selectivity ( $\mathrm{dr} \geq 19: 1)$ [92]. Activation of the $\mathrm{C} 11$ alcohol in $\mathbf{1 4 0}$ as its triflate derivative permitted introduction of the terminal alkynyl chain using an alkyl cuprate substitution to deliver the central fragment 136. Their synthesis of the aldehyde fragment 137 started with a regioselective opening of (S)-propylene oxide with lithiated alkyne 141, and subsequent conversion to selenocarbonate 142 (Scheme 33). $\gamma$-Lactone formation was achieved under radical conditions, and the resulting exo-cyclic alkene isomerised in the presence of a rhodium hydride catalyst to give the butenolide. Acid mediated deprotection gave aldehyde 137 in 36\% overall yield for the 5 steps from alkyne 141. Reaction of the aldehyde 137 with alkyne 136 proceeded with high diastereoselectivity $(\mathrm{dr}=20: 1)$ in the presence of $(R)$-BINOL, and subsequent protecting group manipulations gave allylic alcohol 143 in 8 steps from 138 with a yield of $26 \%$. 
Scheme 33. Synthesis of the C1-C17 allylic alcohol 143.

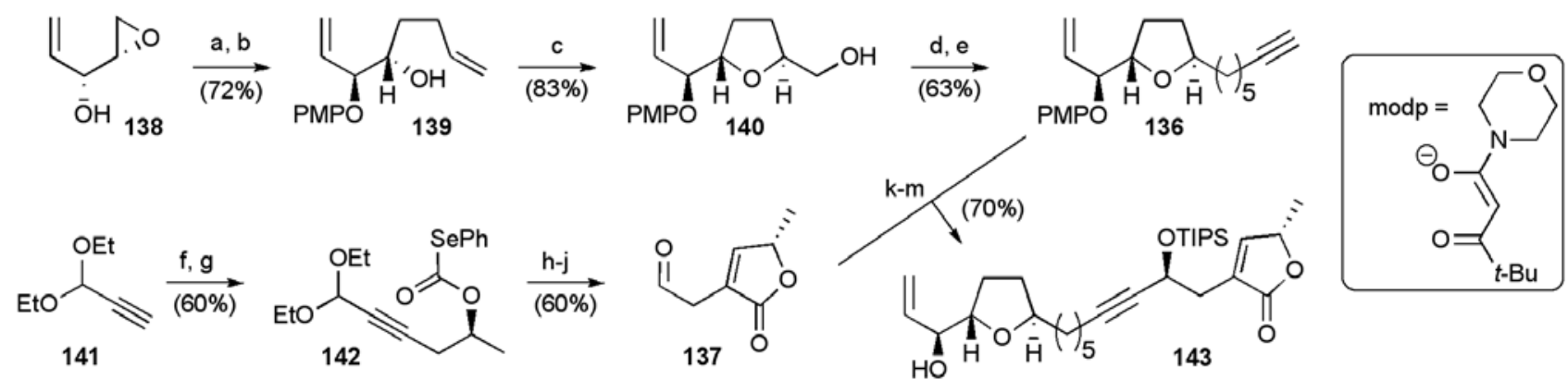

Reagents and conditions a) $p$ - $\mathrm{MeOC}_{6} \mathrm{H}_{4} \mathrm{OH}, \mathrm{DIAD}, \mathrm{PPh}_{3}, \mathrm{THF}$; b) $\mathrm{CH}_{2}=\mathrm{CHCH}_{2} \mathrm{MgBr}, \mathrm{CuCN}$, $\mathrm{Et}_{2} \mathrm{O}$; c) $\mathrm{Co}(\text { modp })_{2}, \mathrm{O}_{2}, t-\mathrm{BuOOH}, i$-PrOH ; d) $\mathrm{Tf}_{2} \mathrm{O}, \mathrm{Et}_{3} \mathrm{~N}, \mathrm{CH}_{2} \mathrm{Cl}_{2}$; e) TMSC $\equiv \mathrm{C}\left(\mathrm{CH}_{2}\right)_{4} \mathrm{MgBr}, \mathrm{CuI}$, THF, then $\mathrm{MeOH}, \mathrm{TBAF}$; f) (S)-propylene oxide, $n$-BuLi, HMPA, THF; g) $\mathrm{COCl}_{2}, \mathrm{Et}_{3} \mathrm{~N}$, benzene, then $\mathrm{PhSeH}$, pyridine, THF/benzene; h) $n-\mathrm{Bu}_{3} \mathrm{SnH}$, AIBN, benzene, $\Delta$; i) $\mathrm{RhH}(\mathrm{CO})\left(\mathrm{PPh}_{3}\right)_{3}$, benzene; j) $\mathrm{HCOOH}$, pentane; k) 136, $\mathrm{Et}_{2} \mathrm{Zn}, \mathrm{PhMe}, \Delta$, then $(R)-\mathrm{BINOL}, \mathrm{Ti}(\mathrm{O} i \text {-Pr })_{4}, \mathrm{THF}$; 1) TIPSOTf, pyridine, DMAP; m) $\left(\mathrm{NH}_{4}\right)_{2} \mathrm{Ce}\left(\mathrm{NO}_{3}\right)_{6}, \mathrm{MeCN} / \mathrm{H}_{2} \mathrm{O}$.

The synthesis of the THP fragment 135 also began with epoxyalcohol 138 (Scheme 34). A Mitsunobu inversion of alcohol 138 with $p$-methoxyphenol, subsequent regioselective epoxide opening with the lithium homoenolate of TBS protected divinyl alcohol, and in situ silylation gave triene $\mathbf{1 4 4 .}$ Asymmetric dihydroxylation and introduction of the left hand alkyl chain using a copper-mediated 1,4-addition afforded the ketone 145, and set the stage for a bismuth-catalysed reductive etherification reaction to deliver the $c i s$-THP ring $(\mathrm{dr} \geq 19: 1)[93,94]$. Final protecting group adjustments gave the required THP fragment 135 in 6 steps from 138 with a yield of $30 \%$.

Scheme 34. Synthesis of THP fragment 135 and tethered RCM to give mucocin (8).

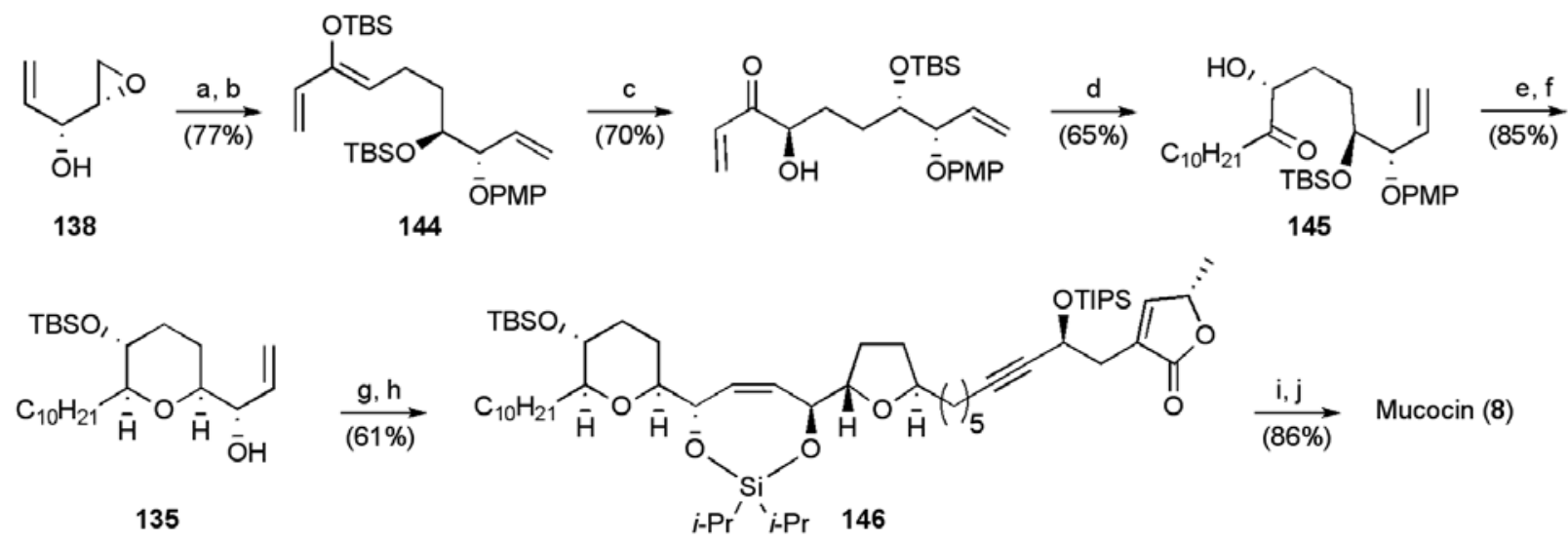

Reagents and conditions: a) $p$ - $\mathrm{MeOC}_{6} \mathrm{H}_{4} \mathrm{OH}$, DIAD, $\mathrm{PPh}_{3}$, THF; b) $\left(\mathrm{CH}_{2}=\mathrm{CH}\right)_{2} \mathrm{CHOTBS,} s$-BuLi, THF, then TBSOTf, 2,6-lutidine; c) AD-mix- $\alpha, t$-BuOH/ $\mathrm{H}_{2} \mathrm{O}, \mathrm{MeSO}_{2} \mathrm{NH}_{2}$; d) $n$-octylMgBr, $\mathrm{CuCN}$, THF; e) $\mathrm{BiBr}_{3}, t$-BuMe $2 \mathrm{SiH}$, MeCN, then 2,6-lutidine, TBSOTf; f) $\left(\mathrm{NH}_{4}\right)_{2} \mathrm{Ce}\left(\mathrm{NO}_{3}\right)_{6}, \mathrm{MeCN} / \mathrm{H}_{2} \mathrm{O}$; g) $i-\mathrm{Pr}_{2} \mathrm{SiCl}_{2}$ (excess), $\mathrm{CH}_{2} \mathrm{Cl}_{2}$, imidazole, then 143, imidazole; h) Grubbs' first generation catalyst (1.8 equiv), 1,2-DCE, $\Delta$; i) $\mathrm{HF} / \mathrm{MeCN}, \mathrm{CH}_{2} \mathrm{Cl}_{2}$; j) TsNHNH${ }_{2}, \mathrm{NaOAc}, 1,2-\mathrm{DME} / \mathrm{H}_{2} \mathrm{O}, \Delta$.

The synthesis was then completed by bringing the fragments 135 and 143 together in a silicon tethered RCM. This tethered coupling reaction required high loadings of the Grubbs' first generation ruthenium complex (1.8 equiv). Subsequent studies by other groups have shown that lower loadings 
may be possible using Grubbs II or other catalysts (for examples see schemes 14 and 25). A global desilylation and selective hydrogenolysis gave mucocin (8) with a longest linear sequence of 13 steps from 1,4-pentadien-3-ol in $13.6 \%$ yield.

Crimmins' approach to mucocin, published in 2006, was also heavily reliant on metathesis in both fragment syntheses and coupling (Figure 20) [95]. Glycolate aldol-RCM chemistry strategies similar to those used in their total synthesis of gigantecin (1) were applied in the assembly of the THP and THF fragments 146 and 147. The butenolide fragment 36 was already available from their earlier total synthesis of gigantecin (1) synthesis [48].

Figure 20. Crimmins' strategy for the synthesis of mucocin (8) (2006).

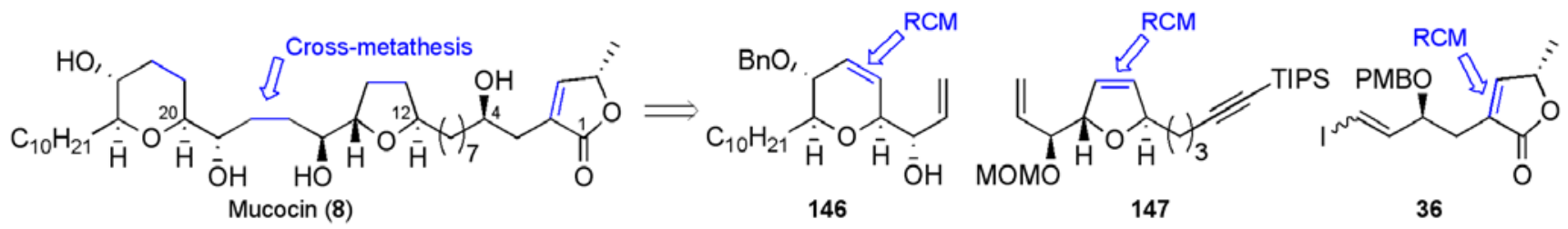

The synthesis of THP fragment 146 started with known epoxyalcohol 148 (available in 2 steps from undecanal in 48\% yield) (Scheme 35) [96,97]. Glycolate aldol reaction between imide 149 and acrolein provided an excess of the threo isomer 150 ( $\mathrm{dr}$ 11:1), which underwent a series of manipulations to deliver triene 151. Judicious choice of protecting groups, and preferential closure of the six-membered ring biased the RCM reaction of the triene to favour of the desired dihydropyran, which was desilylated upon acidic work-up to secure the alyllic alcohol 146 in 14 steps from undecanal in a $11.6 \%$ yield.

Scheme 35. Synthesis of THP fragment 146.
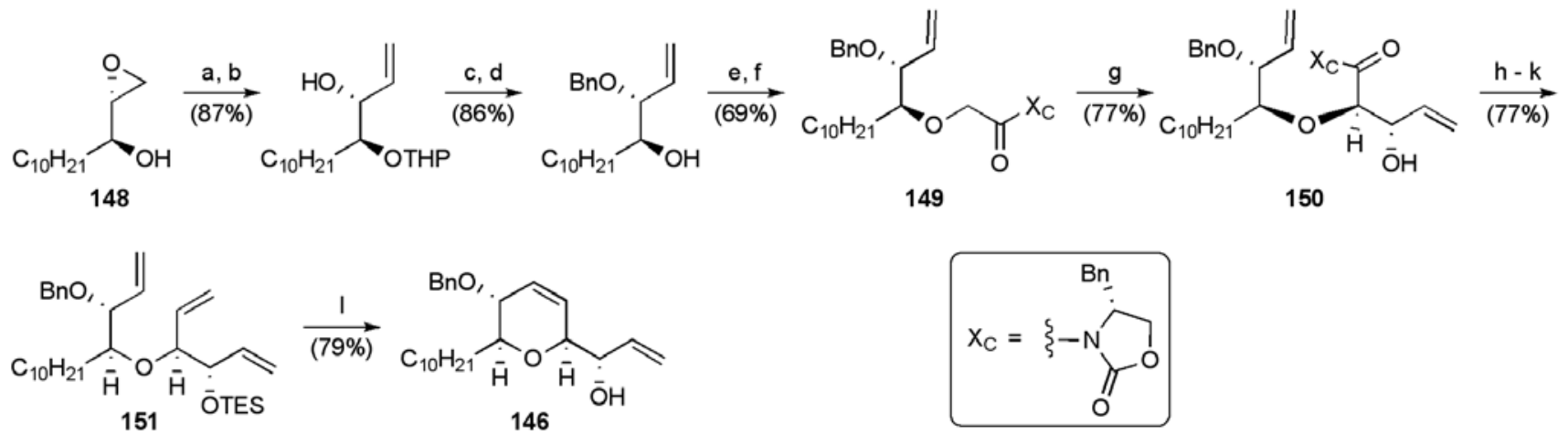

Reagents and conditions: a) DHP, PPTS, $\mathrm{CH}_{2} \mathrm{Cl}_{2}$; b) $\mathrm{Me}_{3} \mathrm{~S}^{+} \mathrm{I}^{-}, n$-BuLi, THF; c) $\mathrm{NaH}, \mathrm{BnBr}, \mathrm{TBAI}$, THF; d) $p$ - TsOH, $\mathrm{MeOH}, \mathrm{CH}_{2} \mathrm{Cl}_{2}$; e) $\mathrm{BrCH}_{2} \mathrm{CO}_{2} \mathrm{H}, \mathrm{NaH}$, THF; f) $\mathrm{Me}_{3} \mathrm{CCOCl}, \mathrm{Et}_{3} \mathrm{~N}, \mathrm{THF},(R)-$ lithio-4-benzyl-oxazolidin-2-one; g) $\mathrm{TiCl}_{4}$, DIPEA, NMP, acrolein, $\mathrm{CH}_{2} \mathrm{Cl}_{2}$; h) TESOTf, 2,6lutidine, $\mathrm{CH}_{2} \mathrm{Cl}_{2}$; i) $\mathrm{LiBH}_{4}, \mathrm{MeOH}, \mathrm{Et}_{2} \mathrm{O}$; j) Swern oxidation; k) $\mathrm{Ph}_{3} \mathrm{PCH}_{3} \mathrm{Br}, \mathrm{KO} t$-Bu, THF; 1) $\mathrm{Cl}_{2}\left(\mathrm{Cy}_{3} \mathrm{P}\right)(\mathrm{IMes}) \mathrm{Ru}=\mathrm{CHPh}(10 \mathrm{~mol} \%)$, benzene, then $p$-TsOH, $\mathrm{MeOH}$.

The substrate for the second glycolate aldol reaction was prepared from the resolved secondary alyllic alcohol 152 (ee 92\%, scheme 36). Reaction between imide 153 and acrolein provided threoaldol product 154 with reasonable selectivity (dr 4:1). Initial efforts to close the dihydrofuran using 
RCM met with some difficulties, which were overcome by implementing Hoye's "activation" strategy [98]. This required a 3-step conversion of alcohol 155 to tetraene 156. With tetraene 156 in hand ruthenium carbene insertion could be controlled and the allylic alcohol 157 was delivered with good levels of regioselectively (7:1). MOM Protection of alcohol 157 completed the synthesis of the THF fragment in 14 steps in $3.3 \%$ overall yield.

Scheme 36. Synthesis of THF fragment 147.
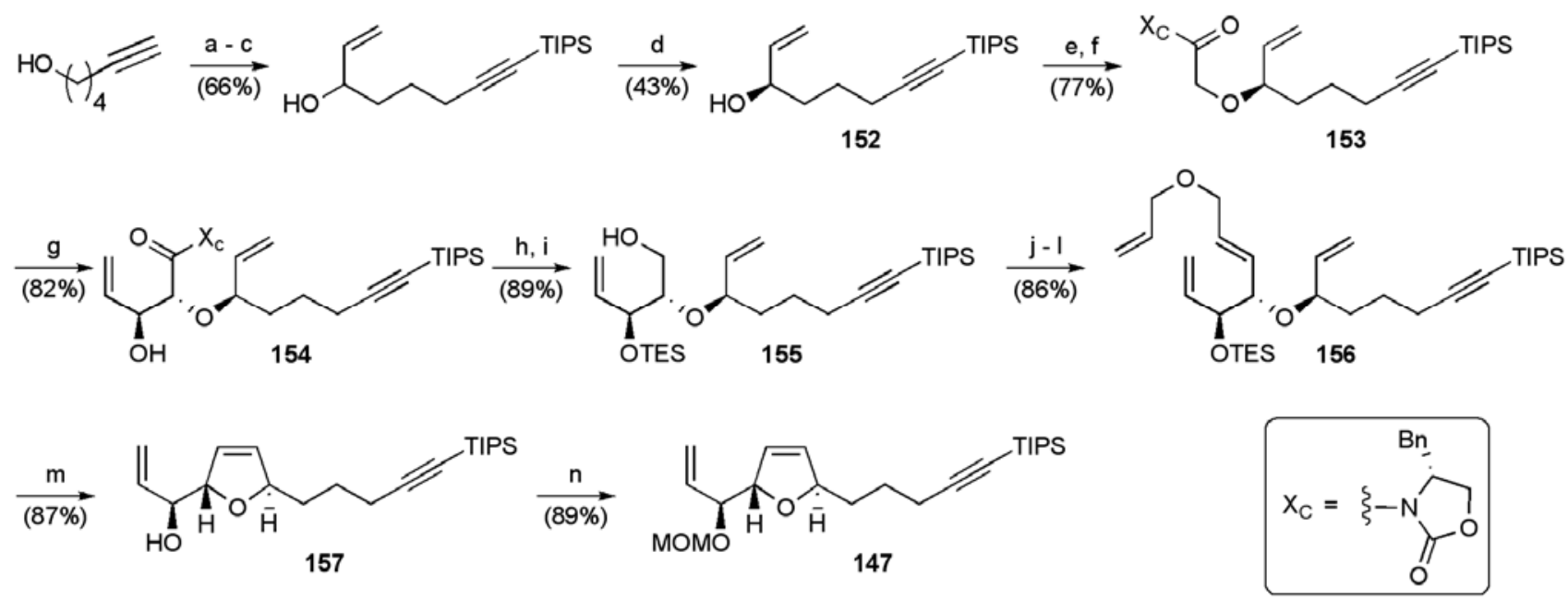

Reagents and conditions: a) EtMgCl, TIPSCl, THF; b) Swern oxidation; c) $\mathrm{CH}_{2}=\mathrm{CHMgBr}$, THF; d) $\mathrm{Ti}(\mathrm{O} i \text {-Pr })_{4}$, (+)-DCHT, $t$-BuOOH, $\mathrm{CH}_{2} \mathrm{Cl}_{2}$; e) $\mathrm{BrCH}_{2} \mathrm{CO}_{2} \mathrm{H}$, NaH, THF; f) $\mathrm{Me}_{3} \mathrm{CCOCl}, \mathrm{Et}_{3} \mathrm{~N}$, THF, ( $R$ )-lithio-4-benzyl-oxazolidin-2-one; g) $\mathrm{TiCl}_{4}$, DIPEA, NMP, acrolein, $\mathrm{CH}_{2} \mathrm{Cl}_{2}$; h) TESOTf, 2,6-lutidine, $\mathrm{CH}_{2} \mathrm{Cl}_{2}$; i) $\mathrm{LiBH}_{4}, \mathrm{MeOH}, \mathrm{Et}_{2} \mathrm{O}$; j) Swern oxidation, $\mathrm{Ph}_{3} \mathrm{P}=\mathrm{CHCO}_{2} \mathrm{Me}$; k) DIBAL-H, $\mathrm{Et}_{2} \mathrm{O}$; 1$) \mathrm{CH}_{2}=\mathrm{CHCH}_{2} \mathrm{Br}, \mathrm{NaH}$, THF; m) $\mathrm{Cl}_{2}\left(\mathrm{Cy}_{3} \mathrm{P}\right)(\mathrm{IMes}) \mathrm{Ru}=\mathrm{CHPh}(10 \mathrm{~mol} \%)$, benzene, then $p$ TsOH, MeOH; n) MOMCl, DIPEA, DMAP, $\mathrm{CH}_{2} \mathrm{Cl}_{2}$.

Scheme 37. Crimmins' total synthesis of mucocin (8).
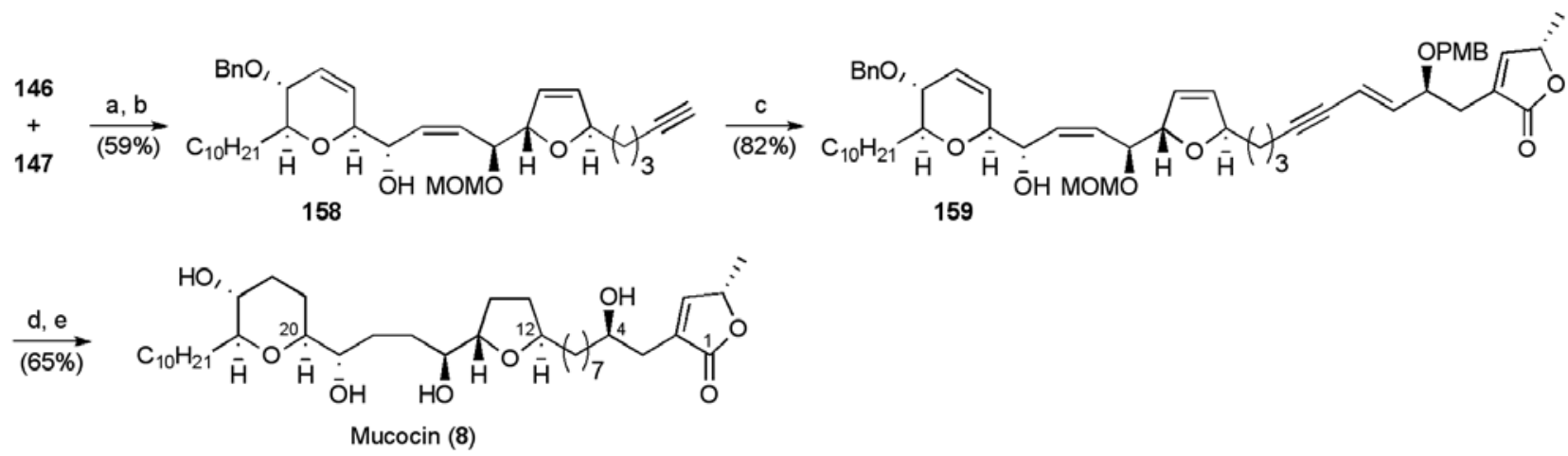

Reagents and conditions: a) $\mathrm{Cl}_{2}(\mathrm{IMes}) \mathrm{Ru}=\mathrm{CH}-\mathrm{o}-\mathrm{O} i-\mathrm{PrC}_{6} \mathrm{H}_{4}(10 \mathrm{~mol} \%), \mathrm{CH}_{2} \mathrm{Cl}_{2}$; b) TBAF, THF; c) 36, $\mathrm{Pd}\left(\mathrm{PPh}_{3}\right)_{2} \mathrm{Cl}_{2}, \mathrm{CuI}, \mathrm{Et}_{3} \mathrm{~N}$; d) $\left.\mathrm{TsNHNH}_{2}, \mathrm{NaOAc}, 1,2-\mathrm{DME} / \mathrm{H}_{2} \mathrm{O}, \Delta ; \mathrm{e}\right) \mathrm{BF}_{3} \cdot \mathrm{OEt}_{2}, \mathrm{Me}_{2} \mathrm{~S}$.

The steric hindrance of the MOM ether group apparently deactivated allylic alcohol 147 towards metathesis relative to allylic alcohol 146. The differences in reactivity allowed successful CM coupling using Hoveyda-Grubbs catalyst (Scheme 37). The CM product was desilylated, delivering alkyne 158 which was used in a Sonogashira coupling with iodide 36 to secure enyne 149. Selective 
hydrogenation and global deprotection gave mucocin (8), with a longest linear sequence of 19 steps from alcohol hex-1-yne-6-ol in 1.0\% yield.

Metathesis was also pivotal in Mootoo's route to mucocin reported in 2006, exploiting CM and olefination reactions to assemble the key fragments paralleling their earlier synthesis of squamostatin$\mathrm{C}$ (Figure 21). Due to the fact that the C1-C18 segments of mucocin and squamostatin $\mathrm{C}$ are identical, Mootoo was able to utilize the same C1-C7 and C8-C17 fragments 68 and 67 (see schemes 16 and 17) $[57,99]$.

Figure 21. CM and olefination approach to mucocin (8) used by Mootoo and co-workers (2006).

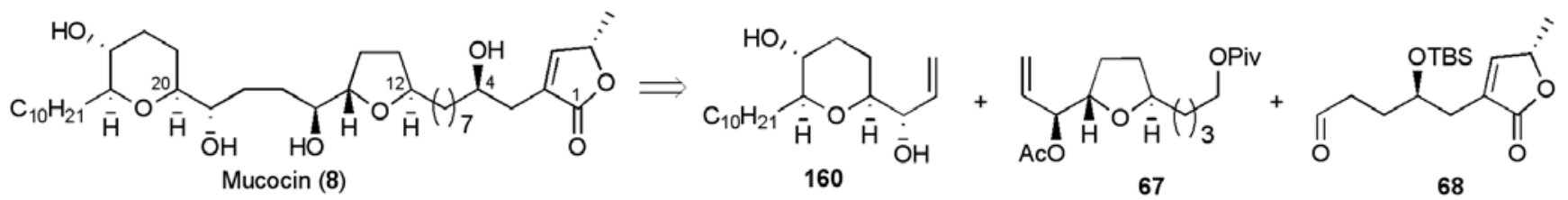

The synthesis of the THP fragment 160 began with aldehyde 162, obtained from Swern oxidation of 71 (Scheme 38) [57]. Addition of lithiated dithiane 161 gave secondary alcohol 163 as an epimeric mixture. Exposure of 163 to mercury (II) perchlorate induced acetal exchange, which allowed the alcohol epimers 164 to be separated using column chromatography. Reductive acetal cleavage furnished the desired THP fragment 160 in 8 steps from 1,4-pentadien-3-ol and 6.7\% yield.

Scheme 38. Synthesis of THP fragment $\mathbf{1 6 0 .}$<smiles>CCCCOCCOCCO</smiles>

161<smiles>C=CC1OC(C)(C)O[C@@H]1CCC=O</smiles>

162<smiles>CCC(O)C1(CO)SCCCS1</smiles>

163<smiles>C=CC1OC(C)(C)O[C@@H]1C</smiles>

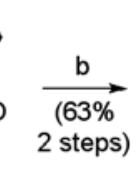
steps)<smiles>C=C[C@@H]1OC2([14CH3])O[C@@H]1CC[C@@H]2O</smiles>

164<smiles>C=C[C@H](O)C1CC[C@@H](O)C([14CH2]O)O1</smiles>

160

Reagents and conditions: a) $n$-BuLi, THF; b) $\mathrm{Hg}\left(\mathrm{ClO}_{4}\right)_{2}$, THF; c) column chromatography;

d) $\mathrm{Et}_{3} \mathrm{SiH}, \mathrm{BF}_{3} \cdot \mathrm{OEt}_{2}, \mathrm{CH}_{2} \mathrm{Cl}_{2}$.

Cross-metathesis of allylic alcohol fragment $\mathbf{1 6 0}$ and a three-fold excess of acetate $\mathbf{6 7}$ in the presence of Grubbs II catalyst afforded the coupled product in 51\% yield (Scheme 39). Hydrogenation and protecting group exchange delivered alcohol 165, which was converted to sulfone 166 to enable union with the aldehyde fragment $\mathbf{6 8}$ under a Julia-Kocienski olefination conditions. Selective hydrogenation and global deprotection completed the synthesis of mucocin (8), with a longest linear sequence of 20 steps from 1,4-pentadien-3-ol in $0.5 \%$ yield. 
Scheme 39. Mootoo's total synthesis of mucocin (8).<smiles>C=CC(O)C1CCC(O)C(C=C)O1</smiles>

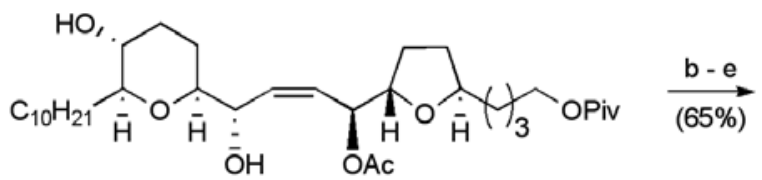

MOMO,

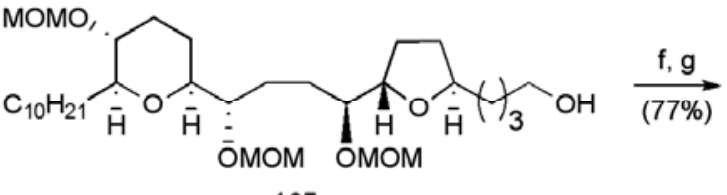

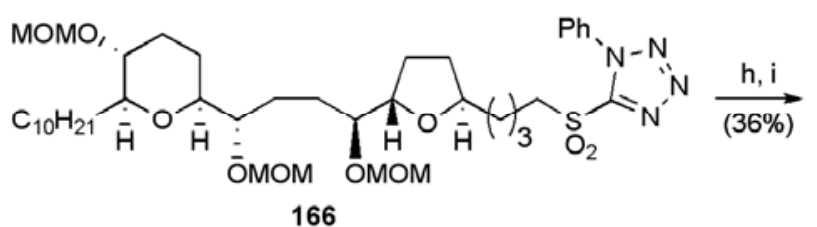

момо,

165

166

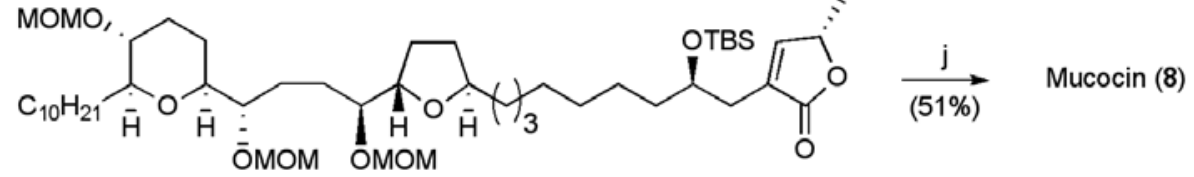

Reagents and conditions: a) $\mathrm{Cl}_{2}\left(\mathrm{Cy}_{3} \mathrm{P}\right)(\mathrm{IMes}) \mathrm{Ru}=\mathrm{CHPh}(10 \mathrm{~mol} \%), \mathrm{CH}_{2} \mathrm{Cl}_{2}, \mathrm{rt}, 18 \mathrm{~h}$, then $\mathrm{Cl}_{2}\left(\mathrm{Cy}_{3} \mathrm{P}\right)(\mathrm{IMes}) \mathrm{Ru}=\mathrm{CHPh}\left(10 \mathrm{~mol} \%\right.$ ), rt, $18 \mathrm{~h} ;$ b) $\left.\mathrm{H}_{2}, \mathrm{Pd} / \mathrm{C}, \mathrm{EtOAc} ; \mathrm{c}\right) \mathrm{K}_{2} \mathrm{CO}_{3}, \mathrm{MeOH}$; d) $\mathrm{MOMCl}$, DIPEA, $\mathrm{CH}_{2} \mathrm{Cl}_{2}$; e) $\mathrm{NaOMe}, \mathrm{MeOH}$; f) $\mathrm{Ph}_{3} \mathrm{P}$, DIAD, 1-phenyl-1H-tetrazole-5-thiol, THF; g) $m$-CPBA, $\mathrm{NaHCO}_{3}, \mathrm{CH}_{2} \mathrm{Cl}_{2}$; h) LiHMDS, THF, then 68; i) $\mathrm{H}_{2}, \mathrm{Rh}_{(}\left(\mathrm{Ph}_{3} \mathrm{P}\right)_{3} \mathrm{Cl}$, benzene$\mathrm{EtOH}$; j) $5 \% \mathrm{AcCl}, \mathrm{MeOH} / \mathrm{CH}_{2} \mathrm{Cl}_{2}$.

Takahashi and Nakata published two distinct total syntheses of mucocin both in 2002. In the first reported approach the natural product was assembled from two major fragments, the more complex bis-cyclic ether fragment 167 deriving from (4E,8E)-dodeca-4,8-dienedial (Figure 22) [100].

Figure 22. Nakata's retrosynthetic analysis of mucocin (8) (2002).

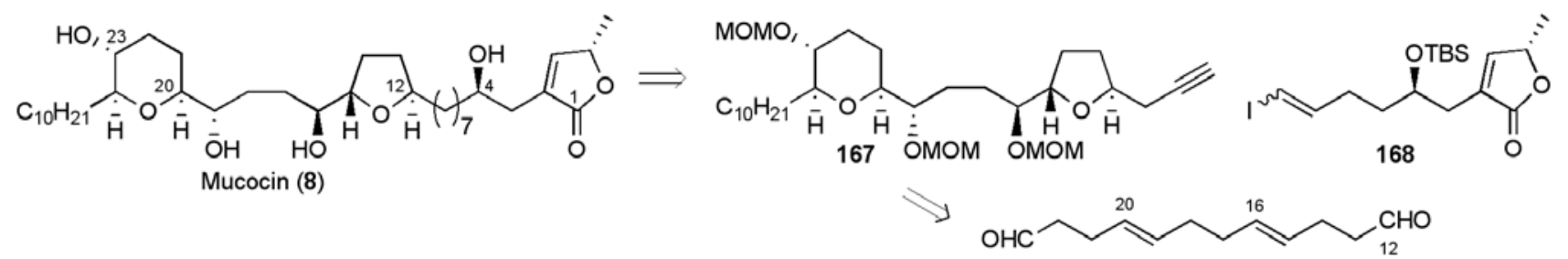

Initial two-directional elaboration of $(4 E, 8 E)$-dodeca-4,8-dienedial (available in 2 steps from $(E, E, E)$-cyclododecatriene, see scheme 31$)$ provided a bis-acetal that was desymmetrised by monobenzylation (Scheme 40). Further manipulations led to $\alpha, \beta$-unsaturated ester 169, which underwent reductive cyclisation mediated by $\mathrm{SmI}_{2}$ to install the cis-THP ring in 170 [101]. Protecting group adjustments gave lactol 171, then Wittig olefination secured the alkenol 172. Nakata et al. employed the trans-selective cobalt oxidative cyclisation, also seen in the Evans synthesis of mucocin (see Scheme 33), to create the THF ring in alcohol 173 with high selectivity [92]. Conversion of alcohol 173 to its triflate and subsequent displacement with lithiated TMS acetylene followed by in situ desilylation gave fragment 167 in 20 linear steps from $(E, E, E)$-cyclododecatriene with an overall yield of $9.9 \%$. 
Scheme 40. Synthesis of alkyne 167.
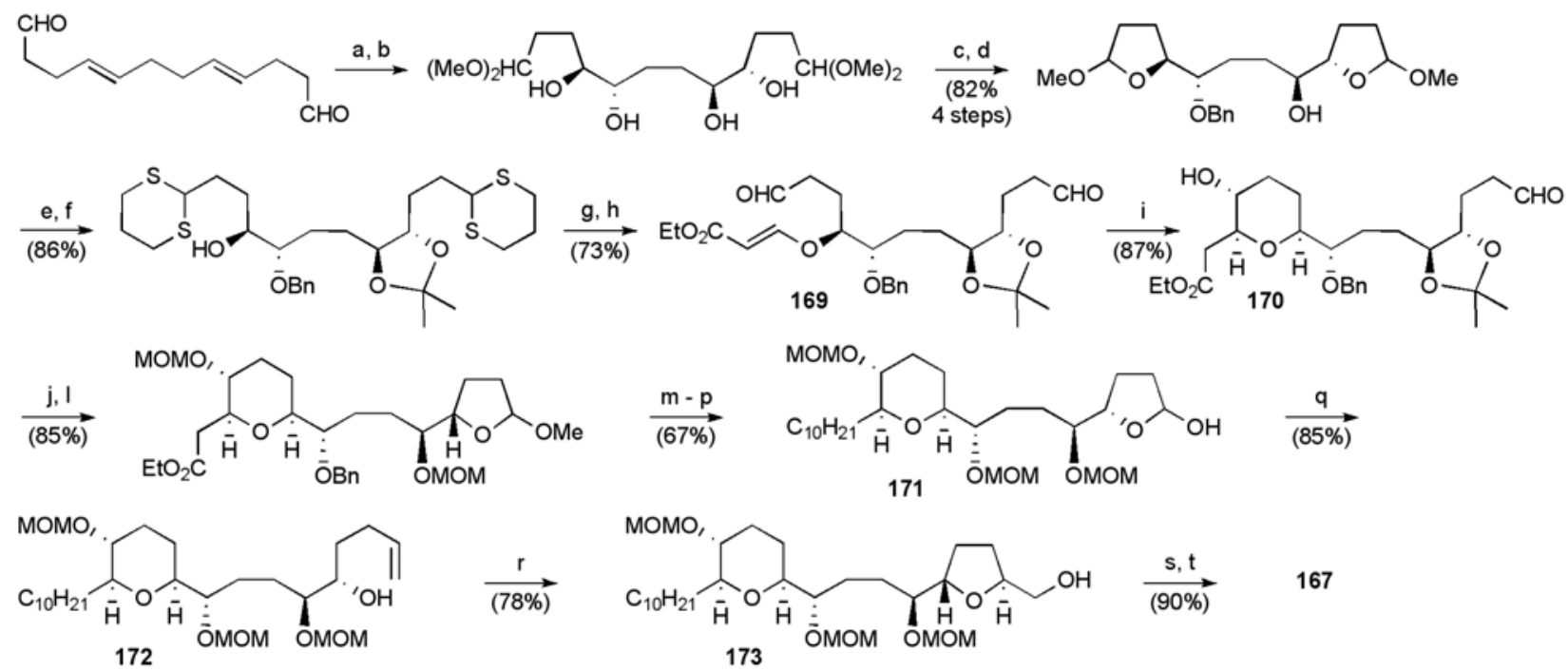

Reagents and conditions: a) $\mathrm{HC}(\mathrm{OMe})_{3}, \mathrm{CSA}, \mathrm{MeOH}$; b) AD-mix- $\alpha, \mathrm{MeSO}_{2} \mathrm{NH}_{2}, \mathrm{H}_{2} \mathrm{O} / t-\mathrm{BuOH}$; c) $\mathrm{CSA}, \mathrm{MeOH}$; d) $\mathrm{BnBr}, \mathrm{NaH}$, THF; e) 1,3-propanedithiol, $\mathrm{Zn}(\mathrm{OTf})_{2}$, DCE; f) $\mathrm{Me}_{2} \mathrm{C}(\mathrm{OMe})_{2}, \mathrm{CSA}$, $\mathrm{CH}_{2} \mathrm{Cl}_{2}$; g) ethyl propiolate, $N$-methylmorpholine, $\mathrm{CH}_{2} \mathrm{Cl}_{2}$; h) $\mathrm{CH}_{3} \mathrm{I}, \mathrm{NaHCO}_{3}, \mathrm{MeCN} / \mathrm{H}_{2} \mathrm{O}$; i) $\mathrm{SmI}_{2}$, $\mathrm{MeOH}, \mathrm{THF}$; j) $\mathrm{HC}(\mathrm{OMe})_{3}, \mathrm{CSA}, \mathrm{MeOH}$; 1$) \mathrm{MOMBr}$, DIPEA, DCE; m) DIBAL-H, $\mathrm{CH}_{2} \mathrm{Cl}_{2}$, then $\mathrm{C}_{8} \mathrm{H}_{17} \mathrm{PPh}_{3} \mathrm{Br}, n$-BuLi, THF; n) $10 \% \mathrm{Pd} / \mathrm{C}, \mathrm{H}_{2}, \mathrm{MeOH}$; o) MOMBr, DIPEA, DCE; p) $\mathrm{AcOH} / \mathrm{H}_{2} \mathrm{O}$; q) $\mathrm{CH}_{3} \mathrm{PPh}_{3} \mathrm{I}$, NaHMDS, THF; r) [Co(modp) $)_{2}$, $\mathrm{O}_{2}, t-\mathrm{BuO}_{2} \mathrm{H}, i$-PrOH; s) Tf $2 \mathrm{O}$, 2,6-lutidine, $\mathrm{CH}_{2} \mathrm{Cl}_{2}$; t) TMSC $\equiv \mathrm{CLi}$, HMPA, THF, then $\mathrm{K}_{2} \mathrm{CO}_{3}, \mathrm{MeOH}$.

During the synthesis of the butenolide fragment 168, the stereochemistry of the $\mathrm{C} 4$ carbinol was controlled using an asymmetric allylation (ee $>98 \%$, scheme 41 ). Subsequent conversion of the allylation product $\mathbf{1 7 5}$ to the ester $\mathbf{1 7 6}$ permitted the creation of the butenolide system using an aldollactonisation-dehydration sequence. Cleavage of the electron-rich PMB group, oxidation of the resulting primary alcohol and Takai olefination delivered the required fragment 168 in 13 steps from 1,4-butandiol in a total yield of $21.1 \%$.

Scheme 41. Synthesis of vinyl iodide $\mathbf{1 6 8}$ and total synthesis of $\mathbf{8}$.

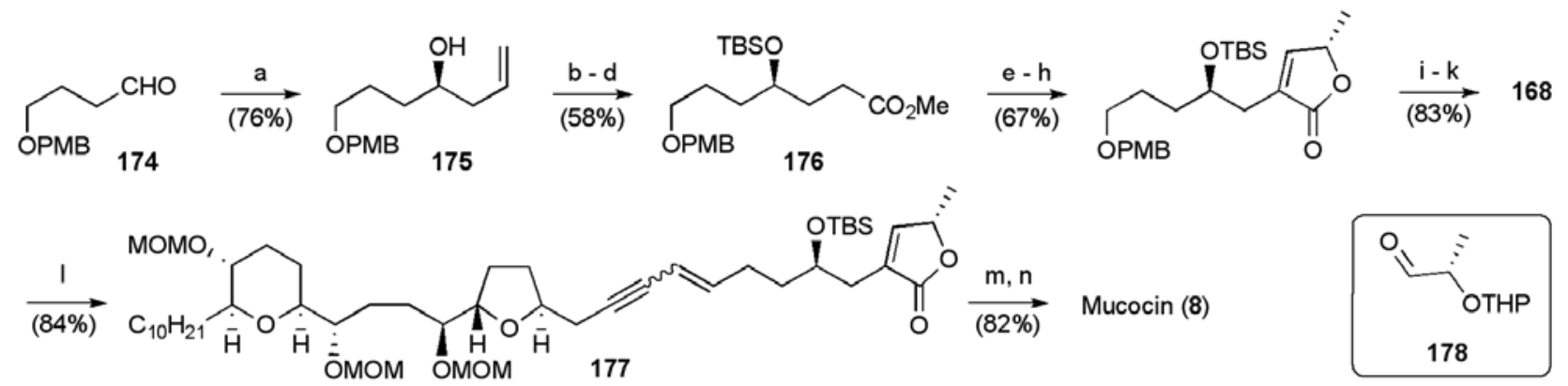

Reagents and conditions: a) (S)-BINOL, Ti(Oi-Pr $)_{4}$, allyltributyltin,; b) TBSCl, imidazole, DMF; c) $\mathrm{BH}_{3} \bullet$ THF, THF then $\mathrm{NaOH}, 30 \% \mathrm{H}_{2} \mathrm{O}_{2}$; d) Jones reagent, acetone then $\mathrm{CH}_{2} \mathrm{~N}_{2}, \mathrm{Et}_{2} \mathrm{O}$; e) LDA, THF, then 178; f) $\mathrm{CSA}, \mathrm{MeOH} / \mathrm{H}_{2} \mathrm{O}$; g) $\mathrm{MsCl}, \mathrm{Et}_{3} \mathrm{~N}, \mathrm{CH}_{2} \mathrm{Cl}_{2}$; h) $\mathrm{DBU}, \mathrm{CH}_{2} \mathrm{Cl}_{2}$; i) DDQ, $\mathrm{CH}_{2} \mathrm{Cl}_{2}$ phosphate buffer (pH 7.4); j) $(\mathrm{COCl})_{2}, \mathrm{DMSO}, \mathrm{CH}_{2} \mathrm{Cl}_{2}$, then $\mathrm{Et}_{3} \mathrm{~N}$; k) $\mathrm{CrCl}_{2}, \mathrm{CHI}_{3}$, THF; 1) $\left.\left[\mathrm{PdCl}_{2}\left(\mathrm{Ph}_{3} \mathrm{P}\right)_{2}\right], \mathrm{CuI}, \mathrm{Et} 3{ }_{3} \mathrm{~N} ; \mathrm{m}\right)\left(\mathrm{Ph}_{3} \mathrm{P}\right)_{3} \mathrm{RhCl}, \mathrm{H}_{2}$, benzene/EtOH; n) $10 \% \mathrm{HCl} / \mathrm{MeOH}, \mathrm{CH}_{2} \mathrm{Cl}_{2}$. 
The fragments 167 and 168 were combined through the well established Sonogashira coupling strategy to give enyne $\mathbf{1 7 7}$ in good yield, which following selective hydrogenation over Wilkinson's catalyst and global deprotection afforded mucocin (8), with a longest linear sequence of 23 steps from $(E, E, E)$-cyclododecatriene and corresponding $6.8 \%$ yield.

Takahashi and Nakata published an alternative route to mucocin, wherein each of the three major fragments 178-180 was constructed from carbohydrate starting materials (Figure 23) [102-104]. Synthesis of THP fragment 178 began with commercially available benzyl ether 181, deoxygenating at $\mathrm{C} 21 / 22$, and introducing the $n$-decyl side-chain through a Grignard addition-oxo-carbenium ion reduction sequence (Scheme 42). THP fragment 178 was synthesised in 12 steps from benzyl ether $\mathbf{1 8 1}$ in $41.3 \%$ yield.

Figure 23. Synthesis of mucocin (8) from carbohydrate starting materials (2002).

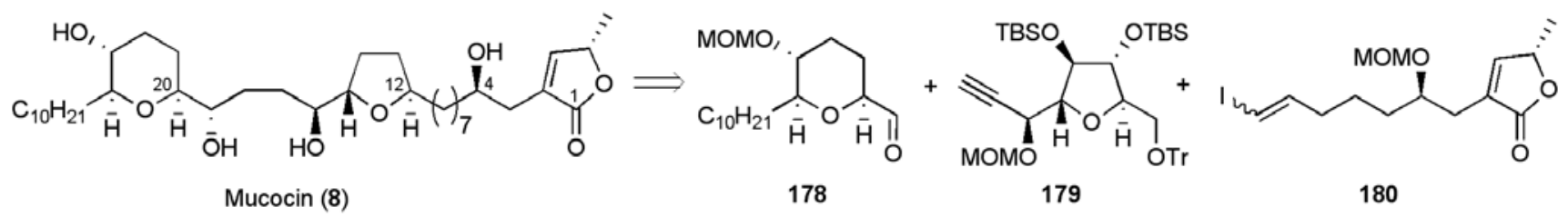

Scheme 42. Synthesis of THP fragment 178.
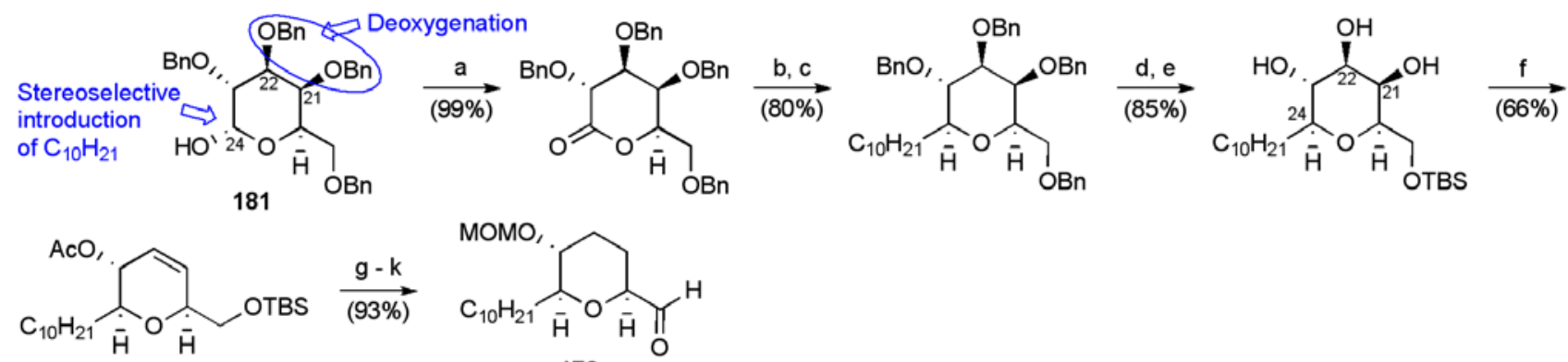<smiles>CO[C@H]1CC[C@@H](C=O)O[C@H]1[C@H](O)CO</smiles>

178

Reagents and conditions: a) Swern oxidation; b) $n$ - $\mathrm{C}_{10} \mathrm{H}_{21} \mathrm{MgBr}$; c) $\mathrm{Et}_{3} \mathrm{SiH}, \mathrm{BF}_{3} \cdot \mathrm{OEt}_{2}, \mathrm{CH}_{2} \mathrm{Cl}_{2}$;

d) $\mathrm{Pd} / \mathrm{C}, \mathrm{H}_{2}$; e) $\mathrm{TBDPSCl}$, imidazole; f) (i) $\mathrm{HC}(\mathrm{OMe})_{3}, \mathrm{CSA}$; (ii) $\mathrm{Ac}_{2} \mathrm{O}, \Delta$; g) $\mathrm{Pd} / \mathrm{C}, \mathrm{H}_{2}$;

h) NaOMe,; i) MOMCl, DIPEA; j) TBAF, THF; k) Swern oxidation.

Commercially available 2,5-anhydro-D-mannitol (182) served as the starting material for the THF containing fragment 179 (Scheme 43). Desymmetrisation of a fully protected intermediate 183 afforded the opportunity to create the $\mathrm{C} 16$ carbinol stereogenic centre by means of a stereoselective acetylide addition to aldehyde $184(\mathrm{dr}=93: 7)$. Protection of the resulting hydroxyl group as its MOM ether gave the required fragment 179 in a total of 5 steps from 2,5-anhydro-D-mannitol in $44.6 \%$ yield, but requiring later deoxygenation at $\mathrm{C} 13 / 14$.

The butenolide fragment 180 derived from L-rhamnose derivative 185 (3 steps from L-rhamnose) (Scheme 44). It is of note that only the C5 carbinol stereogenic centre present in the deoxy sugar was translated directly into mucocin (corresponds to C35 in mucocin). Thioacetal 185 was converted to the selenocarbonate 186, which was the substrate for an acyl radical cyclisation to afford lactone 187. Elimination with DBU followed by silyl deprotection, oxidation and Takai olefination delivered the butenolide $\mathbf{1 8 0}$ in 18 steps from L-rhamnose. 
Scheme 43. Synthesis of THF fragment 179.

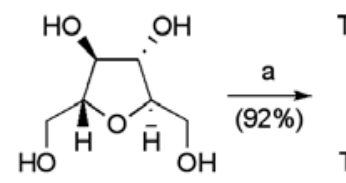

182

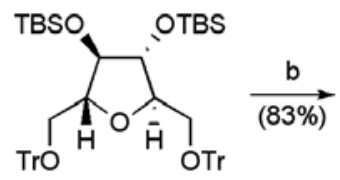

183
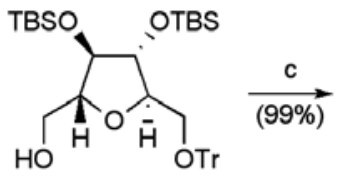

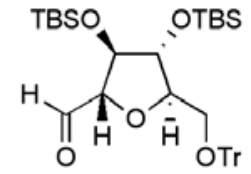

184

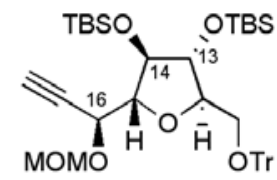

179

Reagents and conditions: a) $\mathrm{TrCl}$, pyridine, then $\mathrm{TBSCl}$, imidazole; b) $\mathrm{Et}_{2} \mathrm{AlCl}$, hexane; c) Swern oxidation; d) $\mathrm{HC} \equiv \mathrm{CMgCl}, \mathrm{ZnCl}_{2}, \mathrm{CH}_{2} \mathrm{Cl}_{2} / \mathrm{Et}_{2} \mathrm{O} / \mathrm{THF}$; e) MOMCl, DIPEA, $\mathrm{CH}_{2} \mathrm{Cl}_{2}$.

Scheme 44. Synthesis of butenolide fragment 180.<smiles>CC(=O)O[C@H](C)[C@H]1O[C@H](c2ccccc2)[C@H]2OC(C)(C)O[C@H]12</smiles>

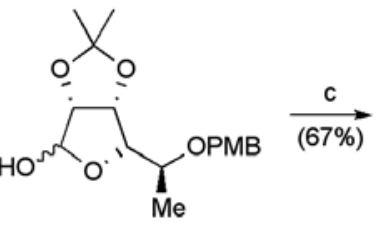

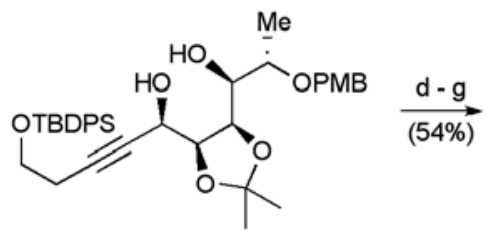

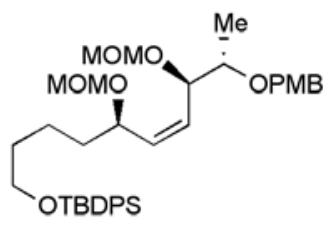

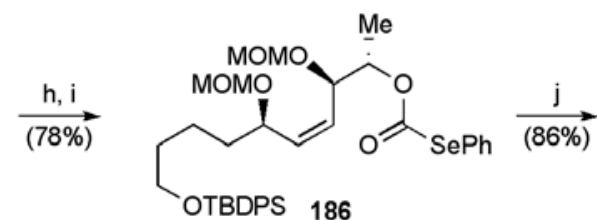<smiles>CO[C@H](CCCCOC(C)(C)C)[C@H]1C(=O)O[C@H](C)[C@@H]1OC</smiles><smiles>[14CH3][As]</smiles><smiles>CO[C@H](CCC/C=C/I)CC1=C[C@@H](C)OC1=O</smiles>

Reagents and conditions: a) NaOMe, MeOH; b) (i) MPMCl, NaH, TBAI, DMF; (ii) NBS, THF; c) $\mathrm{TBDPSOCH} \mathrm{CH}_{2} \mathrm{C} \equiv \mathrm{CH}, n$-BuLi, hexane/Et $\mathrm{E}_{2} \mathrm{O}$; d) $\mathrm{MOMCl}$, DIPEA, $\mathrm{CH}_{2} \mathrm{Cl}_{2}$; e) $5 \% \mathrm{Rh} / \mathrm{Al}_{2} \mathrm{O}_{3}$, $\mathrm{H}_{2}$, EtOAc; f) aq $\mathrm{AcOH}$; g) (i) $\mathrm{HC}(\mathrm{OMe})_{3}, \mathrm{CSA}, \mathrm{CH}_{2} \mathrm{Cl}_{2}$; (ii) $\mathrm{Ac}_{2} \mathrm{O}$; h) $\mathrm{DDQ}, \mathrm{CH}_{2} \mathrm{Cl}_{2}$; i) triphosgene, pyridine, $\mathrm{CH}_{2} \mathrm{Cl}_{2}$, then $\mathrm{PhSeH}, \mathrm{Et}_{3} \mathrm{~N}$; j) $\mathrm{Bu}_{3} \mathrm{SnH}$, AIBN, toluene; k) TBAF, $\mathrm{AcOH}$, THF, then DBU, $\mathrm{CH}_{3} \mathrm{CN}$; 1) Swern oxidation; $\mathrm{m}$ ) $\mathrm{CHI}_{3}, \mathrm{CrCl}_{2}$, THF.

Scheme 45. Takahashi's synthesis of mucocin (8).
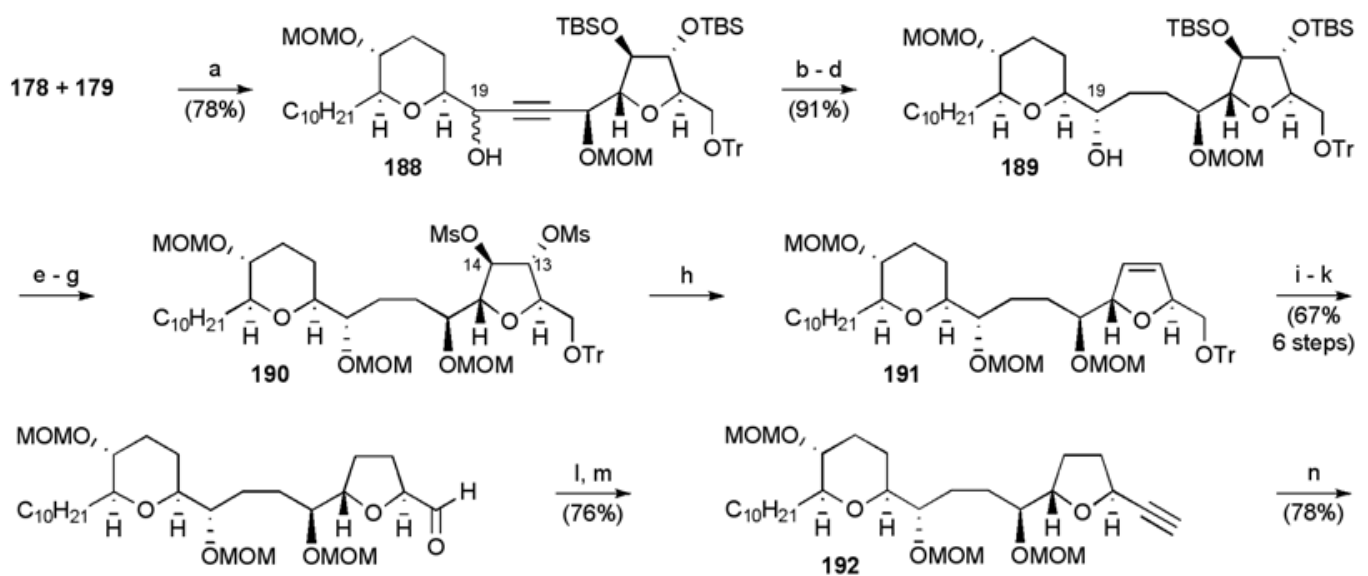<smiles>CO[C@H](C)CC1=C[C@@H](C)OC1=O</smiles>

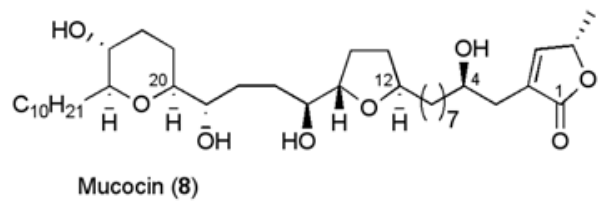

Reagents and conditions: a) $n$-BuLi, $\mathrm{CeCl}_{3}$, THF; b) 5\% $\mathrm{PtO}_{2}, \mathrm{H}_{2}$, EtOAc; c) TPAP, NMO, $\mathrm{CH}_{2} \mathrm{Cl}_{2}$; d) L-selectride, THF; e) MOMCl, DIPEA, $\mathrm{CH}_{2} \mathrm{Cl}_{2}$; f) TBAF, THF; g) $\mathrm{MsCl}, \mathrm{Et}_{3} \mathrm{~N}$, $\mathrm{CH}_{2} \mathrm{Cl}_{2}$; h) $\mathrm{Zn}, \mathrm{NaI}, \mathrm{DMF}$; i) $10 \% \mathrm{Pd} / \mathrm{C}, \mathrm{H}_{2}$, EtOAc; j) aq AcOH; k) Swern oxidation; 1) $\mathrm{Ph}_{3} \mathrm{P}$, $\left.\mathrm{CBr}_{4}, \mathrm{Et}_{3} \mathrm{~N}, \mathrm{CH}_{2} \mathrm{Cl}_{2}, \mathrm{~m}\right)$ EtMgBr, $\mathrm{THF} ;$ n) 180, $\left(\mathrm{Ph}_{3} \mathrm{P}\right)_{2} \mathrm{PdCl}_{2}, \mathrm{CuI}, \mathrm{Et}_{3} \mathrm{~N}$; o) $\left(\mathrm{Ph}_{3} \mathrm{P}\right)_{3} \mathrm{RhCl}, \mathrm{H}_{2}$, benzene/EtOH (6:1); p) $\mathrm{BF}_{3} \cdot \mathrm{OEt}_{2}, \mathrm{Me}_{2} \mathrm{~S}$. 
The THF and THP fragments were united by reacting lithiated alkyne 179 with aldehyde 178, giving a mixture of epimers 188 favouring the undesired diastereomer (Scheme 45). Alkyne reduction, then alcohol oxidation followed by stereoselective hydride reduction corrected the C19 carbinol stereochemistry in 189. The final vicinal deoxygenation at $\mathrm{C} 13 / 14$ was carried out from reductive elimination of the di-mesylate 190, followed by hydrogenation of the resulting dihydrofuran 191 . Further transformations to the alkyne 192 enabled application of the Sonogashira cross-coupling methodology to attach the butenolide fragment 180. Finally, selective hydrogenation and global deprotection of enyne 193 gave mucocin (8) in 28 linear steps from benzyl ether $\mathbf{1 8 1}$ and a corresponding yield of $6.3 \%$.

\section{Summary}

A wide variety of synthetic methodologies have been applied to the synthesis of non-adjacent bisTHF and THF-THP acetogenins. However, some more broadly applicable strategies have emerged. Epoxides and diols have been key intermediates in many of the approaches discussed, taking advantage of well-established catalytic transformations including the Sharpless asymmetric epoxidation and dihydroxylation reactions. Reagent controlled asymmetric C-C bond-forming methodologies such as the glycolate aldol, and the additions of $\gamma$-oxygenated allyl metal reagents and organozincs to aldehydes have been used to correctly establish vicinal oxygen stereochemistry. Cyclic ether formation (THF and THP) has most commonly been achieved via intramolecular epoxide opening reactions or by displacement of sulfonate leaving groups. Highly stereoselective syntheses of trans-THFs have been carried out through iodoetherification and Co-catalysed oxidative cyclisations of bis-homoallylic alcohols and acetals, while metal-oxo mediated oxidative cyclisations have become reliable reactions for the synthesis of cis-THF diols from dienes and dihydroxyalkenes. Subsequently, methodology to transform cis-THF diols into trans-hydroxyalkyl THFs was applied to the synthesis of sylvaticin. For the synthesis of the 2,6-cis-disubstituted THP system found in mucocin, reductive etherification, and $\mathrm{SmI}_{2}$ reductive cyclisation of alkenals have also proved to be highly stereoselective.

In terms of assembling the carbon framework of the non-adjacent bis-THF and THF-THP, two broad strategies can be considered; coupling three major heterocyclic fragments, or approaches where the carbon backbone (or a substantial part of it) is in place prior to forming the cyclic ether core structures. An attractive aspect of the later approach is that the carbon framework can be brought together using robust $\mathrm{C}-\mathrm{C}$ bond-forming reactions such as olefination. However, the subsequent selective transformation of polyenes need to be controlled. Sonogashira coupling has been used extensively as a reliable means to connect the butenolide system to the pre-formed bis-cyclic ether core structures. Other fragment coupling methodologies have included asymmetric additions of acetylides and alkyl metal reagents to aldehydes, and olefination reactions. Metathesis has also emerged as a powerful fragment coupling method, either directly through cross-metathesis, or by the use of a temporary tether. A limitation of the former method has been the requirement for an excess of one of the fragments, although the recovered fragment can be recycled in some cases. In addition, ringclosing metathesis has also been exploited as a method to form the THF and THP ring systems.

It is apparent from the examples discussed above that the groups of Annonaceous acetogenins containing non-adjacent bis-cyclic ether cores have attracted substantial interest from synthetic 
chemists. This interest has derived, in part, due to the potent biological activity of these acetogenins. However, it can be seen from the diversity of chemistries employed that these non-adjacent systems have also stimulated and inspired the development of synthetic methodology and are likely to continue to do so for some time to come.

\section{Acknowledgements}

The authors acknowledge Pfizer Ltd and EPSRC for funding a studentship (I.B.S.).

\section{References}

1. Alali, F.Q.; Liu, X.X.; McLaughlin, J.L. Annonaceous acetogenins: Recent progress. J. Nat. Prod. 1999, 62, 504-540.

2. Bermejo, A.; Figadere, B.; Zafra-Polo, M.C.; Barrachina, I.; Estornell, E.; Cortes, D. Acetogenins from annonaceae: Recent progress in isolation, synthesis and mechanisms of action. Nat. Prod. Rep. 2005, 22, 269-303.

3. Cavé, A.; Figadere, B.; Laurens, A.; Cortes, D. Acetogenins from Annonaceae. In Progress in the Chemistry of Organic Natural Products; Herz, W., Kirby, G.W., Moore, R.E., Steglisg, W. Tamm, C., Eds.; Springer-Verlag: New York, NY, USA, 1997; Volume 70, pp. 81-287.

4. McLaughlin, J.L. Paw paw and cancer: Annonaceous acetogenins from discovery to commercial products. J. Nat. Prod. 2008, 71, 1311-1321.

5. Rupprecht, J.K.; Hui, Y.H.; McLaughlin, J.L. Annonaceous acetogenins - a review. J. Nat. Prod. 1990, 53, 237-278.

6. Zafra-Polo, M.C.; Figadere, B.; Gallardo, T.; Tormo, J.R.; Cortes, D. Natural acetogenins from annonaceae, synthesis and mechanisms of action. Phytochemistry 1998, 48, 1087-1117.

7. Zafra-Polo, M.C.; Gonzalez, M.C.; Estornell, E.; Sahpaz, S.; Cortes, D. Acetogenins from annonaceae, inhibitors of mitochondrial complex I. Phytochemistry 1996, 42, 253-271.

8. Zeng, L.; Ye, Q.; Oberlies, N.H.; Shi, G.; Gu, Z.M.; He, K.; McLaughlin, J.L. Recent advances in annonaceous acetogenins. Nat. Prod. Rep. 1996, 13, 275-306.

9. Fang, X.P.; Rieser, M.J.; Gu, Z.M.; Zhao, G.X.; McLaughlin, J.L. Annonaceous acetogenins - an updated review. Phytochem. Anal. 1993, 4, 27-48.

10. Yu, J.G.; Hu, X.F.E.; Ho, D.K.; Bean, M.F.; Stephens, R.E.; Cassady, J.M.; Brinen, L.S. Clardy, J. Absolute stereochemistry of (+)-gigantecin from annona-coriacea (Annonaceae). J. Org. Chem. 1994, 59, 1598-1599.

11. Curran, D.P.; Zhang, Q.S.; Lu, H.J. Gudipati, V. On the proof and disproof of natural product stereostructures: Characterization and analysis of a twenty-eight member stereoisomer library of murisolins and their Mosher ester derivatives. J. Am. Chem. Soc. 2006, 128, 9943-9956.

12. Hoye, T.R.; Jeffrey, C.S.; Shao, F. Mosher ester analysis for the determination of absolute configuration of stereogenic (chiral) carbinol carbons. Nat. Prot. 2007, 2, 2451-2458.

13. Shi, G.E.; Zeng, L.; Gu, Z.M.; Macdougal, J.M.; Mclaughlin, J.L. Absolute stereochemistries of sylvaticin and 12,15-cis-sylvaticin, bioactive C-20,23-cis non-adjacent bistetrahydrofuran annonaceous acetogenins, from rollinia-mucosa. Heterocycles 1995, 41, 1785-1796. 
14. Born, L.; Lieb, F.; Lorentzen, J.P.; Moeschler, H.; Nonfon, M.; Sollner, R.; Wendisch, D. The relative configuration of acetogenins isolated from annona-squamosa - annonin-I (Squamocin) and annonin-VI. Planta Med. 1990, 56, 312-316.

15. Fujimoto, Y.; Murasaki, C.; Shimada, H.; Nishioka, S.; Kakinuma, K.; Singh, S.; Singh, M.; Gupta, Y.K.; Sahai, M. Annonaceous Acetogenins from the seeds of annona-squamosa - nonadjacent bis-tetrahydrofuranic acetogenins. Chem. Pharm. Bull. 1994, 42, 1175-1184.

16. Hoye, T.R.; Suhadolnik, J.C. On the Stereochemistry of the bistetrahydrofuranyl moiety of uvaricin - proton chemical-shifts can play a crucial role in complex structure determination. $J$. Am. Chem. Soc. 1987, 109, 4402-4403.

17. Hoye, T.R.; Zhuang, Z.P. Validation of the H-1-NMR Chemical-shift method for determination of stereochemistry in the bis(tetrahydrofuranyl) moiety of uvaricin-related acetogenins from annonaceae - rolliniastatin-1 (and asimicin). J. Org. Chem. 1988, 53, 5578-5580.

18. Ghani, S.B.A.; Chapman, J.M.; Figadere, B.; Herniman, J.M.; Langley, G.J.; Niemann, S.; Brown, R.C.D. Total synthesis and stereochemical assignment of cis-uvariamicin I and cisreticulatacin. J. Org. Chem. 2009, 74, 981-988.

19. Hu, Y.L.; Cecil, A.R.L.; Frank, X.; Gleye, C.; Figadere, B.; Brown, R.C.D. Natural cis-solamin is a mixture of two tetra-epimeric diastereoisomers: Biosynthetic implications for annonaceous acetogenins. Org. Biomol. Chem. 2006, 4, 1217-1219.

20. Zhao, G.X.; Hui, Y.H.; Rupprecht, J.K.; Mclaughlin, J.L.; Wood, K.V. Additional bioactive compounds and trilobacin, a novel highly cytotoxic acetogenin, from the bark of asimina-triloba. J. Nat. Prod. 1992, 55, 347-356.

21. Zhao, G.X.; Miesbauer, L.R.; Smith, D.L.; Mclaughlin, J.L. Asimin, asiminacin, and asiminecin novel highly cytotoxic asimicin isomers from asimina-triloba. J. Med. Chem. 1994, 37, 1971-1976.

22. Oberlies, N.H.; Chang, C.J.; McLaughlin, J.L. Structure-activity relationships of diverse annonaceous acetogenins against multidrug resistant human mammary adenocarcinoma (MCF7/Adr) cells. J. Med. Chem. 1997, 40, 2102-2106.

23. Oberlies, N.H.; Croy, V.L.; Harrison, M.L.; McLaughlin, J.L. The annonaceous acetogenin bullatacin is cytotoxic against multidrug-resistant human mammary adenocarcinoma cells. Cancer Lett. 1997, 115, 73-79.

24. Ahammadsahib, K.I.; Hollingworth, R.M.; McGovren, J.P.; Hui, Y.H.; McLaughlin, J.L. Mode of action of bullatacin: A potent antitumor and pesticidal annonaceous acetogenin. Life Sci. 1993, 53, 1113-1120.

25. Degli Esposti, M.; Ghelli, A.; Ratta, M.; Cortes, D.; Estornell, E. Natural substances (Acetogenins) from the family annonanaceae are powerful inhibitors of mitochondrial NADH dehydrogenase (complex I). Biochem. J. 1994, 301, 161-167.

26. Londershausen, M.; Leicht, W.; Lieb, F.; Moeschler, H.; Weiss, H. Molecular mode of action of annonins. Pestic. Sci. 1991, 33, 427-438.

27. Morré, D.J.; de Cabo, R.; Farley, C.; Oberlies, N.H.; McLaughlin, J.L. Mode of action of bullatacin, a potent antitumor acetogenin: Inhibition of NADH oxidase activity. Life Sci. 1995, 56, 343-348. 
28. Abe, M.; Kubo, A.; Yamamoto, S.; Hatoh, Y.; Murai, M.; Hattori, Y.; Makabe, H.; Nishioka, T.; Miyoshi, H. Dynamic function of the spacer region of acetogenins in the inhibition of bovine mitochondrial NADH-ubiquinone oxidoreductase (complex I). Biochemistry 2008, 47, 6260-6266.

29. González, M.C.; Lavaud, C.; Gallardo, T.; Zafra-Polo, M.C.; Cortes, D. New method for the determination of the absolute stereochemistry in antitumoral annonaceous acetogenins. Tetrahedron 1998, 54, 6079-6088.

30. Motoyama, T.; Yabunaka, H.; Miyoshi, H. Essential structural factors of acetogenins, potent inhibitors of mitochondrial complex I. Bioorg. Med. Chem. Lett. 2002, 12, 2089-2092.

31. Tormo, J.R.; Estornell, E.; Gallardo, T.; González, M.C.; Cáve, A.; Granell, S.; Cortes, D.; ZafraPolo, M.C. Gamma-lactone functionalised antitumoral acetogenins are the most potent inhibitors of mitochondrial complex I. Bioorg. Med. Chem. Lett. 2001, 11, 681-684.

32. Marshall, J.A.; Hinkle, K.W. Hagedorn, C.E. Recent Developments in the synthesis of annonaceous acetogenins. Isr. J. Chem. 1997, 37, 97-107.

33. Figadere, B.; Cave, A. Total Stereoselective Synthesis of Acetogenins of Annonaceae: A New Class of Bioactive Polyketides. In Studies in Natural Products Chemistry; Rahman, A.U., Ed.; Elsevier Science: Amsterdam, The Netherlands, 1996; Volume 18, pp. 193-227.

34. Figadere, B. Syntheses of acetogenins of annonaceae: A new class of bioactive polyketides. Acc. Chem. Res. 1995, 28, 359-365.

35. Casiraghi, G.; Zanardi, F.; Battistini, L.; Rassu, G.; Appendino, G. Current Advances in the chemical synthesis of annonaceous acetogenins and relatives. Chemtracts Org. Chem. 1998, 11, 803-827.

36. Hoppe, R.; Scharf, H.D. Annonaceous acetogenins - synthetic approaches towards a novel class of natural products. Synthesis 1995, 1447-1464.

37. Li, N.; Shi, Z.; Tang, Y.; Chen, J.; Li, X. Recent progress on the total synthesis of acetogenins from annonaceae. Beilstein J. Org. Chem. 2008, 4, No. 48.

38. Marshall, J.A.; Jiang, H.J. Total synthesis of the non-adjacent bis-tetrahydrofuran annonaceous acetogenin squamostatin-D. J. Org. Chem. 1998, 63, 7066-7071.

39. Marshall, J.A.; Hinkle, K.W. Synthesis of anti-homoallylic alcohols and monoprotected 1,2-diols through $\mathrm{InCl}_{3}$-promoted addition of allylic stannanes to aldehydes. J. Org. Chem. 1995, 60, 1920-1921.

40. Yao, Z.J.; Wu, Y.L. Total synthesis of $(10-\xi, 15 R, 16 S, 19 S, 20 S, 34 R)$-corossoline. Tetrahedron Lett. 1994, 35, 157-160.

41. Fang, X.P.; Anderson, J.E.; Smith, D.L.; Wood, K.V.; McLaughlin, J.L. Giganenin, a highly potent monotetrahydrofuran acetogenin and 4-deoxygigantecin from goniothalamus-giganteus. Heterocycles 1992, 34, 1075-1083.

42. Makabe, H. Synthesis of annonaceous acetogenins from muricatacin. Biosci. Biotech. Biochem. 2007, 71, 2367-2374.

43. Makabe, H.; Tanaka, A.; Oritani, T. Total synthesis of solamin and reticulatacin. J. Chem. Soc. Perkin Trans. I 1994, 1975-1981.

44. Makabe, H.; Tanaka, A.; Oritani, T. Total synthesis of (+)-4-deoxygigantecin. Tetrahedron 1998, 54, 6329-6340. 
45. Makabe, H.; Tanaka, A.; Oritani, T. Synthesis of (-)-muricatacin. Biosci. Biotech. Biochem. 1993, $57,1028-1029$.

46. White, J.D.; Somers, T.C.; Reddy, G.N. Degradation and absolute configurational assignment to C-34-botryococcene. J. Org. Chem. 1992, 57, 4991-4998.

47. Alkofahi, A.; Rupprecht, J.K.; Liu, Y.M.; Chang, C.J.; Smith, D.L.; McLaughlin, J.L. Gigantecin -A novel antimitotic and cytotoxic acetogenin, with nonadjacent tetrahydrofuran rings, from goniothalamus-giganteus (Annonaceae). Experientia 1990, 46, 539-541.

48. Crimmins, M.T.; She, J. Enantioselective total synthesis of $(+)$-gigantecin: Exploiting the asymmetric glycolate aldol reaction. J. Am. Chem. Soc. 2004, 126, 12790-12791.

49. Hoye, T.R.; Eklov, B.M.; Jeon, J. Khoroosi, M. Sequencing of three-component olefin metatheses: total synthesis of either (+)-gigantecin or (+)-14-deoxy-9-oxygigantecin. Org. Lett. 2006, 8, 3383-3386.

50. Crimmins, M.T.; She, J. An improved procedure for asymmetric aldol additions with $N$-acyl oxazolidinones, oxazolidinethiones and thiazolidinethiones. Synlett 2004, 1371-1374.

51. Crimmins, M.T.; Emmitte, K.A.; Katz, J.D. Diastereoselective alkylations of oxazolidinone glycolates: A useful extension of the evans asymmetric alkylation. Org. Lett. 2000, 2, 2165-2167.

52. Hoye, T.R.; Ye, Z.X. Highly efficient synthesis of the potent antitumor annonaceous acetogenin (+)-parviflorin. J. Am. Chem. Soc. 1996, 118, 1801-1802.

53. Gu, Z.M.; Fang, X.P.; Rieser, M.J.; Hui, Y.H.; Miesbauer, L.R.; Smith, D.L.; Wood, K.V.; McLaughlin, J.L. New cytotoxic annonaceous acetogenins - bullatanocin and cis-bullatanocinone and trans-bullatanocinone, from annona-bullata (Annonaceae). Tetrahedron 1993, 49, 747-754.

54. Gu, Z.M.; Zeng, L.; Fang, X.P.; Colmansaizarbitoria, T.; Huo, M.; McLaughlin, J.L. Determining absolute-configurations of stereocenters in annonaceous acetogenins through formaldehyde acetal derivatives and Mosher ester methodology. J. Org. Chem. 1994, 59, 5162-5172.

55. Shimada, H.; Nishioka, S.; Singh, S.; Sahai, M.; Fujimoto, Y. Absolute stereochemistry of nonadjacent bis-tetrahydrofuranic acetogenins. Tetrahedron Lett. 1994, 35, 3961-3964.

56. Zhu, L.; Mootoo, D.R. Synthesis of nonadjacently linked tetrahydrofurans: An iodoetherification and olefin metathesis approach. Org. Lett. 2003, 5, 3475-3478.

57. Zhu, L.; Mootoo, D.R. Total synthesis of the nonadjacently linked bis-tetrahydrofuran acetogenin bullatanocin (squamostatin C). J. Org. Chem. 2004, 69, 3154-3157.

58. Dabideen, D.; Ruan, Z.M.; Mootoo, D.R. 1,2-O-Isopropylidene-5-alkene templates for the synthesis of oligo-tetrahydrofurans. Tetrahedron 2002, 58, 2077-2084.

59. Evans, P.A.; Murthy, V.S. Enantioselective construction of the tetrahydropyran and tetrahydrofuran fragments of the antitumor agent mucocin from a common intermediate. Tetrahedron Lett. 1999, 40, 1253-1256.

60. Hoye, T.R.; Mayer, M.J.; Vos, T.J.; Ye, Z.X. A general, Practical, and versatile strategy for accessing omega-functional 1,2-Diols of high enantiomeric excess. J. Org. Chem. 1998, 63, 8554-8557.

61. Sinha, S.C.; Sinha, A.; Sinha, S.C.; Keinan, E. Tandem oxidative cyclization with rhenium oxide. Total synthesis of 17,18-bisepi-goniocin. J. Am. Chem. Soc. 1997, 119, 12014-12015.

62. Donohoe, T.J.; Harris, R.M.; Burrows, J.; Parker, J. Total synthesis of (+)-cis-sylvaticin: Double oxidative cyclization reactions catalyzed by osmium. J. Am. Chem. Soc. 2006, 128, 13704-13705. 
63. Donohoe, T.J.; Harris, R.M.; Williams, O.; Hargaden, G.C.; Burrows, J.; Parker, J. Concise syntheses of the natural products (+)-sylvaticin and (+)-cis-sylvaticin. J. Am. Chem. Soc. 2009, $131,12854-12861$.

64. Bhunnoo, R.A.; Hobbs, H.; Laine, D.I.; Light, M.E.; Brown, R.C.D. Synthesis of the non-adjacent bis-thf core of cis-sylvaticin using a double oxidative cyclisation. Org. Biomol. Chem. 2009, 7, 1017-1024.

65. Brown, L.J.; Spurr, I.B.; Kemp, S.C.; Camp, N.P.; Gibson, K.R.; Brown, R.C.D. Total synthesis of cis-sylvaticin. Org. Lett. 2008, 10, 2489-2492.

66. Piccialli, V. Oxidative Cyclization of dienes and polyenes mediated by transition-metal-oxo species. Synthesis 2007, 2585-2607.

67. Donohoe, T.J.; Butterworth, S. Oxidative cyclization of diols derived from 1,5-dienes: Formation of enantiopure cis-tetrahydrofurans by using catalytic osmium tetroxide; formal synthesis of $(+)$ cis-solamin. Angew. Chem. Int. Ed. 2005, 44, 4766-4768.

68. Keum, G.; Hwang, C.H.; Kang, S.B.; Kim, Y.; Lee, E. Stereoselective Syntheses of rolliniastatin 1, rollimembrin, and membranacin. J. Am. Chem. Soc. 2005, 127, 10396-10399.

69. Ready, J.M.; Jacobsen, E.N. A Practical oligomeric [(Salen)Co] catalyst for asymmetric epoxide ring-opening reactions. Angew. Chem. Int. Ed. 2002, 41, 1374-1377.

70. Brown, R.C.D.; Bataille, C.J.; Hughes, R.M.; Kenney, A.; Luker, T.J. Permanganate oxidation of 1,5,9-trienes: Stereoselective synthesis of tetrahydrofuran-containing fragments. J. Org. Chem. 2002, 67, 8079-8085.

71. Hu, Y.L.; Brown, R.C.D. A Metal-oxo mediated approach to the synthesis of 21,22-diepimembrarollin. Chem. Commun. 2005, 5636-5637.

72. Morris, C.L.; Hu, Y.L.; Head, G.D.; Brown, L.J.; Whittingham, W.G.; Brown, R.C.D. Oxidative cyclization reactions of trienes and dienynes: Total synthesis of membrarollin. J. Org. Chem. 2009, 74, 981-988.

73. Cecil, A.R.L.; Hu, Y.L.; Vicent, M.J.; Duncan, R.; Brown, R.C.D. Total synthesis and preliminary biological evaluation of cis-solamin isomers. J. Org. Chem. 2004, 69, 3368-3374.

74. Cepleanu, F.; Ohtani, K.; Hamburger, M.; Gupta, M.P.; Solis, P. Hostettmann, K. Novel acetogenins from the leaves of annona-purpurea. Helv. Chim. Acta 1993, 76, 1379-1388.

75. Mikolajczak, K.J.; Madrigal, R.V.; Rupprecht, J.K.; Hui, Y.H.; Liu, Y.M.; Smith, D.L.; Mclaughlin, J.L. Sylvaticin-A new cytotoxic and insecticidal acetogenin from rollinia-sylvatica (Annonaceae). Experientia 1990, 46, 324-327.

76. Donohoe, T.J.; Williams, O.; Churchill, G.H. Hydride shift generated oxonium ions: Evidence for mechanism and intramolecular trapping experiments to form trans-THF derivatives. Angew. Chem. Int. Ed. 2008, 47, 2869-2871.

77. Takahashi, S.; Hongo, Y.; Tsukagoshi, Y.; Koshino, H. Structural determination of montanacin D by total synthesis. Org. Lett. 2008, 10, 4223-4226.

78. Takahashi, S.; Takahashi, R.; Hongo, Y.; Koshino, H.; Yamaguchi, K.; Miyagi, T. Synthesis of all possible isomers corresponding to the proposed structure of montanacin E, and their antitumor activity. J. Org. Chem. 2009, 74, 6382-6385. 
79. Shi, G.E.; Alfonso, D.; Fatope, M.O.; Zeng, L.; Gu, Z.M.; Zhao, G.X.; He, K.; Macdougal, J.M.; Mclaughlin, J.L. Mucocin-A new annonaceous acetogenin bearing a tetrahydropyran ring. $J$. Am. Chem. Soc. 1995, 117, 10409-10410.

80. Baurle, S.; Hoppen, S.; Koert, U. Total synthesis of (-)-mucocin. Angew. Chem. Int. Ed. 1999, 38, 1263-1266.

81. Hoppen, S.; Baurle, S.; Koert, U. A convergent total synthesis of (-)-mucocin: An acetogenin from annonaceae. Chem. Eur. J. 2000, 6, 2382-2396.

82. Hoppen, S.; Bauerle, S.; Koert, U. A convergent total synthesis of (-)-mucocin: An acetogenin from annonaceae (vol 6, pg 2382, 2000). Chem. Eur. J. 2000, 6, 2906-2906.

83. Nicolaou, K.C.; Prasad, C.V.C.; Somers, P.K.; Hwang, C.K. Activation of 6-Endo over 5-Exo hydroxy epoxide openings - stereoselective and ring selective synthesis of tetrahydrofuran and tetrahydropyran systems. J. Am. Chem. Soc. 1989, 111, 5330-5334.

84. Keinan, E.; Sinha, A.; Yazbak, A.; Sinha, S.C.; Sinha, S.C. Towards Chemical libraries of annonaceous acetogenins. Pure Appl. Chem. 1997, 423-430.

85. Sinha, S.C.; Keinan, E. Total synthesis of $(+)$-aspicilin. The naked carbon skeleton strategy vs the bioorganic approach. J. Org. Chem. 1997, 62, 377-386.

86. Neogi, P.; Doundoulakis, T.; Yazbak, A.; Sinha, S.C.; Sinha, S.C.; Keinan, E. Total synthesis of mucocin. J. Am. Chem. Soc. 1998, 120, 11279-11284.

87. Evans, P.A.; Cui, J.; Gharpure, S.J.; Polosukhin, A.; Zhang, H.R. Enantioselective total synthesis of the potent antitumor agent (-)-mucocin using a temporary silicon-tethered ring-closing metathesis cross-coupling reaction. J. Am. Chem. Soc. 2003, 125, 14702-14703.

88. Evans, P.A.; Murthy, V.S. Enantioselective synthesis of the 4-hydroxy buteneolide terminus of mucocin and related annonaceous acetogenins. Tetrahedron Lett. 1998, 39, 9627-9628.

89. Evans, P.A.; Murthy, V.S. Enantioselective synthesis of the 4-hydroxy buteneolide terminus of mucocin and related annonaceous acetogenins (1998, vol. 39, p. 9627). Tetrahedron Lett. 1999, 40, 1423-1423.

90. Evans, P.A.; Roseman, J.D. Stereoselective synthesis of the 2,6-disubstituted tetrahydropyran-3-ol of the potent antitumor agent mucocin via an acyl radical cyclization. Tetrahedron Lett. 1997, 38, 5249-5252.

91. Evans, P.A.; Cui, B.; Buffone, G.P. Diastereoselective temporary silicon-tethered ring-closingmetathesis reactions with prochiral alcohols: A new approach to long-range asymmetric induction. Angew. Chem. Int. Ed. 2003, 42, 1734-1737.

92. Inoki, S.; Mukaiyama, T. A convenient method for the stereoselective preparation of trans-2hydroxymethyltetrahydrofurans by the oxidative cyclization of 5-hydroxy-1-alkenes with molecular-oxygen catalyzed by cobalt(II) complex. Chem. Lett. 1990, 67-70.

93. Evans, P.A.; Cui, J.; Gharpure, S.J. Stereoselective construction of Cis-2,6-disubstituted tetrahydropyrans via the reductive etherification of $\delta$-trialkylsilyloxy substituted ketones: Total synthesis of (-)-centrolobine. Org. Lett. 2003, 5, 3883-3885.

94. Evans, P.A.; Cui, J.; Gharpure, S.J.; Hinkle, R.J. Stereoselective construction of cyclic ethers using a tandem two-component etherification: Elucidation of the role of bismuth tribromide. $J$. Am. Chem. Soc. 2003, 125, 11456-11457. 
95. Crimmins, M.T.; Zhang, Y.; Diaz, F.A. Total synthesis of (-)-mucocin. Org. Lett. 2006, 8, 2369-2372.

96. Mori, K.; Otsuka, T. Pheromone synthesis. 59. synthesis of both the enantiomers of Erythro-6acetoxy-5-hexadecanolide-The major component of a mosquito oviposition attractant pheromone. Tetrahedron 1983, 39, 3267-3269.

97. Keinan, E.; Sinha, S.C.; Sinhabagchi, A.; Wang, Z.M.; Zhang, X.L.; Sharpless, K.B. Synthesis of all 4 isomers of disparlure using osmium-catalyzed asymmetric dihydroxylation. Tetrahedron Lett. 1992, 33, 6411-6414.

98. Hoye, T.R.; Jeffrey, C.S.; Tennakoon, M.A.; Wang, J.Z.; Zhao, H.Y. Relay ring-closing metathesis (RRCM): A Strategy for directing metal movement throughout olefin metathesis sequences. J. Am. Chem. Soc. 2004, 126, 10210-10211.

99. Zhu, L.; Mootoo, D.R. Synthesis of the non-classical acetogenin mucocin: A Modular approach based on olefinic coupling reactions. Org. Biomol. Chem. 2005, 3, 2750-2754.

100. Takahashi, S.; Kubota, A.; Nakata, T. Stereoselective total synthesis of mucocin, an antitumor agent. Angew. Chem. Int. Ed. 2002, 41, 4751-4754.

101. Hori, N.; Matsukura, H.; Matsuo, G.; Nakata, T. Efficient strategy for the iterative synthesis of trans-fused polycyclic ethers via smi $_{2}$-induced reductive intramolecular cyclization. Tetrahedron 2002, 58, 1853-1864.

102. Takahashi, S.; Nakata, T. Total synthesis of an anticancer agent, mucocin. 1. stereoselective synthesis of the left-half segment. Tetrahedron Lett. 1999, 40, 723-726.

103. Takahashi, S.; Nakata, T. Total synthesis of an anticancer agent, mucocin. 2. A Novel approach to a gamma-hydroxy butenolide derivative and completion of total synthesis. Tetrahedron Lett. 1999, 40, 727-730.

104. Takahashi, S.; Nakata, T. Total synthesis of an antitumor agent, mucocin, based on the "chiron approach". J. Org. Chem. 2002, 67, 5739-5752.

Sample Availability: No samples are available from the authors.

(C) 2010 by the authors; licensee Molecular Diversity Preservation International, Basel, Switzerland. This article is an open-access article distributed under the terms and conditions of the Creative Commons Attribution license (http://creativecommons.org/licenses/by/3.0/). 